PHYSICOCHEMICAL AND STRUCTURAL CHARACTERIZATION OF MICROFLUIDIZED AND SONICATED LEGUME STARCHES

A THESIS SUBMITTED TO

THE GRADUATE SCHOOL OF NATURAL AND APPLIED SCIENCES $\mathrm{OF}$ MIDDLE EAST TECHNICAL UNIVERSITY

BY

AYŞE BİTIK

IN PARTIAL FULFILLMENT OF THE REQUIREMENTS FOR

THE DEGREE OF MASTER OF SCIENCE

IN

FOOD ENGINEERING

MAY 2019 

Approval of the thesis:

\section{PHYSICOCHEMICAL AND STRUCTURAL CHARACTERIZATION OF MICROFLUIDIZED AND SONICATED LEGUME STARCHES}

submitted by AYŞE BITIKK in partial fulfillment of the requirements for the degree of Master of Science in Food Engineering Department, Middle East Technical University by,

Prof. Dr. Halil Kalıpçılar

Dean, Graduate School of Natural and Applied Sciences

Prof. Dr. Serpil Şahin

Head of Department, Food Engineering

Prof. Dr. Gülüm Şumnu

Supervisor, Food Engineering, METU

Assoc. Prof. Dr. Mecit Halil Öztop

Co-Supervisor, Food Engineering, METU

\section{Examining Committee Members:}

Prof. Dr. Serpil Şahin

Food Engineering, METU

Prof. Dr. Gülüm Şumnu

Food Engineering, METU

Assoc. Prof. Dr. Mecit Halil Öztop

Food Engineering, METU

Assoc. Prof. Dr. Özge Şakıyan Demirkol

Food Engineering, Ankara University

Assist. Prof. Dr. Emin Burçin Özvural

Food Engineering, Çankırı Karatekin University

Date: 24.05.2019 
I hereby declare that all information in this document has been obtained and presented in accordance with academic rules and ethical conduct. I also declare that, as required by these rules and conduct, I have fully cited and referenced all material and results that are not original to this work.

Name, Surname: Ayşe Bitik

Signature: 


\title{
ABSTRACT \\ PHYSICOCHEMICAL AND STRUCTURAL CHARACTERIZATION OF MICROFLUIDIZED AND SONICATED LEGUME STARCHES
}

\author{
Bitik, Ayşe \\ Master of Science, Food Engineering \\ Supervisor: Prof. Dr. Gülüm Şumnu \\ Co-Supervisor: Assoc. Prof. Dr. Mecit Halil Öztop
}

May 2019, 104 pages

Modified starches gained importance in food industry due to their improved functional properties. In this study, two legume starches (chickpea and lentil) were modified by using ultrasonication and microfluidization techniques. The objective of the study was to investigate the effects of these methods on the functional, rheological, thermal properties and particle size, morphology and crystal structure of modified starch samples. Time Domain NMR relaxometry experiments were also conducted to understand the changes in the microstructure. Results showed that swelling power of starches increased, but their solubility values decreased significantly with both treatments $(\mathrm{p}<0.05)$. Apparent viscosities of both samples showed a decreasing trend with increasing shear rate. Gelatinization temperatures of starches decreased with treatments significantly $(\mathrm{p}<0.05)$. Both methods resulted in significantly lower volume mean diameter (D [4,3]) and span values as compared to the native ones. SEM images demonstrated that morphology of the treated starches changed significantly. Time Domain (TD) NMR results showed that modified starch samples had longer $T_{2}$ relaxation times. After treatments, the structural change was also observed through FTIR experiments. Both ultrasonication and microfluidization were found to be effective for the modification of chickpea and lentil starches. 
Keywords: Chickpea Starch, Lentil Starch, Modification, Ultrasonication, Microfluidization 


\title{
MIKROAKIŞKANLAŞTIRMA VE ULTRASONIKASYON UYGULANMIŞ \\ BAKLAGİL NIŞASTALARININ FİZIKOKIMYASAL VE YAPISAL KARAKTERIZASYONU
}

\author{
Bitik, Ayşe \\ Yüksek Lisans, Gıda Mühendisliği \\ Tez Danışmanı: Prof. Dr. Gülüm Şumnu \\ Ortak Tez Danışmanı: Doç. Dr. Mecit Halil Öztop
}

May1s 2019, 104 sayfa

Geliştirilmiş fonksiyonel özelliklerinden dolayı modifiye nişastalar gıda endüstrisinde önem kazanmıştır. Bu çalışmada, iki baklagil nişastası (nohut ve mercimek) ultrasonikasyon ve mikroakışkanlaştırma yöntemleri kullanılarak modifiye edilmiştir. Çalışmanın amacı bu yöntemlerin modifiye nişasta numunelerinin fonksiyonel, reolojik, termal özellikleri, parçacık boyutu, morfoloji ve kristal yapısı üzerindeki etkilerini araştırmaktır. Aynı zamanda, zaman alanlı nükleer manyetik rezonans (NMR) deneyleri mikro yapıdaki değişimleri gözlemlemek amacı ile yapılmıştır. Sonuçlar her iki uygulama ile nişastaların şişme güçlerinin önemli ölçüde arttığını ve çözünürlüklerinin önemli ölçüde azaldığını göstermiştir $(\mathrm{p}<0.05)$. Tüm numunelerin görünür viskozite değerleri artan kayma hızı ile azalan bir eğilim göstermiştir. Uygulamalar ile nişastaların jelatinizasyon sıcaklıkları önemli ölçüde azalmıştır $(\mathrm{p}<0.05)$. Doğal numuneler ile kıyaslandığında, her iki uygulama da önemli ölçüde daha düşük hacimsel ortalama çap (D [4,3]) ve aralık değerleri ile sonuçlanmıştır. Taramalı elektron mikroskobu görüntüleri nişastaların morfolojilerinin önemli ölçüde değiştiğini göstermiştir. Zaman alanlı nükleer manyetik rezonans sonuçları ile modifiye nişasta numunelerinin daha uzun gevşeme süresine sahip olduğu görülmüştür. Uygulamalar ile oluşan yapısal değişlikler FTIR (Fourier Dönüşümlü 
İnfrared Spektroskopisi) deneyleri ile gözlemlenmiştir. Ultrasonikasyon ve mikroakışkanlaştırma yöntemlerinin her ikisi de nohut ve mercimek nişastalarının modifikasyonu için etkili ve yeni teknolojilerdir.

Anahtar Kelimeler: Nohut Nişastası, Mercimek Nişastası, Modifikasyon, Ultrasonikasyon, Mikroakışkanlaştırma 
To my family 


\section{ACKNOWLEDGEMENTS}

I would like to express my sincere gratitude to my supervisor Prof. Dr. Gülüm Şumnu for her valuable support, assistance and guidance throughout the study. I would also thank to my co-supervisor Assoc. Prof. Dr. Mecit Halil Öztop for his valuable support and guidance throughout the study.

I would like to express my grateful thanks to Ayça Aydoğdu, Betül Çilek Tatar, Eda Yıldız, Selen Güner, Sevil Çıkrıkcı, and Pelin Poçan for their help and supports in doing analysis and their precious suggestions.

My sincere thanks go to Osman Gökhan Akın for his precious support and encouragement throughout study.

My very special thanks go to Seçil Kocakulak and Uğur Can Güler for their endless encouragement and support.

My special thanks extended to my friends Aylin Bekil, Aybüke Gülen, Fadime Yücel, Zuhal Acar and Elif Atalay for their valuable encouragement and support.

I would like to express my grateful thanks to my friends Ceren Narin, Büşra Nur Gezer and Sezgin Seza for their supportive suggestions and encouragement.

Finally, my deepest appreciation goes to my family; my mother Şefika Bitik, my grandfather Esat Bitik, my grandmother Zehra Bitik, my brother Mahmut Esat Bitik, and my father Ahmet Cevdet Bitik, who is no longer with us but whose love made this journey possible, for their endless love, precious support, and valuable encouragement through my life. They are superheroes of my life. All that I am I owe to my precious family. Their share in this thesis as well as my life is beyond counting. This study was supported by the Middle East Technical University of Turkey (Project code: GAP-314-2018-2856). 
TABLE OF CONTENTS

ABSTRACT

CHAPTERS

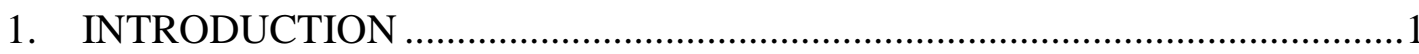

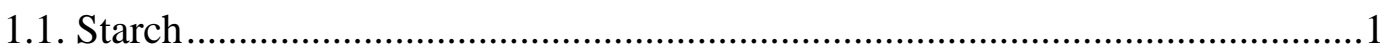

1.1.1. Starch Structure and Synthesis ...............................................................

1.1.2. Starch Properties ...................................................................................6

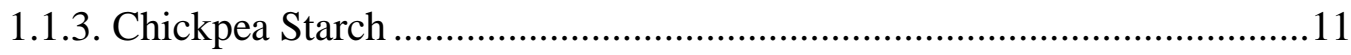

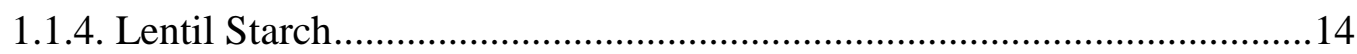

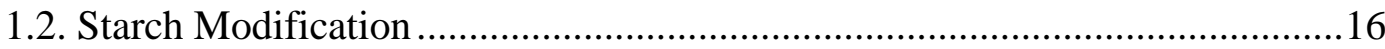

1.2.1. Chemical Modification ...........................................................................17

1.2.2. Enzymatic Modification ....................................................................... 18

1.2.3. Physical Modification ............................................................................. 19

1.2.3.1. Ultrasonication ...................................................................................21

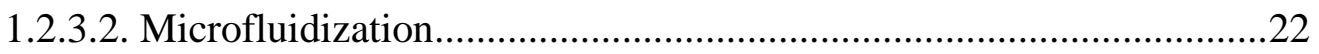

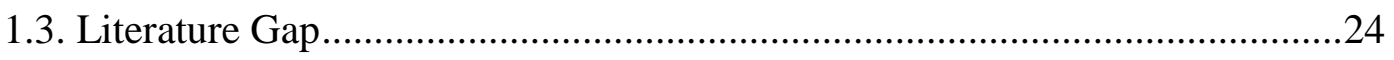

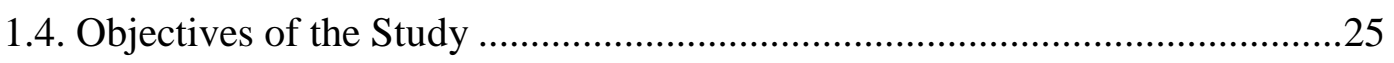




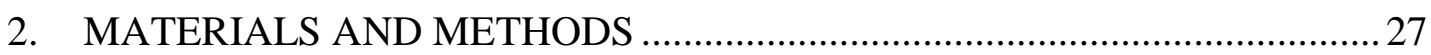

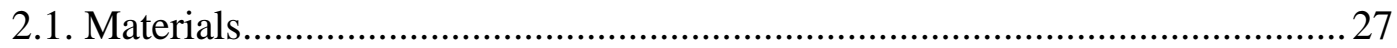

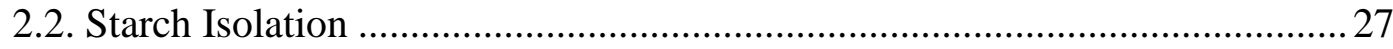

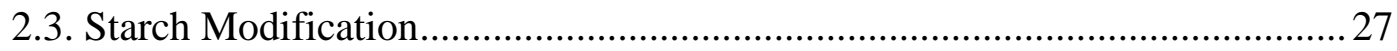

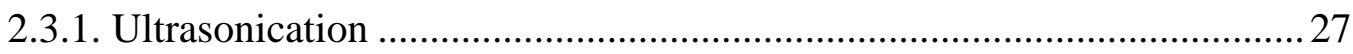

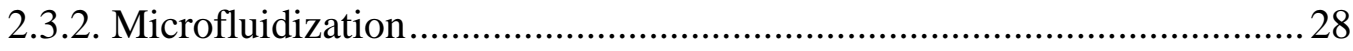

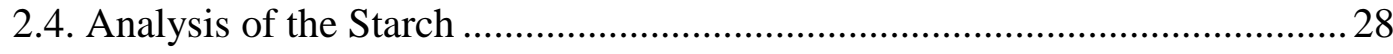

2.4.1. Functional Properties (Solubility and Swelling Power) .........................2 28

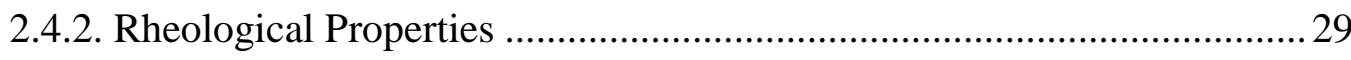

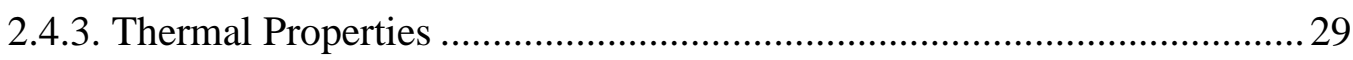

2.4.4. Scanning Electron Microscopy (SEM) .............................................. 30

2.4.5. Measurement of the Mean Particle Size.................................................. 30

2.4.6. TD-NMR and Relaxation Experiments .................................................... 31

2.4.7. Fourier Transform Infrared Spectroscopy (FTIR)................................. 31

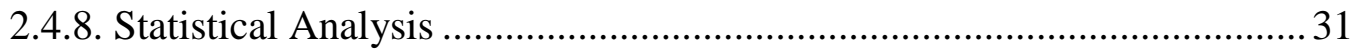

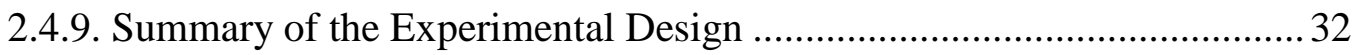

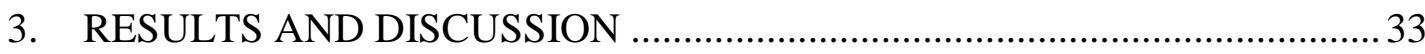

3.1. Functional Properties (Solubility and Swelling Power)............................... 33

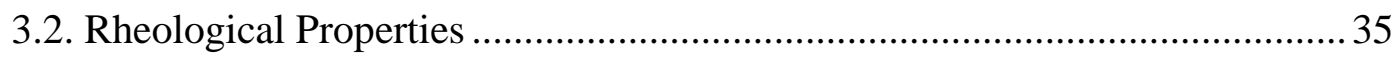

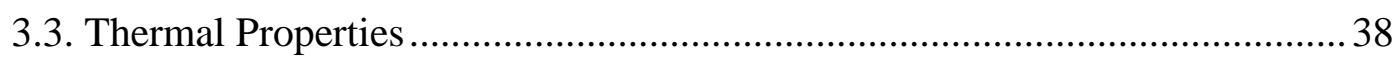

3.4. Scanning Electron Microscopy (SEM) .................................................... 41

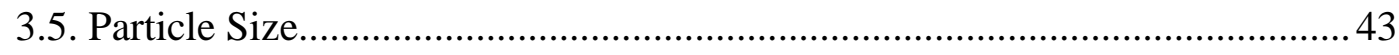

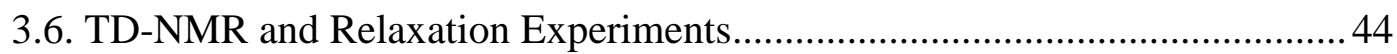

3.7. Fourier Transform Infrared Spectroscopy (FTIR) ....................................... 46 
4. CONCLUSION AND RECOMMENDATIONS .............................................

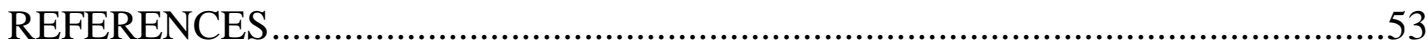

APPENDICES

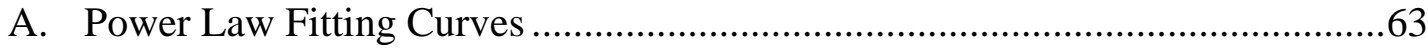

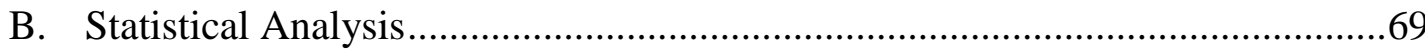




\section{LIST OF TABLES}

\section{TABLES}

Table 1.1. Chemical composition of chickpea grains (De Almeida Costa et al., 2006)

Table 1.2. Chemical composition of chickpea starch (Wani et al., 2016) .................. 13

Table 1.3. Chemical composition of lentil grains (De Almeida Costa et al., 2006).. 15

Table 1.4. Chemical composition of lentil starch (Wani et al., 2016) ....................... 15

Table 2.1. Factors, levels and responses used in the study ...................................... 32

Table 3.1. Functional properties (Solubility (S) and Swelling Power (SP)) of the

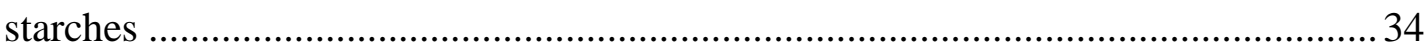

Table 3.2. Rheological properties (flow behavior index (n), consistency index (K) and

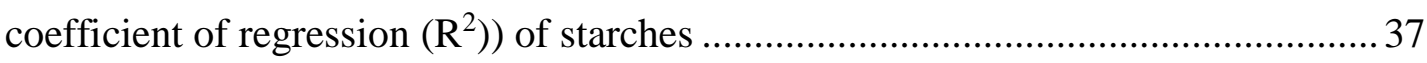

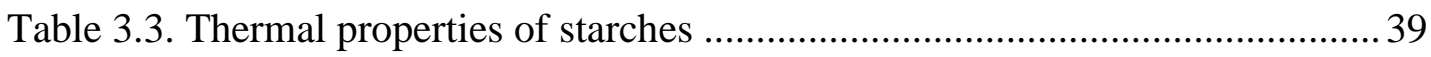

Table 3.4. Particle size analysis results (D[4,3] and span values) of the starches ..... 44

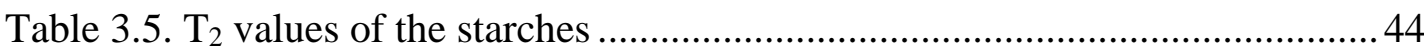

Table B. 1. Rheological properties of chickpea starches ........................................69

Table B. 2. Rheological properties of lentil starches............................................ 72

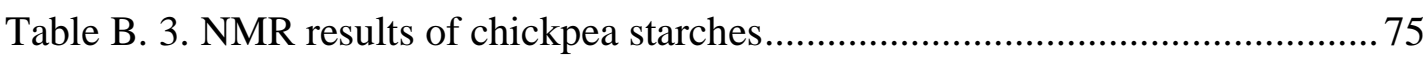

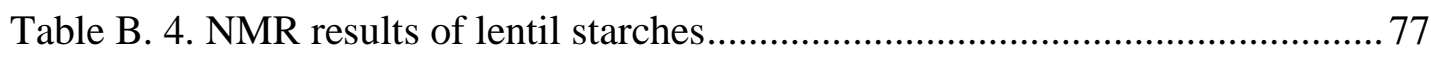

Table B. 5. Particle size analysis results of chickpea starches ..................................79

Table B. 6. Particle size analysis results of lentil starches ..................................... 82

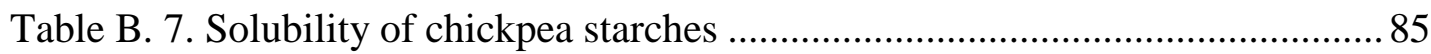

Table B. 8. Swelling power of chickpea starches ................................................ 87

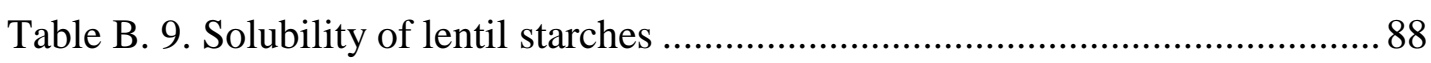

Table B. 10. Swelling power of lentil starches ...................................................... 90

Table B. 11. Thermal properties of chickpea starches........................................... 91

Table B. 12. Thermal properties of lentil starches..................................................... 98 


\section{LIST OF FIGURES}

\section{FIGURES}

Figure 1.1. Structures of amylose and amylopectin (Kalita \& Netravali, 2017) .........3 Figure 1.2. A-type double helices, B-type double helices and their packing. Crystalline packed structure projected in $(\mathrm{a}, \mathrm{b})$ plane. (Buléon et al., 1998) ................................4 Figure 1.3. Maltese cross in amylose and amylopectin molecules. a) Basic glucose unit, b) Amylose, c) Amylopectin (Alcázar-Alay \& Meireles, 2015) .........................7

Figure 1.4. Schematic of microfluidizer (Karagiannidis et al., 2017).......................23 Figure 3.1. Variation of shear stress with shear strain of the native, sonicated and

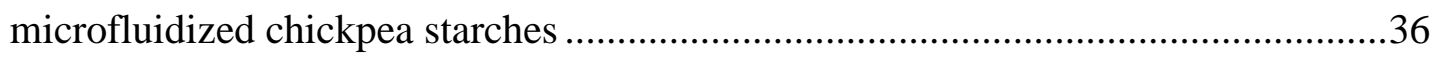

Figure 3.2. Variation of shear stress with shear strain of the native, sonicated and

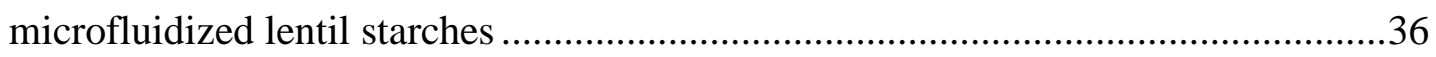
Figure 3.3. Scanning electron micrographs of the native and modified starches. $a, b$ and $\mathrm{c}$ for the native, sonicated and microfluidized chickpea starch respectively; $d, e$ and $\mathrm{f}$ for the native, sonicated and microfluidized lentil starch respectively. .42 Figure 3.4. FTIR spectra of the native, sonicated and microfluidized chickpea starches

Figure 3.5. FTIR spectra of the native, sonicated and microfluidized lentil starches 49 Figure A. 1. Power law fitting curve for native chickpea starch (sample 1).............63

Figure A. 2. Power law fitting curve for native chickpea starch (sample 2).............63

Figure A. 3. Power law fitting curve for sonicated chickpea starch (sample 1) .......64

Figure A. 4. Power law fitting curve for sonicated chickpea starch (sample 2) ........64

Figure A. 5. Power law fitting curve for microfluidized chickpea starch (sample 1) 65

Figure A. 6. Power law fitting curve for microfluidized chickpea starch (sample 2) 65

Figure A. 7. Power law fitting curve for native lentil starch (sample 1)...................66

Figure A. 8. Power law fitting curve for native lentil starch (sample 2)..................66

Figure A. 9. Power law fitting curve for sonicated lentil starch (sample 1) .............67 
Figure A. 10. Power law fitting curve for sonicated lentil starch (sample 2) 67

Figure A. 11. Power law fitting curve for microfluidized lentil starch (sample 1) ...68

Figure A. 12. Power law fitting curve for microfluidized lentil starch (sample 2) ...68 



\section{CHAPTER 1}

\section{INTRODUCTION}

\subsection{Starch}

Starch is the most abundant carbohydrate that is found in plan tissues. It is synthesized by plants as the main storage carbohydrate. Structure and functionality of starch have become an important research area since differences in starch synthesizing genes and enzymes cause synthesis of different starch types. There are various starch types with different functions such as forming clear solutions and providing stickiness during cooking (Keeling \& Myers, 2010).

Starch is not only used in the food industry but also in other industries such as paper and textile (Ölçer, Akin, \& Kampüs, 2008). The industrial use of the starch granule is determined by its functional properties which are affected by amylose/amylopectin ratio and structure, granule structure and lipid, and protein content (Ölçer et al., 2008). It is also nutritionally very important since it supplies the major portion of the carbohydrates in the diet (Li et al., 2018). Keeling and Myers stated (2010) that more than 80 percent of the calories in the world arouse from starch which was a unique supplement in our nutrition.

Origin of the plant determines the shape, size and composition of the starch (Joshi et al., 2013). Cereals, roots, tubers, legumes and some immature fruits can be listed as the major starch sources among plants (Alcázar-Alay \& Meireles, 2015). According to Singh et al. (2004) consumption of the legumes in diet has importance due to their high protein content which is twice of the amount found in cereals and significantly higher than the one found in the root-crops. Although legumes are consumed as whole throughout the history, separation of legumes into its constituents such as starch and protein has become the focus of interest (Singh et al., 2004). 
In this study, two different legume starches: chickpea and lentil were examined. Starch content of the legumes changes between $22-45 \%$ which makes starch as the most abundant carbohydrate in legumes (Aguilera et al., 2009).

\subsubsection{Starch Structure and Synthesis}

Starch is a polysaccharide which is composed of mainly two polymers which are amylose and amylopectin. It is composed of amylose constituting 15-30\% and amylopectin constituting 70-85\% of the starch (Alcázar-Alay \& Meireles, 2015). The ratio of these two polymers depends on the origin of the plant (Tester, Karkalas, \& Qi, 2004). Amylose is a linear chain which comprises of $\alpha-1,4$ glucans and these glucans branch at the $\alpha-1,6$ positions limitedly. On the other hand, linear chains of the glucose which are linked by $\alpha-1,4$ linkages comprise amylopectin. Unlike amylose, this polymer is known to be highly branched at the $\alpha-1,6$ position with an interval of 10 nm. Small glucose chains contribute to branching (Alcázar-Alay \& Meireles, 2015).

In plants, amylopectin branching, amylose/amylopectin ratio and $\alpha$-glucan chain length have an important role on the size and structure of the starch granule (AlcázarAlay \& Meireles, 2015). Figure 1. 1 shows the structures of amylose and amylopectin molecules (Kalita \& Netravali, 2017). 

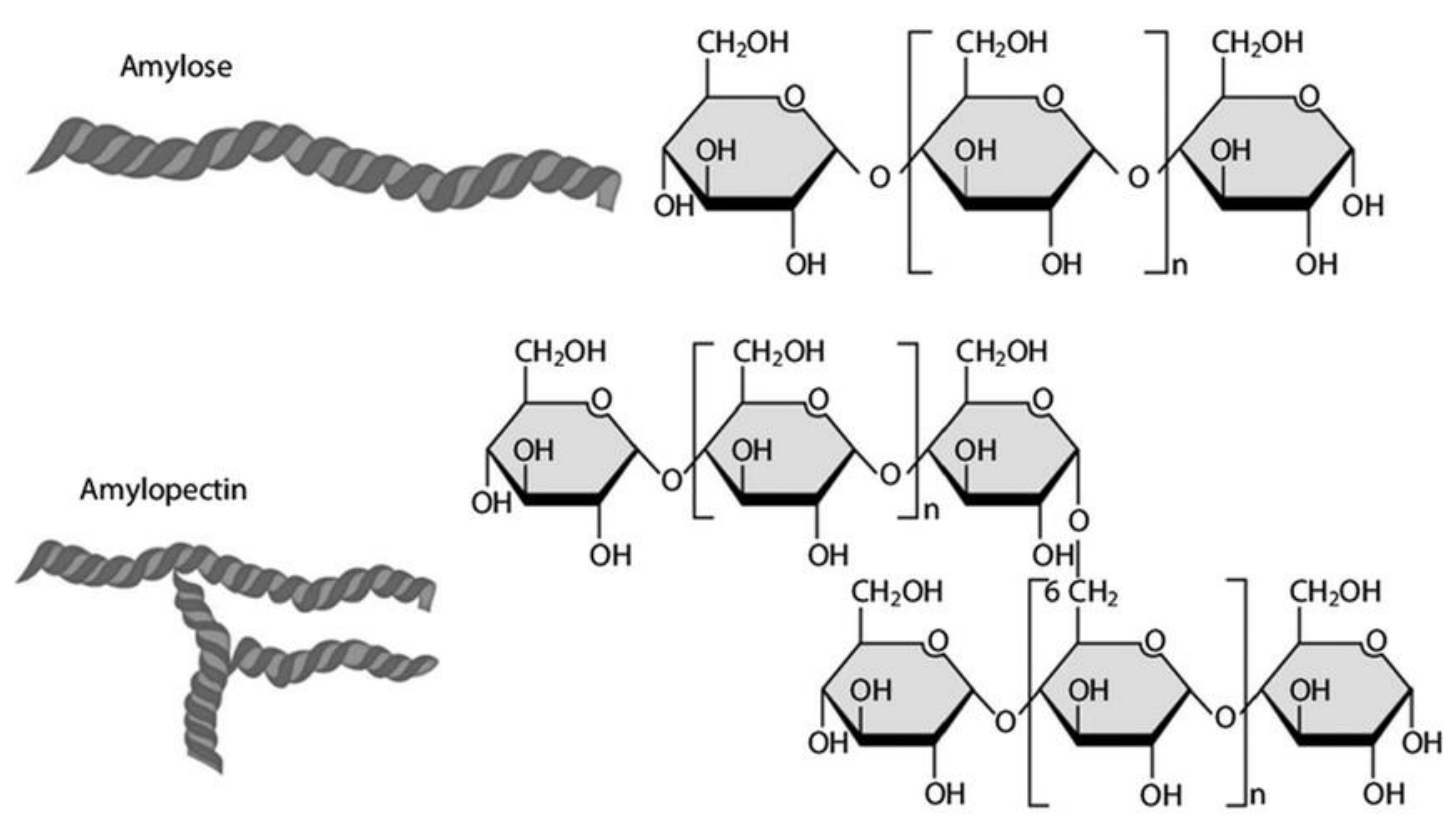

Figure 1.1. Structures of amylose and amylopectin (Kalita \& Netravali, 2017)

The helical chains are formed by the change in the size of the chains and amylopectin's branch points. Semi crystalline structure of the starch originates from the amorphous and crystalline parts of it which are amylose and amylopectin respectively (AlcázarAlay \& Meireles, 2015). Due to the alteration in conformation of these two parts, starches have different degrees of crystallinity values which affect their properties (Buléon et al., 1998). There are three types of crystals in a starch molecule which are A-type, B-type and C-type. Figure 1.2 shows the packing of A-type double helices, Btype double helices and projection of the crystalline packed structures (Buléon et al., 1998). A-type crystals have closely packed double helices and eight $\mathrm{H}_{2} \mathrm{O}$ molecules. B-type crystals have hexagonal packed double helices and have thirty-six $\mathrm{H}_{2} \mathrm{O}$ molecules which cover the channel in this type crystal (Bertoft, 2017). When A type and B type crystals are found in a starch simultaneously, this type starch crystals are named as $\mathrm{C}$ type. Characteristic crystal type of the legume starches is known as $\mathrm{C}$ type. In accordance with similarity to the A type, B type or a type between these two, C type crystals can be classified as $C_{A}, C_{B}$ or $C_{C}$ types (Miao, Zhang, \& Jiang, 2009). 
Cereal starches show A-type crystal characteristics whereas tubers and legumes show B-type and C-type characteristics respectively (Alcázar-Alay \& Meireles, 2015).

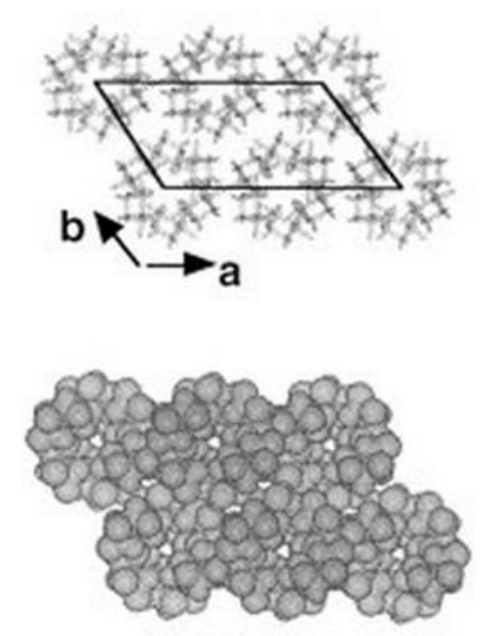

A

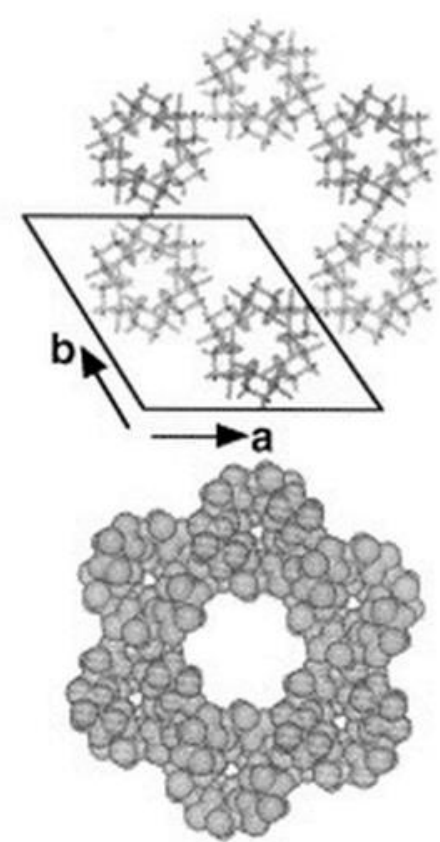

B

Figure 1.2. A-type double helices, B-type double helices and their packing. Crystalline packed structure projected in (a, b) plane. (Buléon et al., 1998)

The starch can be divided into three main groups based on its amylose content. Endosperm tissue of the waxy starches contains less than $15 \%$ of amylose and "waxy" classification for this starch type is originated from the waxy look of the endosperm tissue. Crystallinity of this starch type is higher thus their essential gelatinization energy is higher (Alcázar-Alay \& Meireles, 2015). High amylose starches composed of $30 \%$ of amylose or higher. Granule structures of these starches may be deformed due to containing different types of polysaccharides such as intermediate materials between two main components of it. Minor components of the starches can be categorized into three different groups which are particulate materials, surface constituents and internal constituents. While proteins, enzymes, amino acids and some nucleic acids are the basic surface constituents that can be extracted from starch 
granules, lipids are the major portion of the internal constituents (Buléon et al., 1998). In cereal starches, there are lipid molecules which are related to the amylose portion of the starch and they form free fatty acids and phospholipids. These lipids can cause significantly lower swelling power even if they are found in really small amounts in the granule (Alcázar-Alay \& Meireles, 2015). There is a positive correlation between the amylose content of the starch and lipid fraction (Tester et al., 2004). Also, protein molecules exist on the surface of the starch granule. These proteins and lipids may play a role on the functionality of the starch (Tester et al., 2004). Minerals can be found in starch composition in relatively small amounts. The main mineral that starch contains is phosphorous. Three major forms of the phosphorous in the granule are phosphate monoesters, phospholipids and inorganic phosphate (Alcázar-Alay \& Meireles, 2015). Tester et al. stated (2004) that phosphate monoesters were bounded to the amylopectin molecules in particular regions.

In order to understand the synthesis, storage and degradation process of the starch, it is important to analyze it from different perspectives such as biology, biochemistry and genetics (Keeling \& Myers, 2010). In order to release carbon and energy, plants use starch (Alcázar-Alay \& Meireles, 2015). Starch synthesis is a chain process which includes photosynthesis for the glucose formation in the cells. Chloroplasts of the leaves and amyloplasts are the organelles which are responsible for the formation of the starch granule in the cereals and tubers. Endosperm is the basic position for the formation and storage of the starch granule. This granule is used by the plant for many purposes such as germination, maturation and sprouting (Alcázar-Alay \& Meireles, 2015).

There are three main enzymes that play role on the synthesis of starch. These enzymes are ADP- glucose pyrophosphorylase, starch synthase and starch branching enzymes (Martinl \& Smith, 1995). The first step of the starch biosynthesis is the synthesis of the glucosyl-nucleotide substrate (Buléon et al., 1998). Both amylose and amylopectin is synthesized from ADP-glucose which is synthesized by ADP-glucose pyrophosphorylase (Martinl \& Smith, 1995). The next step is the elongation of the $\alpha$ - 
1,4 linked glucans (Buléon et al., 1998). Synthesis of the $\alpha-1,4$ linkage between ADPglucose and glucan chain is catalyzed by the enzyme starch synthase. Then, starch branching enzyme forms the $\alpha-1,6$ branch. Starch branching enzyme catalyzes the hydrolysis of the $\alpha-1,4$ linkage and the synthesis of the $\alpha-1,6$ linkage in a chain (Martinl \& Smith, 1995). Linear branches are added to the amylopectin by starch branching enzymes. Origin of the plant determines the properties of the starch such as particle size, shape, composition and distribution (Tester et al., 2004).

\subsubsection{Starch Properties}

Physicochemical properties of the starch can be listed as morphology, particle size, shape, crystallinity, composition, solubility and swelling capacity, rheological and thermal properties.

Physicochemical properties of the starch are related to the particle size (Fernando et al., 2015). Diameters of the starch granules are between 0.1 and $200 \mu \mathrm{m}$ which are microscopic sizes. Starch granules may have unimodal, bimodal or polymodal size distribution (Alcázar-Alay \& Meireles, 2015). Reducing the particle size of starch granules gained importance to improve their properties. Ultrasonication is an environmentally friendly method for reducing the size of the starch granules (Fernando et al., 2015). According to Carmona-García et al. (2016), the effect of the ultrasonication depends on the starch granule size due to the differences in energy capture. In addition, optimal cavitation and shear forces in microfluidization makes it suitable for size reduction and dispersion purposes (Kasemwong, Meejaiyen, Srisiri, \& Itthisoponkul, 2011). Origin of the plant determines different morphological characteristics of the starch granules such as oval, ellipsoidal, spherical, smooth, angular and lenticular shapes (Alcázar-Alay \& Meireles, 2015). Even if the plant origin plays an important role on the characteristics of the starch granules, the structure is the same with containing growth rings, blocklets, crystalline lamellae and amorphous lamellae (Bertoft, 2017). Some cereals contain two different granules which differ by their sizes. A-type granules are known as large granules with sizes 
ranging from 15 to $19 \mu \mathrm{m}$. However, B-type granules are known as small granules with sizes ranging from 3.1 to $3.7 \mu \mathrm{m}$ (Bertoft, 2017). Alcázar-Alay and Meireles (2015) stated that shapes of the A-type granules and B-type granules were lenticular and spherical respectively. There may be one or more Maltese cross which is the central line of the starch granule morphology. Having Maltese cross decreases the birefringence ability of the granule which is refracting the polarized light two times (Alcázar-Alay \& Meireles, 2015). Maltese cross is also an important indicator of starch gelatinization as this pattern disappears after gelatinization. Figure 1.3 shows maltese cross in amylose and amylopectin molecules.
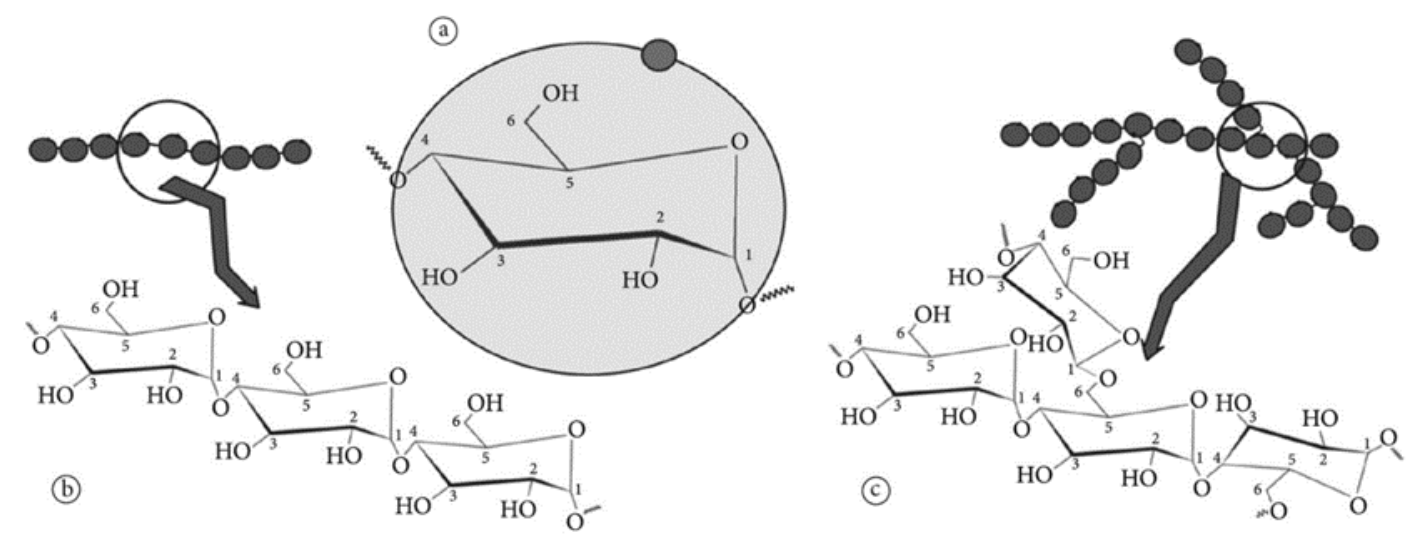

Figure 1.3. Maltese cross in amylose and amylopectin molecules. a) Basic glucose unit, b) Amylose, c) Amylopectin (Alcázar-Alay \& Meireles, 2015)

Complex structure of the starch is related to its composition, structure of its components and differences in amorphous and crystalline regions. Starch granules are semi-crystalline. Amylose and amylopectin are related to the amorphous and crystalline regions respectively. Thus, high amylopectin containing starches have higher degree of crystallinity (Alcázar-Alay \& Meireles, 2015). Short and external chains of amylopectin constitute the crystallites. The relative crystallinity values range from $17-50 \%$ depending on the botanical origin of the starch and waxy starch types have higher crystallinity values than amylose containing starches (Bertoft, 2017). 
Solubility and swelling power are important functional properties of starch and these properties directly affect the utilization of starch. Amorphous and crystalline phases of the granule interact with water molecules and this interaction shows the swelling and solubility characteristics (Alcázar-Alay \& Meireles, 2015). Origin of the plant, granule size distribution, amylose/amylopectin ratio, crystallinity and gelatinization degree affect the solubility and swelling power of the starch granules (Fu, Luo, BeMiller, Liu, \& Liu, 2015). Moreover, solubility and the swelling power are temperature dependent properties (Sujka \& Jamroz, 2013). Amylose portion of the granule shows resistance to swelling and solubility. Thus, there is a direct relation between the swelling behavior of the starch granule and its amylopectin content. When amylose leaches away from the granule, swelling becomes easier (Alcázar-Alay \& Meireles, 2015). After leaching of amylose, absorption of water and swelling of the granule cause the separation of amylose/amylopectin parts and loss of the crystallinity. In the presence of phospholipids in starch granule, granule shows low solubility due to the formation of amylose-phospholipid or amylopectin-phospholipid complexes.

Different processes could result in different changes in the starch structure. Microfluidization which is a high-pressure homogenization technique, causes alterations in morphology and crystalline structure of the starch granules which can change the solubility. Another treatment, ultrasonication was shown to result in destruction of the crystalline structure and formation of hydrogen bonding between amylose and amylopectin and water molecules (Carmona-García et al., 2016).

Microstructural changes in the starch can be analyzed by Nuclear Magnetic Resonance (NMR) which is non-destructive and cost-effective method to analyze the relaxation of protons. Proton mobility and distribution in starch gels has been recently studied by using Time Domain (TD) NMR which allows to analyze the hydrogen atoms' mobility (Ozel et al., 2017). In TD-NMR experiments, spin-spin relaxation times $\left(\mathrm{T}_{2}\right)$ are mostly used for that purpose. Changes in the $T_{2}$ are indicators of the change in microstructure. Thus, for modified starches relaxation times could give information on the changes occurred on the samples. NMR relaxometry was also used by Botosoa 
et al. (2015) to determine how the freshness of the sponge cakes changes during storage. In the study of Botosoa et al. (2015) NMR relaxometry was combined by Thermogravimetric Analysis (TGA) and Differential Scanning Calorimetry (DSC) in order to observe the chemical, physical reactions and molecular changes in cakes. In this study, NMR (Nuclear Magnetic Resonance) relaxometry and DSC was used in order to analyze how the physical modification methods improve the properties of legume starches for various usage in the food industry, not to analyze the aging of the final product.

FTIR is useful method to analyze the molecular changes in the samples and measure the quality after applied processes (Kizil, Irudayaraj, \& Seetharaman, 2002). FTIR measures short range order of starch systems and it has some advantages among other methods used to analyze the structure. It is inexpensive and user friendly (easy to use and maintain). Also, it gives high flexible sample presentation (Warren, Gidley, \& Flanagan, 2016). In this study, native and modified starch samples were analyzed by FTIR in order to observe the changes in the structure.

Starch is glucan that has the ability to gelatinize. Gelatinization is a phase transition process which occurs upon heating in the presence of excess water (Alcázar-Alay \& Meireles, 2015). Granules absorb the water and start to swell. Depending on the type of starch, temperature range and enthalpy for gelatinization process differ. Starches with high degree of crystallinity, stability resists to gelatinization and consequently it occurs at a higher temperature range (Alcázar-Alay \& Meireles, 2015). Amorphous part of the granule contains weak hydrogen bonds which makes it more convenient to gelatinization. Thus, gelatinization energy decreases in the presence of amylose. After amorphous part, the process propagates in the crystalline section (Alcázar-Alay \& Meireles, 2015). Rheological properties and paste viscosity of starch are directly affected by gelatinization (Alcázar-Alay \& Meireles, 2015). Like heat, pressure may also induce gelatinization process in excess water which ends up with starch paste or gel. Heat induced and pressure induced gelatinized starches show alterations in properties which result in alternative starch types to be used in different products 
(Vallons, Ryan, \& Arendt, 2014). Pressure induced gelatinization gained importance due to obtaining starch pastes with unique properties. There are three different starch groups depending on the pressure susceptibility. The first one is the waxy starch type with lower amylose content and, thus higher-pressure susceptibility. Normal starches form the second group with medium pressure susceptibility. High amylose containing starch types form the third group with lower pressure susceptibility (Vallons et al., 2014). Vallons et al. (2014) stated that barroresistance of the high amylose starches resulted from their B-type crystal structure. Effect of the pressure on starch was found to be similar to that of the temperature (Vallons et al., 2014). Swelling starts with the hydration of the amorphous portion of the granule. Then, bending of the crystalline part results in the damage of the granule. Crystalline part becomes easily reachable for water molecules. This mechanism is known as the two-step mechanism (Vallons et al., 2014). Following gelatinization, retrogradation is observed. Retrogradation occurs upon gelatinization at cooling stages (Alcázar-Alay \& Meireles, 2015). Molecular order of the starch granules was lost during gelatinization since swelling proceeds in excess water. Solubilized amylose molecules result in the formation of a gel. In the cooling stage, partial crystallization of this gel is known as "retrogradation" process (Adebowale \& Lawal, 2003).

After swelling, starch granules become susceptible to disruption by shear force. Insolubility of the starch granule in cold water results from the hydrogen bonds and crystal structure. When it is heated, granules start to swell and paste formation occurs which leads to the rise in the viscosity which is an important rheological property. Viscosity is a measure of the thickness and internal friction of a fluid. Based on the viscosity, the energy needed for flow changes. There is an increasing trend for the viscosity control of the starch solutions since it is promising in the industry. Iida et al. state that change in the viscosity is a measure of the effectiveness of process (Iida, Tuziuti, Yasui, Towata, \& Kozuka, 2008). Phase transition of starch into a gel affects its important functions such as thickening, binding, increasing stability and improving mouth feel, and use in the industry (Iida et al., 2008). Viscosity of the starch is one of 
the important properties since it directly effects its functional use. In this study, rheometer was used in order to analyze the flow behavior and viscosity of the starch samples. Obtained shear stress versus shear strain data was analyzed to determine the flow behavior. Data were fitted to Power law model. Power law model was also used to describe the flow behavior of starch pastes in many studies such as rheological analysis of starches from different oat cultivars (Singh \& Kaur, 2017), ultrasonication of corn starch (Jambrak et al., 2010), high pressure homogenization of potato and cassava starches (Che et al., 2009), and dynamic high-pressure microfluidization of rice amylose (Duan, Tu, Wang, Sha, \& Zhu, 2017). In addition to viscosity, texture, clarity, shear strength and retrogradation tendency are other important physical properties of the starch. Commercial utilization of the starch is strongly dependent on these properties, but viscosity is the most important property among them (AlcázarAlay \& Meireles, 2015).

Different Scanning Calorimetry is another technique used to measure the gelatinization temperature of starch. Onset temperature $\left(T_{o}\right)$, peak temperature $\left(T_{p}\right)$, conclusion temperature $\left(\mathrm{T}_{\mathrm{c}}\right)$, gelatinization enthalpy are the thermal properties that can extracted from a Differential Scanning Calorimeter (DSC) thermogram. When the starch is subjected to heat, the temperature at which viscosity of the paste starts to rise is called $T_{o}$, the temperature at which maximum viscosity is obtained is called $T_{p}$ and the final temperature for rise in the viscosity is called as $T_{c}$. The difference between conclusion and onset temperature $\left(\mathrm{T}_{\mathrm{c}^{-}} \mathrm{T}_{\mathrm{o}}\right)$ is a measure of changes in the granule structure in amorphous and crystalline regions (Alcázar-Alay \& Meireles, 2015). Also, DSC results not only shows gelatinization temperature and enthalpy but also gives an idea about degree of gelatinization and retrogradation.

\subsubsection{Chickpea Starch}

There is an increasing trend for eating plant-based foods such as legumes which are also known as whole grains. Legumes are rich in carbohydrates, proteins, fibers, thiamine, calcium, iron and niacin (Han \& Baik, 2006). Legume fibers can be used in 
food applications for fiber enrichment, nutrient fortification, fat binding and retention (Tosh \& Yada, 2010). Their rich composition, low cost and long shelf life make them important sources of human nutrition especially in developing countries. Chickpea and lentil are the most widely preferred among legume types in many countries because of their polysaccharide composition and starch functionality (Aguilera et al., 2009).

Chickpea (C. arietinum) is the widest crop which is planted and harvested at many countries including Middle East, southern Europe, India, North Africa, America and Australia (Kocakulak, Sumnu, \& Sahin, 2019). India produces $75 \%$ of the world's total chickpea which is followed by Turkey, Pakistan and Mexico (Singh et al., 2004). Alternate names of the chickpea are garbanzo beans in US and Bengal gram in India. Length of the chickpea grains ranges from 14 to $30 \mu \mathrm{m}$ and their width ranges from 9 to $30 \mu \mathrm{m}$. Their shape can be oval and spherical (Wani et al., 2016).

Table 1.1 shows the composition of chickpea grains. Total carbohydrates comprise the highest percentage of the chickpea grain with $54.00 \%$. Percentages of protein, lipid, ash, crude fiber and moisture are $18.50,6.69,3.15,9.88,7.79$ respectively. After total carbohydrates, proteins have the second highest percentage. Chickpea provides an important amount of the nutrients required daily. In order to increase their usage in different areas, legumes are separated into their components such as proteins and starches by different ways (Wani et al., 2016).

Table 1.1. Chemical composition of chickpea grains (De Almeida Costa et al., 2006)

\begin{tabular}{ll}
\hline Component & Composition $(\mathbf{g} / \mathbf{1 0 0} \mathbf{g})$ \\
\hline Protein & $18.50 \pm 1.74$ \\
Lipids & $6.69 \pm 0.56$ \\
Ash & $3.15 \pm 0.20$ \\
Crude Fibre & $9.88 \pm 2.11$ \\
Carbohydrates & $54.00 \pm 3.30$ \\
Moisture & $7.79 \pm 0.85$ \\
\hline
\end{tabular}


Composition of the chickpea starch is given in Table 1.2. Amylose content of the chickpea starch ranges from 23.00 to $33.81 \%$. Moisture, lipid, ash and nitrogen of the chickpea starch ranges from $8.78,0.29,0.05,0.08 \%$ to $11.45,0.50,0.06,0.10 \%$ respectively. Moreover, crystal type of the chickpea starch is $\mathrm{C}_{\mathrm{A}}$ type (Miao et al., 2009). Crystallinity of the two chickpea types is different. Due to the differences in the amylopectin fraction, Kabuli starch has higher degree of crystallinity than Desi starch. In Desi type starches, amylose content is higher which reduces double helical content (Miao et al., 2009).

Table 1.2. Chemical composition of chickpea starch (Wani et al., 2016)

\begin{tabular}{ll}
\hline Component & Composition (\%) \\
\hline Moisture (\%) & $8.78-11.45$ \\
Lipid (\%) & $0.29-0.50$ \\
Ash (\%) & $0.05-0.06$ \\
Nitrogen (\%) & $0.08-0.10$ \\
Amylose (\%) & $23.00-33.81$ \\
\hline
\end{tabular}

Due to its high resistant starch content, chickpea starch also helps to prevent foodbased health problems such as diabetes and obesity. Sandhu and Lim (2008) stated that chickpea starch has resistant starch content between $53.4 \%$ and $55.2 \%$. The fact that diabetes risk decreases with chickpea consumption can be explained by its resistant starch content that slows down the digestion. Arp et al. (2018) conducted a study on characterization of wheat dough that was prepared by different amounts of Hi-Maize (HM, type-2 resistant starch). It was stated that resistant starches were helpful to contribute to the daily fiber intake since they were classified as nondigestible carbohydrates (Arp et al., 2018). 


\subsubsection{Lentil Starch}

Lentil (Lens Culinaris) is planted throughout the world and its tolerance to drought is high. Lentils are grown mostly in the India, Mediterranean regions and dry parts of the Middle East (Kaur, Sandhu, \& Lim, 2010). India produces $36 \%$ of the world's lentil since most of the Indian people are vegetarian and lentil is an important source of protein in the Indian diet. Lentils are not only rich sources of carbohydrates and proteins but also dietary fibers, minerals and vitamins such as folate, thiamine, niacin and riboflavin (Kaur et al., 2010)

Color of the lentil grains changes from the yellow, red orange to green, brown and black (Kaur et al., 2010). Mainly, they are separated into two classes depending on their seed coat and cotyledon colors. While green lentils which are also known as Macrosperma are characterized by their green to brown seed coat color and yellow cotyledon color, red lentils which are also known as Macrosperma have grey to dark seed coat color and red cotyledon color (Kaur et al., 2010). Length of the lentil grains ranges from 6 to $37 \mu \mathrm{m}$ and their width ranges from 6 to $32 \mu \mathrm{m}$. Their shape can be oval, spherical and elliptical (Wani et al., 2016). Kaur et al. (2010) stated that lentil starch shows C-type crystal pattern.

Table 1.3 shows the composition of lentil grains. Total carbohydrates comprise the highest percentage of the lentil grain with $56.40 \%$. Percentages of protein, lipid, ash, crude fiber and moisture are 20.60, 2.15, 2.80, 6.83 and 11.20 respectively. After total carbohydrates, proteins have the second highest percentage. 
Table 1.3. Chemical composition of lentil grains (De Almeida Costa et al., 2006)

\begin{tabular}{ll}
\hline Component & Composition $(\mathbf{g} / \mathbf{1 0 0 g})$ \\
\hline Protein & $20.60 \pm 0.37$ \\
Lipids & $2.15 \pm 0.14$ \\
Ash & $2.80 \pm 0.15$ \\
Crude Fibre & $6.83 \pm 2.42$ \\
Carbohydrates & $56.40 \pm 4.08$ \\
Moisture & $11.20 \pm 0.28$ \\
\hline
\end{tabular}

Composition of the lentil starch is given in Table 1.4. Amylose content of the lentil starch ranges from 22.10 to $33.90 \%$. Moisture, lipid, ash and nitrogen of the chickpea starch ranges from $8.90,0.09,0.03,0.03 \%$ to $9.40,0.40,0.25,0.09 \%$ respectively.

Table 1.4. Chemical composition of lentil starch (Wani et al., 2016)

\begin{tabular}{ll}
\hline Component & Composition (\%) \\
\hline Moisture (\%) & $8.90-9.40$ \\
Lipid (\%) & $0.09-0.40$ \\
Ash $(\%)$ & $0.03-0.25$ \\
Nitrogen (\%) & $0.03-0.09$ \\
Amylose (\%) & $22.10-33.90$ \\
\hline
\end{tabular}

Like chickpea, lentil is also a rich source of numerous essential nutrients which supplies an important portion of the daily intake. Starch is the most abundant nutrient in lentil. It has low glycemic index since it contains high amounts of resistant starch that escapes digestion and absorption in the intestines. Sandhu and Lim (2008) stated that lentil starch has resistant starch content between $64.3 \%$ and $66.1 \%$. Resistant starches are similar to the dietary fibers in the diet with their unique characteristics (Kaur et al., 2010). Hence, consumption of this type of starch decreases the diabetes risk like the consumption of chickpea starch. 


\subsection{Starch Modification}

Due to the unstable nature of the native starch to changes in temperature, $\mathrm{pH}$ and shear forces, its application in the industry is restricted (Alcázar-Alay \& Meireles, 2015). To make the starch stable and to make its functional properties proper for use in the industry, various modification strategies have been applied over the last decades (Kaur, Ariffin, Bhat, \& Karim, 2012). Modification is important in terms of increasing starch's positive characteristic and the elimination of its shortcomings (Bemiller, Lafayette, \& In, 1997). Starch modification is an effective method used to increase stability, processability and resistant starch content, increase or decrease viscosity and gelatinization time (Joshi et al., 2013). Also, retrogradation and syneresis tendency of the native ones can be prevented by the modification. Besides, modification can result in the improvement of paste clarity, texture, film formation and adhesion.

Modification of starch is an important process for enhancing cooking characteristics, decreasing retrogradation tendency, increasing freeze-thaw stability, decreasing syneresis, improving paste or gel clarity, improving paste or gel texture, improving film formation and adhesion, and improving emulsion stabilization (Bemiller, Lafayette, \& In, 1997). Also, starch modification not only results in desirable functional properties but also provides an economic alternative to hydrocolloid ingredients like gums (Tharanathan, 2005). These starches can be used in preparation of several products such as ice creams, baked products, infant foods, ready-to-eat foods, high RS containing low GI foods, frozen foods, processed foods like candies, soups, puddings and salad dressings (Tharanathan, 2005).

Modified starches are used for their different functions such as thickening agents, stabilizers and emulsifiers. In industry, modified starches are prepared by treating the native starch physically, chemically and enzymatically to change its properties. The differences in the physicochemical properties of starch determines its specific utilization area (Joshi et al., 2013). 


\subsubsection{Chemical Modification}

Chemical modification is mainly based on introducing functional groups to the starch granules so that physicochemical properties are changed. For starch ester and ether preparations hydroxyl groups are the basis of the chemical modification which enable intramolecular and intermolecular bonding at random places (Ashogbon \& Akintayo, 2014). Starches from different origins can be modified by chemical modification methods in order to change the gelatinization, pasting and retrogradation behaviors. Properties of the chemically modified starches are affected by treatment conditions such as $\mathrm{pH}$, temperature, reactant concentration, reaction time and the presence of catalyst. Moreover, origin of the starch, type of substituent, and degree of substitution have effect on the physicochemical properties of the modified ones (Ashogbon \& Akintayo, 2014).

Acetylation, cationization, oxidation, acid hydrolysis and cross linking are derivatization methods used in chemical modification of starch. Since there is some environmental and human health related concerns about these chemical methods, dual modification methods are developed recently (Ashogbon \& Akintayo, 2014). Dual methods such as microwave assisted acetylation or high hydrostatic pressure (HHP) assisted phosphorylation combines physical and chemical methods (Ashogbon \& Akintayo, 2014). These methods reduces the modification time and increases the production (Kaur et al., 2012). Dual modification is an effective method for obtaining emulsifiers, binders and thickeners for the food industry and heavy metal adsorbents for the non-food industries (Ashogbon \& Akintayo, 2014). Cationic starches are obtained by reacting the starches with reagents that includes amino, ammonium, sulphonium or phosphonium groups. Granule morphology and physicochemical properties are improved by cationization methods (Ashogbon \& Akintayo, 2014). Cross-linked starches are prepared by various cross-linking agents. Type of the reagent affects the functional properties of the starch after modification since different agents causes different molecular structures (Ashogbon \& Akintayo, 2014). Native starch is esterified with acetic anhydrate or vinyl acetate in the presence of alkaline 
catalyst to obtain acetylated starches which can be used in various functions such as film forming, binding, thickening, stabilizing and texturing (Ashogbon \& Akintayo, 2014). Acid hydrolyzed starches are applicable in the industries such as food, paper, textile and pharmaceutical. Moreover, oxidation treatment supplies starches with surface sizing and coating properties for usage in food and non-food industries (Ashogbon \& Akintayo, 2014). Although chemical modification results in improved starch properties, these methods are not environmentally friendly and consumers have significant concerns about these methods (Kaur et al., 2012).

\subsubsection{Enzymatic Modification}

Enzymatic modification is mainly based on hydrolyzing the starch with different enzymes (Kaur et al., 2012). Amylo-maltase is one of these enzymes which helps to obtain starches that form thermoreversible gels and its usage results in chemical free alternative to gelatin. It is obtained from Eukarya, bacteria, and archaea which are the living organism types. Amylo-maltase treated starches can be used in foods, cosmetics, pharmaceutics, detergents, adhesives and drilling fluids (Kaur et al., 2012). This modified starch type is known as the plant-derived substitute for gelatin. The only restriction is the turbidity of the gels prepared by this starch since gels prepared by gelatin are transparent (Kaur et al., 2012). Also, amylomaltase modified starches with extended amylopectin chain lengths can be used as fat replacers. Moreover, treating the native starch with a glycogen branching enzyme causes highly branched structure and retrogradation is delayed by the reaction that takes place. Cyclomaltodextrinase obtained from alkalophilic Bacillus can be used to decrease the amylose content of the native starch (Kaur et al., 2012).

Enzymatic modification can also be used to obtain slowly digested starches. By enzymatic reaction, branching increases and crystalline structure forms which helps to obtain slowly digested starches which are the basis of low glycemic index (GI) 
foods. Low GI foods gained importance since they contribute to the control of some diseases such as diabetes, cardiovascular diseases and obesity (Kaur et al., 2012).

In food industry, starch syrups are prepared by enzymatic modification. This technology is known to be the most advanced one among enzyme technologies in the food industry because of higher yield, wider product range, higher product quality and higher energy saving (Tharanathan, 2005).

\subsubsection{Physical Modification}

Nowadays, physical modification methods have become popular to meet the increasing needs for functional modified starches to be used in various areas. Physical methods are environmentally friendly and sustainable techniques. Since chemicals are not used in these methods, this type of modified starches are inexpensive (Ashogbon \& Akintayo, 2014). Reduction of particle size of the starch can be achieved by physical modification methods which are mainly based on treatment under pressure, shear, sonication, and variant temperature/moisture conditions. These methods gained attraction since they don't contain any chemical usage and they are not harmful for human health (Ashogbon \& Akintayo, 2014).

Physical methods can be divided into three groups which are pre-gelatinization, hydrothermal and non-thermal processes (Ashogbon \& Akintayo, 2014). Physically modified starches are categorized depending on whether the integrity of molecules disrupted or conserved. Pre-gelatinization processes such as spray drying, drum drying and extrusion cooking cause destruction of the molecular integrity by partial depolymerization of components. However, hydrothermal processes such as annealing (ANN) and heat-moisture treatment (HMT) conserve the molecular integrity of the starch (Ashogbon \& Akintayo, 2014).

In the pre-gelatinization process, the main purpose is to obtain completely gelatinized and dried starches (Alcázar-Alay \& Meireles, 2015). Granule structure was disrupted, 
and it results in fragmentation of the molecule. Pre-gelatinized starches have improved water solubilities and they can be used to obtain instant starch slurries without heat treatment. Physicochemical properties of these starches are affected by cooking and drying conditions and the origin of the starch (Ashogbon \& Akintayo, 2014).

Hydrothermal processes are used to modify starches to improve its properties without disruption of the granule. ANN and HMT are the two hydrothermal modification methods which are applied at temperatures between the gelatinization temperature and glass transition temperature and they both cause significant changes in the physiochemical properties (Alcázar-Alay \& Meireles, 2015). Moisture level, temperature and application time are specific for both two methods. HMT treatment is conducted at low moisture levels, whereas ANN treatment is conducted in excess water. ANN treatment targets increasing the molecular mobility without gelatinizing the starch (Ashogbon \& Akintayo, 2014). By HMT, morphological and physiochemical properties such as crystallinity, swelling power, gelatinization, paste properties and retrogradation can be significantly altered (Alcázar-Alay \& Meireles, 2015).

Non-thermal physical modification methods are important in terms of preservation of the nutritional value and extending the shelf life of the products (Alcázar-Alay \& Meireles, 2015). Pathogenic or spoilage microorganisms are destroyed and enzymes are inactivated by non-thermal modification methods so that taste, texture, nutrients, color and components that are unstable to heat are preserved (Ashogbon \& Akintayo, 2014). These methods are mainly based on the use of ultrasound, high-pressure, microwaves and electric pulses. In food industry, starch is treated by high pressure ranging from 400 to $900 \mathrm{MPa}$ to increase its functionality (Alcázar-Alay \& Meireles, 2015). Also, high power ultrasound is used by researchers to improve the properties of starch. Application of electric pulses inactivates microorganisms without heat treatment, and it is known as non-thermal food preservation method. 
In this thesis, two physical modification methods were examined to improve the properties of two legume starches. Effect microfluidization and ultrasonication on the physical properties were investigated.

\subsubsection{Ultrasonication}

Although ultrasonication method gained importance in recent years, this technology dates back to the Second World War. It can be used for many purposes such as emulsification, homogenization, and extraction (Soria \& Villamiel, 2010). Ultrasonication is a rapid, effective and reliable method for improving the quality of the foods. It is also used in developing new food products with specific characteristics (Soria \& Villamiel, 2010).

In ultrasonication of starch, the main mechanism is that granules are disrupted, cavitation bubbles collapse and crystalline structure is broken (Carmona-García et al., 2016). Ultrasonic waves pass through a liquid medium leading to formation, growth and collapse of microbubbles in very short times that is called as cavitation. When ultrasonication is performed in a liquid medium, pressure change on each volume element is observed (Czechowska-Biskup, Rokita, Lotfy, Ulanski, \& Rosiak, 2005). The first mechanism is that if the pressure reduction is lower than the threshold value for the tensile strength, small bubbles filled with gas are formed. Cavitation triggers the chemical reactions in a medium (Czechowska-Biskup et al., 2005). Collapse of the bubbles during cavitation causes physical and chemical changes such as shear, turbulence and reactive radical formations (Koh et al., 2013). High pressure gradients and local velocities are formed by these collapsing bubbles leading to the shear forces. Shear forces can destroy the polymer chains by the mechanism known as mechanochemical action of ultrasonication (Czechowska-Biskup et al., 2005). Due to strong hydrodynamic shear-forces caused by cavitation, ultrasonication can be used as an alternative to high-speed mixers and it is used as a technique to disperse nanomaterials in different matrices (Koh et al., 2013). In the second mechanism called 
radial attack, solvent molecules of the formed bubble diverge and cause the formation of free radicals. The hydroxyl radicals and hydrogen atoms are formed by disruption of the water molecules. Formed radicals spread around and react with the solute molecules. Solvent radical formation and reaction of these radicals with solute molecules are the basis of the radial attack mechanism (Czechowska-Biskup et al., 2005). Both mechanisms are known as shear induced degradation of the polymer which is restricted by the minimum chain length (Czechowska-Biskup et al., 2005).

Ultrasonication medium and parameters such as power, frequency and temperature are important in terms of optimization of the process. As sonication intensity increases, the effect of ultrasonication increases as well. Temperature affects the number of cavitation bubbles. Sujka and Jamroz (2013) also stated that frequency, power, temperature and time of sonication and starch properties affects the ultrasonication intensity. In food applications, ultrasonication method cause an alteration of the structure and thus selecting the process parameters is an important step to prevent the losses in the quality of the product (Kaltsa \& Gatsi, 2014).

\subsubsection{Microfluidization}

High pressure processes are novel technologies for obtaining modified starches with improved properties. Microfluidization (high pressure homogenization) technology is a continuous high-pressure process which combines high velocity, vibration, pressure drop, cavitation, shear and ultra-high pressures (Tu, Yin, Wang, Liu, Chen, Zhang, Kou, et al., 2013).

Kasemwong et al. state that starch microstructure is modified by microfluidization treatment (Kasemwong et al., 2011). Microfluidization treatment is applied by using microfluidizer which operates generally at pressure range of 5-200 MPa. This pressure causes a force on the liquid to pass through interaction chamber. The mechanism is to separate the pressure into two lines and routing the flows at each other (Kasemwong et al., 2011). Between the inlet and outlet of the valve in which the fluid is forced throughout pressure, there is high pressure gradient. The generated shear and 
cavitation affects the disruption of the aggregate (Koh et al., 2013). In microfluidization, high pressure experienced over very short time causes formation of smaller particles. The cavitation, shear and turbulence are induced concurrently by the pressure in microfluidization (Koh et al., 2013). During cavitation, cavities filled with gas are formed due to the pressure drop and these cavities collapse because of the rise in the pressure. The collision of the bubbles causes high pressure and velocity gradients which bring about shear forces (Che et al., 2009). Microfluidization is a dynamic phenomenon in which covalent bonds of polymer chains are disrupted by shear forces. This process is known as the mechanochemical action of homogenization (Che et al., 2009). Schematic of the microfluidizer is shown in Figure 1.4.

Inlet reservoir

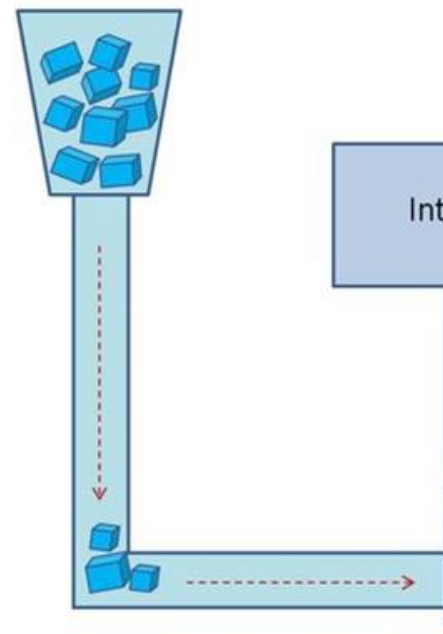

Outlet reservoir Intensifier Pump
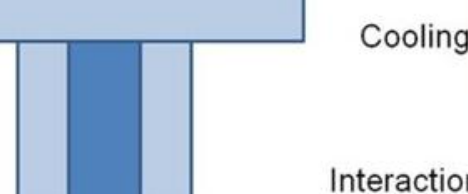

Interaction chamber

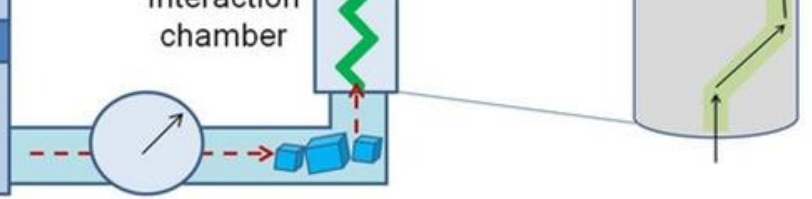

Pressure Gauge

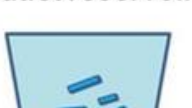


can be combined to obtain more stable products by microfluidization treatment. Properties and thus quality of the product can be enhanced by this mechanical process (Che et al., 2009). Lower gelatinization temperature, higher swelling and higher viscosity are some of the improved properties of starches which are obtained by highpressure treatments (Kasemwong et al., 2011).

Microfluidization was used by Tu et al. (2013) for modification of maize amylose, by Kasemwong et al. (2011) to observe the changes in cassava starch granule and by Duan et al. (2017) for modification of rice amylose.

\subsection{Literature Gap}

There are many studies conducted by different researchers on the physical modification of the starch.

Li et al. (2011) studied the high hydrostatic pressure (HHP) which is also a physical method for the modification of rice starch (Li et al., 2011). Ultrasonication method was also used by Sit et al. (2014) for starch isolation purpose. Starch from Taro tubers were isolated by using sonication and the aim of the study was to investigate the effect of the sonication parameters on the yield and functional properties of the taro starch. The study conducted by Sit et al. (2014) focused on the tuber starch isolation by sonication method and analysis of the functional and textural properties. In the study of Koh et al. (Koh et al., 2013), sonication, high shear mixing and homogenization techniques were compared in terms of effectiveness in improving heat stability of whey protein gels. While the methods used showed similarity, the purpose of the study conducted by Koh et al. (2013) was different from this study in terms of the raw material. Researchers also investigated the modification of rice starch by high-speed jet method. It was found that rheological properties of the starch changed and integrity of the starch granules was lost by high-speed-jet method (Fu et al., 2015). In another study, cassava starch was modified by microfluidization. The results showed that granules were partially gelatinized after the treatment, and destruction of the crystal structure was observed (Kasemwong et al., 2011). Rice amylose was also modified by 
researchers by dynamic high-pressure microfluidization (Duan et al., 2017). It was found that high pressure microfluidization had an important effect on the crystalline structure and morphology of the starch granule. Luo et al. (2008) conducted a study on the modification of maize starch by ultrasound. They found out that modified samples showed higher swelling power and lower gelatinization enthalpy values than native starch (Luo et al., 2008). Ahmeda et al. (2016) stated that destruction of starch granule caused a change in the functional properties of lentil starch when high pressure treatment was applied.

In this thesis, ultrasonication and microfluidization (a high-pressure technique) were investigated for the modification of chickpea and lentil starches which are legume starches. In addition to the conventional characterization techniques which were performed in afore mentioned studies (such as functional, rheological, physical and thermal analysis), NMR relaxometry and FTIR experiments were also performed for the modified starches.

\subsection{Objectives of the Study}

The studies on the investigation of ultrasonication and microfluidization on properties of starches are limited in literature. Although conducted studies are helpful to understand how treatments affect the physicochemical properties of modified starch, there are no studies in literature about the modification of chickpea and lentil starches by using microfluidization and ultrasonication methods. Chickpea and lentil starches are legume starches which have high resistant starch content and excellent functionality. It makes their use in food applications important. Since starch is sensitive to processing it is possible that microfluidization and ultrasonication could result in the improvement of the properties of starch such as rheological properties, thermal properties, functional properties and morphology. Thus, the main objective of the study is to obtain modified legume starches from different sources (lentil and chickpea) by using microfluidization and ultrasonication methods. It was also aimed 
to determine the effects of these methods on the functional (solubility and swelling power), rheological and thermal properties, particle size, morphology and crystal structure of modified starch samples. Time Domain NMR relaxometry experiments were also conducted to understand the changes in the microstructure of modified starches. This study could fill the knowledge gap of comparison of ultrasonication and microfluidization methods on modification of two legume starches. 


\section{CHAPTER 2}

\section{MATERIALS AND METHODS}

\subsection{Materials}

The chickpea and lentil flours from Aro-Tech (İzmir, Turkey) were used for the starch isolation.

\subsection{Starch Isolation}

The method of the Lim et al. (1992) for the isolation of starch by using high shear was used with slight modifications (Lim et al., 1992). Flour of $10 \mathrm{~g}$ was mixed with 30 milliliters of distilled water and soaked for 12 hours at room temperature. Following soaking, the mixture was homogenized at $8,000 \mathrm{rpm}$ for 10 minutes by using high speed homogenizer (T18 Digital UltraTurrax,IKA, Staufen, Germany). A centrifuge (MF 80 General Centrifuge, Hanil, Incheon, South Korea) was used for the separation of starch. The mixture was mixed at 4,000 rpm for 4 minutes and the supernatant was discarded. The precipitate was taken to a petri dish and dried overnight at $40^{\circ} \mathrm{C}$. The dried starch samples were ground (Fakir, Germany) to obtain powder samples. Samples were finally stored in an air tight container for further analysis.

\subsection{Starch Modification}

Two starch types (chickpea and lentil starches) were modified by ultrasonication and microfluidization methods using the parameters determined by preliminary experiments.

\subsubsection{Ultrasonication}

For ultrasonication, $5 \%(\mathrm{w} / \mathrm{w})$ starch suspension was prepared by mixing 5 grams of powder sample with $100 \mathrm{ml}$ of distilled water (Carmona-García et al., 2016). The 
solution was mixed gently by using magnetic stirrer at $450 \mathrm{rpm}$ for 5 minutes. Ultrasonic Homogenizer (Sonic Ruptor 400, Omni International, Kennesaw, GA, USA) which operates at total power of 400 watts and output frequency of $20 \mathrm{kHz}$ was used. Sonication of native samples was conducted at $30 \%$ power and $50 \%$ pulse for 15 minutes in an ice bath. Then the solution was centrifuged at 4,000 rpm for 4 minutes and the precipitate was dried overnight at $40^{\circ} \mathrm{C}$. After grinding the dried samples, sonicated powder was obtained for further analysis.

\subsubsection{Microfluidization}

For the microfluidization method, starch suspension $(6 \% \mathrm{w} / \mathrm{w})$ was prepared by mixing 6 grams of starch sample and 100 milliliters of distilled water (Tu et al., 2013). The suspension was mixed gently by using magnetic stirrer at $450 \mathrm{rpm}$ for 5 minutes. Treatment of the suspension was conducted with a laboratory scale microfluidizer (ISA-N-10M Nano Disperser, Ilshin Autoclave Co. Ltd., Daejeon, South Korea) at $130 \mathrm{MPa}$ pressure level for five passes. After centrifuging the suspension at 4,000 rpm for 4 minutes, the precipitate was collected and dried overnight at $40^{\circ} \mathrm{C}$. Microfluidized powder was obtained by grinding the dried precipitate.

\subsection{Analysis of the Starch}

\subsubsection{Functional Properties (Solubility and Swelling Power)}

Solubility and swelling power of the starches were determined by using the method of Choi (2009) with slight modifications (Choi et al., 2009). Preparation of $40 \mathrm{ml} \mathrm{starch}$ suspension $(1 \%(\mathrm{w} / \mathrm{v}))$ was completed in a centrifuge tube which was tared before the experiment. For 30 minutes, the suspension was allowed to stand in a shaking water bath at $90^{\circ} \mathrm{C}$. After centrifuging at 3,000 rpm for 30 minutes, the weight of the precipitate was recorded instantly. Drying of the supernatant at $120^{\circ} \mathrm{C}$ for 4 hours, which was the next step, was important in terms of reaching the constant weight. When the constant weight was obtained, the starch sample remaining in the supernatant was weighed and recorded (Tu et al., 2013). For the calculation of the solubility and swelling power of the starch samples, equations 1 and 2 were used respectively: 
Solubility $\left(\frac{\mathrm{g}}{100 \mathrm{~g}}\right)=\frac{\text { Weight of the soluble material in the supernatant }(\mathrm{g}, \text { dry basis })}{\text { Weight of the starch sample }(\mathrm{g}, \text { dry basis })} \times 100$

Swelling Power $\left(\frac{\mathrm{g}}{100 \mathrm{~g}}\right)=\frac{\text { Weight of the precipitate }(\mathrm{g}, \text { dry basis })}{\text { Weight of the starch sample }(\mathrm{g}, \text { dry basis }) *(100-\text { Solubility })} \times 100$

\subsubsection{Rheological Properties}

Rheological properties were analyzed by a rheometer (Kinexus lab+, Malvern Instruments Ltd., Worcestershire, UK). For the analysis, cup and bob geometry was filled with 20 milliliters of 10\% (w/w) starch suspensions (Jambrak et al., 2010). The shear stress values of the samples with increasing shear rate (from $0.1 \mathrm{~s}^{-1}$ to $100 \mathrm{~s}^{-1}$ ) were recorded and measurements were conducted at room temperature. The values were fitted to the power law by using the following formula:

$\tau=\mathrm{k}+\gamma^{\mathrm{n}}$

$\log \tau=\log \mathrm{k}+\mathrm{n} \log \gamma$

where;

$\mathrm{n}$ : flow behavior index, $\mathrm{k}$ : consistency index $\left(\mathrm{Pa} . \mathrm{s}^{\mathrm{n}}\right), \tau$ : shear stress $(\mathrm{Pa})$ and $\gamma$ : shear $\operatorname{rate}\left(\mathrm{s}^{-1}\right)$.

\subsubsection{Thermal Properties}

The gelatinization properties of the native and modified starch samples were analyzed by using Differential Scanning Calorimeter DSC 4000 (Perkin Elmer, Waltham, MA, U.S.A.).

The starch suspension with a starch to water ratio of 1:2(w/w) was prepared by mixing on magnetic stirrer (Fu et al., 2015). The suspension was loaded into the aluminum pans (Perkin Elmer, Waltham, MA, U.S.A.) with a capacity of $30 \mu 1$. Sealing of the samples was completed hermetically. The samples were heated from $25^{\circ} \mathrm{C}$ to $120^{\circ} \mathrm{C}$ with a heating rate of $10^{\circ} \mathrm{C} / \mathrm{min}$. Onset temperature $\left(T_{o}\right)$, peak temperature $\left(T_{p}\right)$, conclusion temperature $\left(\mathrm{T}_{\mathrm{c}}\right)$ and enthalpy of gelatinization $\left(\Delta \mathrm{H}_{\mathrm{gel}}\right)$ were determined as 
the thermal properties of the samples. Enthalpy values $(\mathrm{J} / \mathrm{g})$ of the starch samples were expressed on dry starch basis (Kasemwong et al., 2011). Gelatinization degree of the samples were calculated by using the following formula (Sakiyan et al., 2011);

Degree of gelatinization $(\%)=\frac{(\Delta \text { Hnative }-\Delta \text { Htreated })}{\Delta \text { Hnative }} \times 100$

\subsubsection{Scanning Electron Microscopy (SEM)}

Morphology of the native and modified starches was characterized by Field Emission Scanning Electron Microscopy (FESEM) (JEOL, Japan). After sticking the samples on metal stubs, they were coated with gold palladium for the analysis. Coated samples were analyzed using a voltage of $10 \mathrm{kV}$ (Claver et al., 2010). The images taken by 5000x magnification were analyzed. Experiments were conducted at SEM (Scanning Electron Microscopy) Laboratory of METU Metallurgical and Materials Engineering Department.

\subsubsection{Measurement of the Mean Particle Size}

Particle size distribution of the native and modified samples was analyzed by Mastersizer 3000 (Malvern Instruments Ltd., Worcestershire, UK). The particle refractive index and the particle absorption index values were selected as 1.51 and 0.01 respectively (Devi et al., 2009). For water, the refractive index value was 1.33. $\mathrm{D}[4,3]$ (volume mean diameter) and span values of the samples were determined from the software (Ahmeda et al. 2016).

$$
\begin{aligned}
& \mathrm{D}[4,3]=\frac{\sum_{1}^{n} D_{i}^{4} v_{i}}{\sum_{1}^{n} D_{i}^{3} v_{i}} \\
& \text { Span }=\frac{D_{90}-D_{10}}{D_{50}}
\end{aligned}
$$

Where $D_{i}$ is the diameter $(\mu \mathrm{m})$ of the $i^{\text {th }}$ particle and $v_{i}$ is the fraction. 


\subsubsection{TD-NMR and Relaxation Experiments}

Time Domain NMR (Nuclear Magnetic Resonance) was used for the analysis of native and modified starches. Spin Track NMR Spectrometer (Resonance Systems, Mary el, Russia) operating at a frequency of $20.34 \mathrm{MHz}$ with an $\mathrm{rf}$ coil size of $10 \mathrm{~mm}$ was used for the experiments (Grunin et al., 2016) .

$\mathrm{T}_{2}$ relaxation times for the samples were measured using a CPMG (Carr-PurcellMeiboom-Gill) sequence with echo time of 40 us, 128 scans and 400 ms repetition time. $T_{2}$ values were calculated using MATLAB 2017 (Mathworks, NJ, USA). Mono and biexponential fitting of the $T_{2}$ decay curves were conducted to calculate the $T_{2}$ values.

\subsubsection{Fourier Transform Infrared Spectroscopy (FTIR)}

Fourier Transform Infrared Spectroscopy (FTIR) spectra of the native and treated samples were analyzed by IR Affinity-1 Spectrometer with Attenuated Total Reflectance (ATR) attachment (Shimadzu Corporation, Kyoto, Japan). Powder starch samples were used, and the region was selected as $550 \mathrm{~cm}^{-1}-4000 \mathrm{~cm}^{-1}$. Scans of 32 were collected, and background correction was carried out after each scan. The mean of the scans was recorded to report the results for each spectrum.

\subsubsection{Statistical Analysis}

To determine whether there was significant difference between the analysis results of the native starch samples and their modified ones, analysis of variance (ANOVA) was performed by using Minitab Software (Version 17) (Minitab, UK). Tukey's test was used $(\mathrm{p}<0.05)$ for the comparison of the means. Significantly different values were specified with different letters. 


\subsubsection{Summary of the Experimental Design}

Factors and their corresponding levels and responses are summarized in Table 2.1.

Table 2.1. Factors, levels and responses used in the study

\begin{tabular}{lll} 
Factors & Levels & Responses \\
& & \\
\hline Starch Type & Chickpea Starch & 1. Solubility \\
& Lentil Starch & 2. Swelling Power \\
& 3. Rheological Properties \\
Modification Method & Ultrasonication & 4. Thermal Properties \\
& Microfluidization & 5. Particle Size \\
& 6. Microstructure
\end{tabular}




\section{CHAPTER 3}

\section{RESULTS AND DISCUSSION}

\subsection{Functional Properties (Solubility and Swelling Power)}

Functional properties of the native and modified starches are given in the Table 3.1 for two types of legumes (chickpea and lentil). The solubility of the native, sonicated and microfluidized chickpea starches were found as 15.22, 7.44 and $12.54 \mathrm{~g} / 100 \mathrm{~g}$, respectively (Table 3.1). The results showed that solubility of the chickpea starch decreased significantly (Table B.7) with both treatments $(p<0.05)$. However, ultrasonication was found to have more effect on the solubility $(\mathrm{p}<0.05)$. The reason could be the effect of cavitation forces on the partial assembly of amylose (Gonçalves et al., 2014). For lentil, just like chickpea, solubility decreased significantly (Table B.9) by both treatments $(\mathrm{p}<0.05)$. For two types of modified lentil starches, there was no significant difference in the solubility values $(\mathrm{p}<0.05)$. It was reported that solubility of maize amylose showed significant decrease at high microfluidization pressures which might have resulted from the gelatinization and retrogradation of amylose portion of the starch (Tu et al., 2013) . Fu et al. (2015) stated that the origin of starch, granule size distrubution, amylose to amylopectin ratio, gelatinization and crystalline structure had important effects on the solubility of starches. In this study, microfluidization treatment caused a decrease in starch solubility $(\mathrm{p}<0.05)$ as it might have altered the crystalline structure and morphology of the starch (Fu et al., 2015). 
Table 3.1. Functional properties (Solubility (S) and Swelling Power (SP)) of the starches

\begin{tabular}{llll}
\hline Starch & Treatment & Solubility $(\mathbf{g} / \mathbf{1 0 0 g})$ & Swelling Power $(\mathbf{g} / \mathbf{1 0 0 g})$ \\
\hline Chickpea & Native & $15.22 \pm 0.09^{\mathrm{a}^{*}}$ & $8.21 \pm 0.08^{\mathrm{c}^{*}}$ \\
& Sonicated & $7.44 \pm 0.12^{\mathrm{c}}$ & $9.33 \pm 0.12^{\mathrm{b}}$ \\
& Microfluidized & $12.54 \pm 0.20^{\mathrm{b}}$ & $10.22 \pm 0.19^{\mathrm{a}}$ \\
& & & \\
Lentil & Native & $14.63 \pm 0.53^{\mathrm{a}^{*}}$ & $10.26 \pm 0.07^{\mathrm{b}^{*}}$ \\
& Sonicated & $10.45 \pm 0.24^{\mathrm{b}}$ & $11.23 \pm 0.04^{\mathrm{a}}$ \\
& Microfluidized & $12.01 \pm 0.33^{\mathrm{b}}$ & $11.37 \pm 0.04^{\mathrm{a}}$ \\
\hline
\end{tabular}

* Values with different letters are significantly different $(\mathrm{p}<0.05)$. Values are expressed as mean \pm SE mean.

The swelling power values of the native, sonicated and microfluidized chickpea starches were found to be $8.21,9.33$ and $10.22 \mathrm{~g} / 100 \mathrm{~g}$ respectively. Swelling power of the chickpea starch showed significant increase (Table B.8) as compared to native one $(\mathrm{p}<0.05)$. There was also significant difference between the swelling power values of the sonicated and microfluidized chickpea starches $(\mathrm{p}<0.05)$. Microfluidization was found to be more efficient in increasing swelling power value of the native chickpea starch $(\mathrm{p}<0.05)$. In addition, swelling power values of the lentil starch increased significantly (Table B.10) with both treatments $(\mathrm{p}<0.05)$. Unlike modified chickpea starches, swelling power of the modified lentil starches did not show significant difference $(p<0.05)$. Both methods were found to be effective in increasing the swelling power of the native lentil starch $(\mathrm{p}<0.05)$. Increasing swelling power values with both of the treatments might have resulted from the decreased granule size which provided more surface area and more interaction with hydroxyl groups of the water molecules and thus more swelling (Tu et al., 2013). According to the study conducted by Luo et al. (2008), swelling power values of the sonicated starches showed an increase as compared to native one. Arrangement of the amylose and amylopectin might have caused changes in the swelling behavior since ultrasound energy is responsible for the breakage of molecular bonds thus arrangements of the granules changes (Luo et al., 2008). Increasing swelling power values of both chickpea and 
lentil starches when ultrasound or microfluidization were applied might be the result of the change in the granule arrangements .

Inter-associative forces between the amorphous and crystalline parts of the starches mainly affect their solubility and swelling characteristics. Moreover, amylose to amylopectin ratio is found to have an important effect on these characteristics (Kusumayanti et al., 2015). The significant difference in the solubility and swelling power values of the sonicated and microfluidized chickpea starches, which have solubility values of 7.44 and $12.54 \mathrm{~g} / 100 \mathrm{~g}$ and swelling power values of 9.33 and $10.22 \mathrm{~g} / 100 \mathrm{~g}$ for sonicated and microfluidized respectively, may be due to its amylose/amylopectin ratio and crystalline structure.

\subsection{Rheological Properties}

The relationships between shear stress and shear strain of the native, sonicated and microfluidized starches (chickpea and lentil) are shown in Figure 3.1 and Figure 3.2 respectively. The starches showed typically Non-Newtonian and shear thinning behavior since the viscosities of both samples showed a decrease with increasing shear rate. There are some factors that play important roles on the shear thinning behavior such as the fine structure and amounts of amylose and amylopectin found in the starch. Shear thinning behavior is observed due to the broken structural network (Subramanian et al., 1994). 


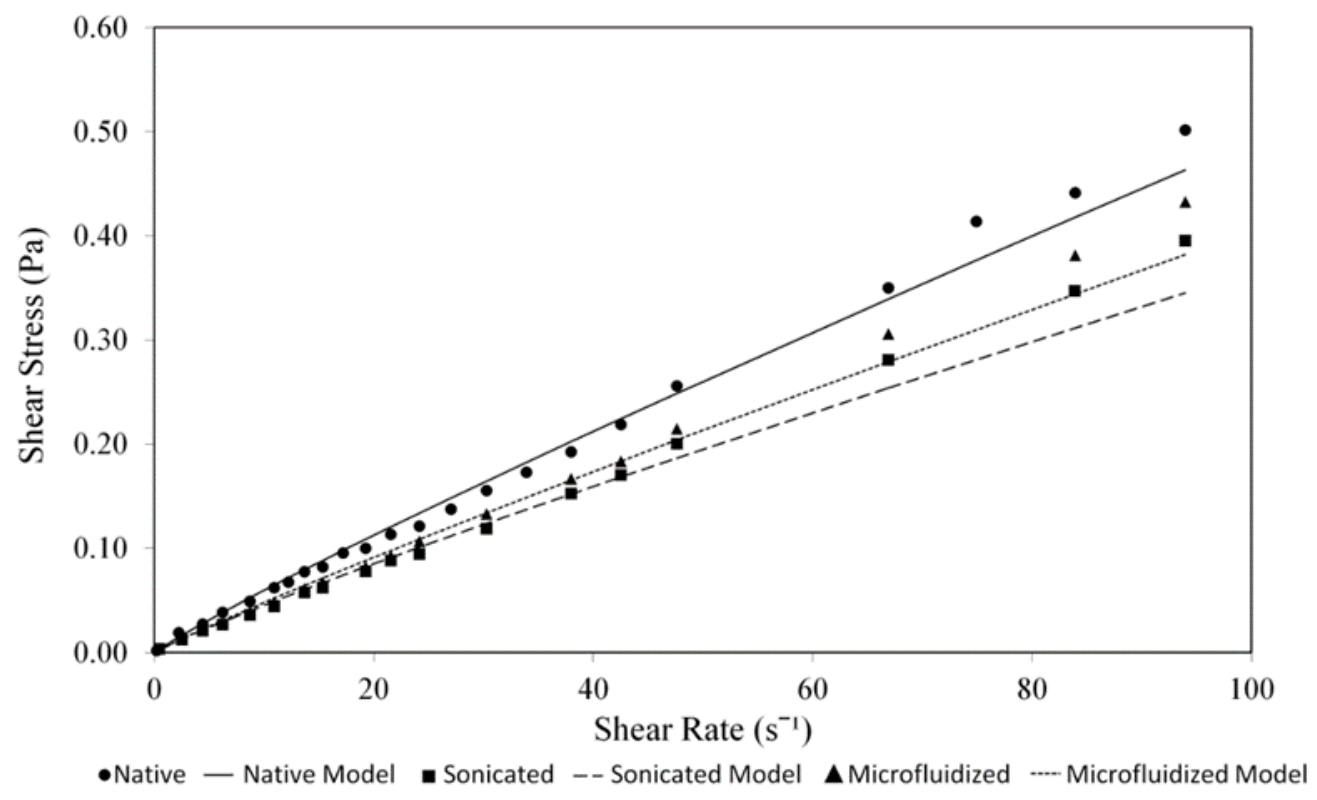

Figure 3.1. Variation of shear stress with shear strain of the native, sonicated and microfluidized chickpea starches

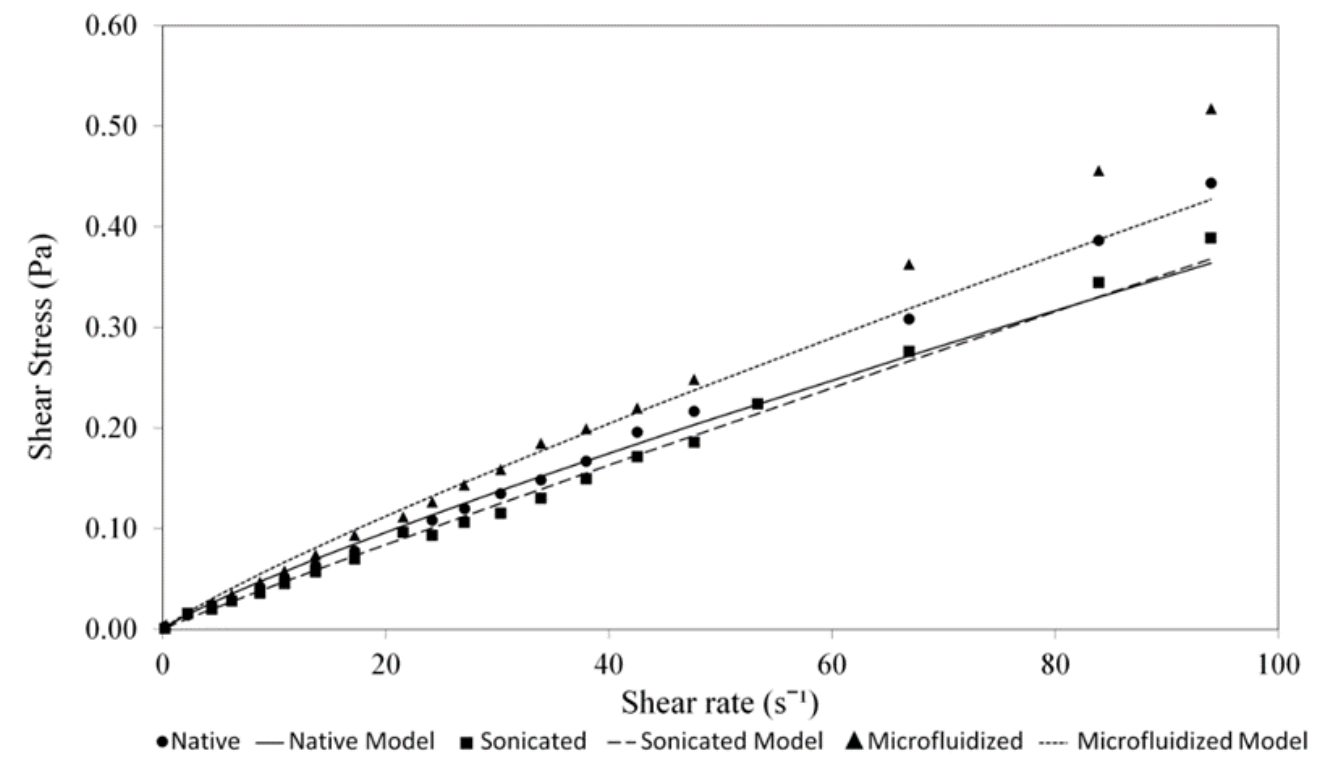

Figure 3.2. Variation of shear stress with shear strain of the native, sonicated and microfluidized lentil starches 
The Power law constants and $\mathrm{R}^{2}$ values of native and modified starches are shown in Table 3.2. Flow behavior index of the both starches did not show significant change (Tables B.1 and B.2) with ultrasonication and microfluidization ( $<<0.05)$. Consistency index of the native chickpea starch was found to be significantly higher than that of the modified samples (Table B.1). Degradation of starch molecule caused by ultrasonic shear force resulted in lower consistency coefficient. The similar results were reported by Jambrak et al. (2010). The untreated starch sample showed the highest consistency coefficient (Jambrak et al., 2010). Although the consistency index value of the native lentil starch did not change significantly with applied treatments (Table B.2), the significant difference was observed between the consistency index value of sonicated and microfluidized samples. In another study conducted on different starch types obtained by oat cultivars, Singh and Kaur (2017) reported that the samples with higher structural strength showed higher consistency index $(\mathrm{K})$ values. The similar results were reported by Duan et al. (2017) in the modification of rice amylose by Dynamic High Pressure Microfluidization (DHPM). The results indicated that DHPM treatments resulted in degraded amylose and apparent viscosity of the rice amylose samples decreased with increasing shear rate which showed NonNewtonian and shear thinning behavior (Duan et al., 2017).

Table 3.2. Rheological properties (flow behavior index ( $n$ ), consistency index $(K)$ and coefficient of regression $\left(R^{2}\right)$ ) of starches

\begin{tabular}{lllll}
\hline Starch & Treatment & $\mathbf{n}$ & $\mathbf{K}\left(\mathbf{P a .} \mathbf{s}^{\mathbf{n}}\right) \mathbf{\times} \mathbf{1 0}^{\mathbf{- 3}}$ & $\mathbf{R}^{\mathbf{2}}$ \\
\hline Chickpea & Native & $0.88 \pm 0.00^{\mathrm{a}^{*}}$ & $7.96 \pm 0.23^{\mathrm{a}^{*}}$ & 0.99 \\
& Sonicated & $0.89 \pm 0.01^{\mathrm{a}}$ & $5.83 \pm 0.18^{\mathrm{b}}$ & 0.99 \\
& Microfluidized & $0.89 \pm 0.01^{\mathrm{a}}$ & $6.29 \pm 0.30^{\mathrm{b}}$ & 0.99 \\
& & & \\
Lentil & Native & $0.85 \pm 0.03^{\mathrm{a}^{*}}$ & $7.50 \pm 0.82^{\mathrm{ab}^{*}}$ & 0.99 \\
& Sonicated & $0.93 \pm 0.00^{\mathrm{a}}$ & $5.26 \pm 0.03^{\mathrm{b}}$ & 0.99 \\
& Microfluidized & $0.85 \pm 0.02^{\mathrm{a}}$ & $8.68 \pm 0.14^{\mathrm{a}}$ & 0.98 \\
\hline
\end{tabular}

* Values with different letters are significantly different $(\mathrm{p}<0.05)$. Values are expressed as mean $\pm \mathrm{SE}$ mean. 
As can be seen in Figure 3.1 and Figure 3.2, different behavior of the microfluidization treated starches was observed for different starches. Shear stress vs shear rate curve of the microfluidization treated chickpea starch was below that of the native sample. However, shear stress $(\mathrm{Pa})$ vs shear rate $\left(\mathrm{s}^{-1}\right)$ curve of the microfluidization treated lentil starch was above that of the native sample. In microfluidization, there is partial starch gelatinization which affects the viscosity of the samples. When Table 3.3 was examined, it was seen that lentil starch had lower gelatinization temperature and gelatinization enthalpy. This fact clarified that lentil starch could gelatinize easier than the chickpea starch in microfluidization so that viscosity of the lentil starch was higher. While percent degree of gelatinization for microfluidized lentil starch was $44.7 \%$, the value was $20.5 \%$ for the microfluidized chickpea starch as will be discussed in section 3.3. Analysis of functional properties revealed that swelling power of the lentil starch was higher than the chickpea starch as shown in Table 3.1. Thermal and functional properties of the starches could be used to explain the different rheologic trend of the microfluidized samples.

\subsection{Thermal Properties}

Thermal properties of the native and modified starches are shown in Table 3.3. It was observed that both treatments had significant effects (Table B.11 and Table B.12) on decreasing the onset $\left(\mathrm{T}_{\mathrm{o}}\right)$ and conclusion $\left(\mathrm{T}_{\mathrm{c}}\right)$ temperatures of gelatinization of both starches $(\mathrm{p}<0.05) . \mathrm{T}_{\mathrm{o}}$ of the chickpea and lentil starches decreased with sonication and microfluidization significantly $(\mathrm{p}<0.05)$. The results demonstrated that $\mathrm{T}_{\mathrm{o}}$ values of the microfluidized samples were significantly lower than the native and sonicated ones for both starch types $(\mathrm{p}<0.05)$. The decrease in the $\mathrm{T}_{\mathrm{o}}$ values might have resulted from the change in the granule structure due to microfluidization treatment (Tu et al., 2013). $\mathrm{T}_{\mathrm{c}}$ values of both starches were affected by sonication and microfluidization treatments significantly $(\mathrm{p}<0.05)$. The peak temperature of gelatinization $\left(\mathrm{T}_{\mathrm{p}}\right)$ of chickpea and lentil starches showed decreasing trend when treatment was applied. For the chickpea starch, $\mathrm{T}_{\mathrm{p}}$ values were $74.13^{\circ} \mathrm{C}, 70.20^{\circ} \mathrm{C}, 68.62^{\circ} \mathrm{C}$ for the native, sonicated and microfluidized samples respectively. Both treatments reduced the peak 
temperature significantly $(\mathrm{p}<0.05)$. However, microfluidized sample showed significantly lower (Table B.11) peak temperature than the native and sonicated chickpea starch $(\mathrm{p}<0.05)$. For the lentil starch, $\mathrm{T}_{\mathrm{p}}$ value decreased from $65.02^{\circ} \mathrm{C}$ to $62.61^{\circ} \mathrm{C}$ and $62.38^{\circ} \mathrm{C}$ with sonication and microfluidization treatments, respectively. There was significant difference (Table B.12) between the $T_{p}$ values of the native lentil starch sample and treated lentil starches $(p<0.05)$. Lower $T_{p}$ values for the microfluidized starches could be due to high pressure microfluidization that could have induced the gelatinization of granular starch samples which resulted in lower gelatinization temperatures. Also, lower $\mathrm{T}_{\mathrm{p}}$ values of the sonicated samples was due to gelatinization effect of sonication which depended on the organization of components of starch (amylose, amylopectin) (Carmona-García et al., 2016).

Table 3.3. Thermal properties of starches

\begin{tabular}{llllll}
\hline Starch & Treatment & $\mathbf{T}_{\mathbf{o}}\left({ }^{\circ} \mathbf{C}\right)$ & $\mathbf{T}_{\mathbf{p}}\left({ }^{\circ} \mathbf{C}\right)$ & $\mathbf{T}_{\mathbf{c}}\left({ }^{\circ} \mathbf{C}\right)$ & $\Delta \mathbf{H}(\mathbf{J} / \mathbf{g})$ \\
\hline Chickpea & Native & $67.14 \pm 0.62^{\mathrm{a}^{*}}$ & $74.13 \pm 0.47^{\mathrm{a}^{*}}$ & $81.38 \pm 0.83^{\mathrm{a}^{*}}$ & $9.21 \pm 0.19^{\mathrm{a}^{*}}$ \\
& Sonicated & $64.01 \pm 0.18^{\mathrm{b}}$ & $70.20 \pm 0.15^{\mathrm{b}}$ & $77.74 \pm 0.24^{\mathrm{b}}$ & $8.89 \pm 0.29^{\mathrm{a}}$ \\
& Microfluidized & $60.77 \pm 0.14^{\mathrm{c}}$ & $68.62 \pm 0.06^{\mathrm{c}}$ & $78.88 \pm 0.02^{\mathrm{b}}$ & $7.32 \pm 0.20^{\mathrm{b}}$ \\
& & & & & \\
Lentil & Native & $58.92 \pm 0.12^{\mathrm{a}^{*}}$ & $65.02 \pm 0.15^{\mathrm{a}^{*}}$ & $74.64 \pm 0.22^{\mathrm{a}^{*}}$ & $7.14 \pm 0.05^{\mathrm{a}^{*}}$ \\
& Sonicated & $56.94 \pm 0.03^{\mathrm{b}}$ & $62.61 \pm 0.11^{\mathrm{b}}$ & $70.60 \pm 0.00^{\mathrm{b}}$ & $6.42 \pm 0.03^{\mathrm{b}}$ \\
& Microfluidized & $55.00 \pm 0.14^{\mathrm{c}}$ & $62.38 \pm 0.16^{\mathrm{b}}$ & $71.41 \pm 0.09^{\mathrm{b}}$ & $3.95 \pm 0.02^{\mathrm{c}}$ \\
\hline
\end{tabular}

* Values with different letters are significantly different $(\mathrm{p}<0.05)$. Values are expressed as mean \pm SE mean.

As can be seen in Table 3.3, the enthalpy of gelatinization $(\Delta \mathrm{H})$ of the native lentil starch decreased from $7.14 \mathrm{~J} / \mathrm{g}$ to $6.42 \mathrm{~J} / \mathrm{g}$ and $3.95 \mathrm{~J} / \mathrm{g}$ with sonication and microfluidization treatments, respectively. Percent degree of gelatinization of sonicated chickpea starch was found as $3.4 \%$ and sonication did not affect the enthalpy value significantly. On the other hand, significant effect of microfluidization was observed on percent degree of gelatinization with a value of $20.5 \%(p<0.05)$. The significant decrease was observed in the $\Delta \mathrm{H}$ value of the lentil starch with percent 
degree of gelatinization of $10.1 \%$ and $44.7 \%$ for the sonicated and microfluidized samples, respectively. The study conducted by Kasemwong et al. (2011) also showed that $\Delta \mathrm{H}$ of the cassava starch decreased from $12 \mathrm{~J} / \mathrm{g}$ to $3 \mathrm{~J} / \mathrm{g}$ by microfluidization treatment which corresponded a decrease in percent degree of gelatinization of $75 \%$. The possible reason for the alteration is the partial gelatinization of starch granule at higher pressures (Kasemwong et al., 2011). In addition, the swollen starch granule might have been destroyed more at high pressures due to increased shear stress, thus leaching of amylose from the granule might have become easier. The mechanism was described as the microstructural modification of the starch granule (Kasemwong et al., 2011). Vallons et al. (2014) reported that high amylose starches required higher pressures to complete gelatinization since their pressure susceptibility is low. Moreover, hydration of the amorphous part caused swelling which ended up with increased accessibility of the crystalline region to water (Vallons et al., 2014). Hence, amylose content of the starch might affect how the thermal properties change with treatments. Moreover, Jambrak et al. (2010) stated that sonication treatment also destroyed the crystalline structure of the starch granule which caused a decrease in gelatinization enthalpy. Arrangment of the amylose and amylopectin in a starch granule was important to analyze the effect of sonication on thermal properties (Carmona-García et al., 2016).

Thermal properties of the starches was a proof that microfluidized samples had lower gelatinization temperature and gelatinization enthalpy. Thus, microfluidization was found to be more effective for obtaining easily gelatinized starches. Although efficiency of microfluidization was found to be higher, Kaltsa and Gatsi (2014) stated that contamination of equipment used in microfluidization and higher production cost made it less practicable. 


\subsection{Scanning Electron Microscopy (SEM)}

Scanning electron micrographs of native, sonicated and microfluidized samples can be seen in the Figure 3.3 for the chickpea and lentil starches. Native chickpea and lentil starches (Figure 3.3-a and Figure 3.3-d) were characterized by the rough surfaces and spherical-oval shapes. It could be clearly seen that the native starches showed an important change after the ultrasound treatment. The surface of the granules became smooth and the granule had some cracks at the surface which might have aroused from the ultrasonic energy. In the same manner, Sujka and Jamroz (2013) stated that sonicated starches showed visible cracks which might be due to the ultrasonic degradation of the granule. Furthermore, the observations obtained from the Figure 3.3 were correlated with the DSC results since the change in granular structure was observed in both sonicated and microfluidized samples. It was observed that both ultrasound and microfluidization treatments influenced the thermal properties of chickpea and lentil starches. DSC results showed that microfluidization caused a significant decrease in the gelatinization enthalpy of the chickpea and lentil starches due to the possible partial gelatinization of the starch granules at high pressures. SEM observations confirmed the gelatinization effect of the microfluidization since native starch granules were damaged significantly and irregular shape of the microfluidized samples was observed. In the study of the microfluidization of the maize amylose, it was also reported that granular structure of the maize amylose changed by the dynamic high pressure microfluidization (Tu et al., 2013). In addition, integrity loss and damage was observed in the morphology of the gelatinized rice starch granule in the study of Fu et al. (2015). Microfluidization was found to be more effective in terms of obtaining partially gelatinized starches. 

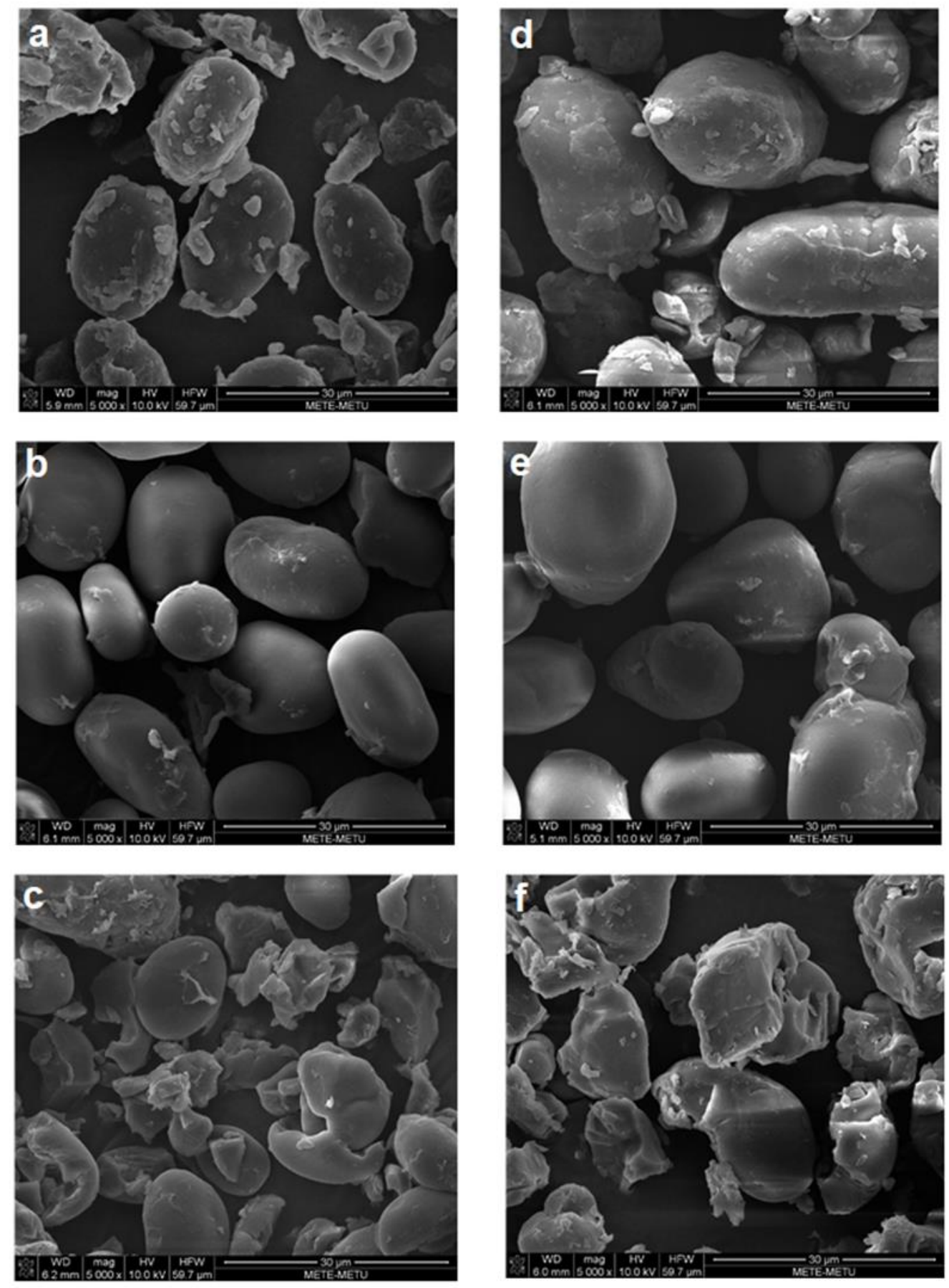

Figure 3.3. Scanning electron micrographs of the native and modified starches. a, $\mathrm{b}$ and $\mathrm{c}$ for the native, sonicated and microfluidized chickpea starch respectively; $\mathrm{d}$, e and f for the native, sonicated and microfluidized lentil starch respectively. 


\subsection{Particle Size}

The volume mean diameter ( $\mathrm{D}[4,3])$ and span values of the starch samples are given in Table 3.4. There were significant effects (Table B.5 and Table B.6) of the ultrasound and microfluidization treatments on the volume mean diameters (D $[4,3])$ of the native chickpea and lentil starches $(\mathrm{p}<0.05)$. Although there was no significant difference (Table B.5) between the D [4,3] values of the two modified chickpea starches, the significant difference (Table B.6) was observed between the D [4,3] values of the two modified lentil starches. Results showed that ultrasonication was more effective in terms of decreasing volume mean diameter of the lentil starch (Table B.6). The effect of the ultrasound strongly depends on the type and origin of the starch chains. In the study, it was pointed out that the ultrasound energy can be easily trapped by the larger starch granules due to the larger surface area (Carmona-García et al., 2016). Moreover, it is also stated that having different amylose to amylopectin ratio has an important role on the size reduction effect of ultrasonication (Carmona-García et al., 2016). The size decreasing effect of the microfluidization was confirmed by the results of the study conducted by Liu et al. (2009). It was reported that microfluidization was an effective method to reduce the particle size of the starches. The results showed that both ultrasound and microfluidization treatments decreased the span value of the native chickpea starch sample significantly $(\mathrm{p}<0.05)$. Only ultrasound treatment was found to be effective in decreasing the span value of native lentil starch $(\mathrm{p}<0.05)$. 
Table 3.4. Particle size analysis results (D[4,3] and span values) of the starches

\begin{tabular}{llll}
\hline Starch & Treatment & D [4,3] & Span \\
\hline Chickpea & Native & $73.85 \pm 0.05^{\mathrm{a}^{*}}$ & $5.94 \pm 0.12^{\mathrm{a}^{*}}$ \\
& Sonicated & $44.70 \pm 2.20^{\mathrm{b}}$ & $3.76 \pm 0.16^{\mathrm{b}}$ \\
& Microfluidized & $37.30 \pm 0.20^{\mathrm{b}}$ & $3.14 \pm 0.01^{\mathrm{b}}$ \\
& & & \\
Lentil & Native & $41.25 \pm 0.35^{\mathrm{a}^{*}}$ & $2.75 \pm 0.13^{\mathrm{a}^{*}}$ \\
& Sonicated & $34.40 \pm 0.30^{\mathrm{c}}$ & $1.58 \pm 0.04^{\mathrm{b}}$ \\
& Microfluidized & $38.25 \pm 0.05^{\mathrm{b}}$ & $2.59 \pm 0.03^{\mathrm{a}}$ \\
\hline
\end{tabular}

* Values with different letters are significantly different $(\mathrm{p}<0.05)$. Values are expressed as mean \pm SE mean.

\subsection{TD-NMR and Relaxation Experiments}

NMR is an effective, time saving and non-destructive method which provides information about the structure and physicochemical properties of starch systems (Zhu, 2017). It can be used to analyze the moisture content and moisture distribution of starch which is directly related to the molecular mobility (Choi \& Kerr, 2003). NMR relaxometry has been used to analyze the internal structure of the samples by proton relaxation profile analysis (Ozel et al., 2017). Spin-spin interactions are quantified by $T_{2}$ relaxation times. $T_{2}$ times are closely associated with microstructure of the samples and give information about the water-polymer interactions.

Table 3.5. $T_{2}$ values of the starches

\begin{tabular}{lll}
\hline Starch & Treatment & $\mathbf{T}_{\mathbf{2}}(\mathbf{m s})$ \\
\hline Chickpea & Native & $0.17 \pm 0.00^{\mathrm{c}^{*}}$ \\
& Sonicated & $0.34 \pm 0.00^{\mathrm{a}}$ \\
& Microfluidized & $0.23 \pm 0.02^{\mathrm{b}}$ \\
& & \\
Lentil & Native & $0.18 \pm 0.00^{\mathrm{b}^{*}}$ \\
& Sonicated & $0.29 \pm 0.02^{\mathrm{a}}$ \\
& Microfluidized & $0.31 \pm 0.00^{\mathrm{a}}$ \\
\hline
\end{tabular}

$*$ Values with different letters are significantly different $(\mathrm{p}<0.05)$. Values are expressed as mean \pm SE mean. 
In this study, the mono-exponential fitting was used to determine the relaxation time $\left(\mathrm{T}_{2}\right) . \mathrm{T}_{2}$ relaxation time of the native and modified starches are given in Table 3.5 for chickpea and lentil. Although $\mathrm{T}_{2}$ value of the native chickpea starch showed significant increase with both treatments (Table B.3), sonication was found to have more significant effect on the $\mathrm{T}_{2}$ value of chickpea starch $(\mathrm{p}<0.05)$. Both sonication and microfluidization caused a statistically significant increase (Table B.4) in the $\mathrm{T}_{2}$ value of the native lentil starch $(\mathrm{p}<0.05)$. The increase in the $\mathrm{T}_{2}$ value of both starches might be related to the higher water absorption capacity of the sonicated and microfluidized samples. Closely packed conformation of the solids causes shorter $\mathrm{T}_{2}$ values since the solid protons are close to each other which results in quick dephasing with applied pulse. Thus, longer $T_{2}$ values are obtained for the samples due to the higher water content. Also, when treatments are applied free water become more available thus the $T_{2}$ values of the treated becomes higher (Ozel et al., 2017). Ozel et al. (2017) conducted a study on the NMR relaxometry of corn, rice and wheat starches to obtain information about starch-water interactions and gelatinization behaviour. The results indicated that corn starch showed lower $\mathrm{T}_{2}$ values than others which might be related to the higher amylose content since amylose has structure building and mobility decreasing effect (Ozel et al., 2017). The results stated by Ozel et al. (2017) confirmed the present result of the experiment. Gelatinization is affected by different ratios of amylose to amylopectin. Starches with higher amylose content have limited interaction of water molecules with starch granule (Ozel et al., 2017). For the chickpea starch, DSC results showed that percent degree of gelatinization of microfluidized sample was higher, thus $\mathrm{T}_{2}$ value of the sample was lower than the sonicated sample which might be due to the limited interaction with water. For the lentil starch, there was no significant difference between the $\mathrm{T}_{2}$ values of the modified starches. Also, swelling power values of the native chickpea and lentil starches were significantly lower than the modified ones which confirmed the NMR results of the native samples with lower $\mathrm{T}_{2}$ values. 


\subsection{Fourier Transform Infrared Spectroscopy (FTIR)}

Fourier Transform Infrared Spectra of samples are shown in the Figure 3.4 and Figure 3.5 for the chickpea and lentil starches, respectively. The similar characteristic peaks were observed in the spectra of chickpea and lentil starches. The peak at $3290 \mathrm{~cm}^{-1}$ was related to the $\mathrm{O}-\mathrm{H}$ stretching. For both native starches, the intensity of the peak at $3290 \mathrm{~cm}^{-1}$ was lower than the sonicated and microfluidized samples. When both treatments applied, the increase in the intensity of the peak indicated that functional group related to the bond showed an increase in number. Although the peak intensity was nearly same for the sonicated and microfluidized chickpea starches, the intensity of the peak for the microfluidized lentil starch was higher than the sonicated one. Fang et al. similarly reported that hydroxyl groups bonded to hydrogen caused intensively wide peak at $3403 \mathrm{~cm}^{-1}$. The results of the study conducted about the properties of lentil starch were in agreement with the present results. It was stated that the band observed at $3296 \mathrm{~cm}^{-1}$ was related to the O-H stretching (Ahmeda et al., 2016). It could be concluded that $\mathrm{O}-\mathrm{H}$ stretching of the native samples were lower than the modified ones.

An apparent peak at $2925 \mathrm{~cm}^{-1}$ was detected in the FTIR spectra of both starches (Figures 3.4 and 3.5). Intensities of the peaks ranged as sonicated> microfluidized> native for the chickpea starch and microfluidized> sonicated> native for the lentil starch. It could be concluded that both treatments increased the peak intensity. Although chickpea starch was more affected by sonication, lentil starch was affected by microfluidization significantly. Kizil et al. (2002) stated that $\mathrm{CH}_{2}$ deformation and $\mathrm{C}-\mathrm{H}$ stretching could be observed on the region between $2800 \mathrm{~cm}^{-1}$ and $3000 \mathrm{~cm}^{-1}$ and amylose to amylopectin ratio strongly affected the intensity of the observed peak. In the study, it was concluded that differences in amylose content of the corn and potato starches resulted in different peak intensities in the spectra (Kizil et al., 2002). Also, there might be a peak shift which was due to the alteration of ordered structure (Warren et al., 2016). Moreover, Fang et al. observed a significant band at $2926 \mathrm{~cm}^{-1}$ which was related to $\mathrm{C}-\mathrm{H}$ stretching (2002). 
The intensity of the peak observed at $1643 \mathrm{~cm}^{-1}$ decreased with both treatments. The similar result was reported by Kizil et al. (2002). In the study, the peak at $1642 \mathrm{~cm}^{-1}$ was dependent on how much water was adsorbed by the amorphous region. Alteration of crystallinity had an important role on the intensity of the band. The band at 1640 $\mathrm{cm}^{-1}$ was associated with the tightly bound water content of the starch granule in another study conducted by Fang et al. (2002). Result obtained from the FTIR spectra of both starches well corresponded to the NMR results. Both ultrasonication and microfluidization treatments resulted in higher $T_{2}$ values for both starches which was related to the higher free water content of the modified samples. Also, the band seen at $1643 \mathrm{~cm}^{-1}$ confirmed that tightly bound water content of the modified starch samples were lower than the native ones.

For both starches, the intensity of the peak at $1336 \mathrm{~cm}^{-1}$ showed an increase with both treatments. The peak might have been originated from the carbon and hydrogen atoms which caused vibrations in the region between 1300-1500 $\mathrm{cm}^{-1}$ (Kizil et al., 2002).

The intensity of the peak at $1145 \mathrm{~cm}^{-1}$ showed an important rise with both treatments. However, the peak intensities of microfluidized chickpea and lentil starches was significantly higher. According to Ahmeda et al. (2016), FTIR spectra of high pressure treated lentil starch showed a peak at $1145 \mathrm{~cm}^{-1}$ due to $\mathrm{C}-\mathrm{O}$ and $\mathrm{CH}_{2}$ stretching.

The change in the intensity of the peak at $1000 \mathrm{~cm}^{-1}$ was the sharpest difference for both starches. Even if both sonicated and microfluidized starches showed an increase in peak intensity, the effect of microfluidization treatment was more significant. Warren et al. (2016) reported that the spectrum region between $1000-1022 \mathrm{~cm}^{-1}$ is highly sensitive to water. Also, the water sensitivity of the peak at $1000 \mathrm{~cm}^{-1}$ was confirmed by Ahmeda et al. (2016). The peak was associated with the intramolecular hydrogen bonding of hydroxyl groups and the destruction effect of high pressure on the crystalline structure. In the study, where the impact of high pressure on the lentil starch was investigated, it was stated that high pressure destroyed the crystalline structure of the starch granule (Ahmeda et al., 2016). The present results are in 
agreement with this finding as significant difference was observed in the peak intensities of the native and modified starches. The FTIR spectra of chickpea and lentil starches shown in Figure 3.4 and Figure 3.5 confirmed that ultrasonication and microfluidization treatments cause significant changes in the structure of the starch granules. Also, the results obtained from the figures well correspond to the morphology observations due to the observed change in the structure of native starches with both treatments. 


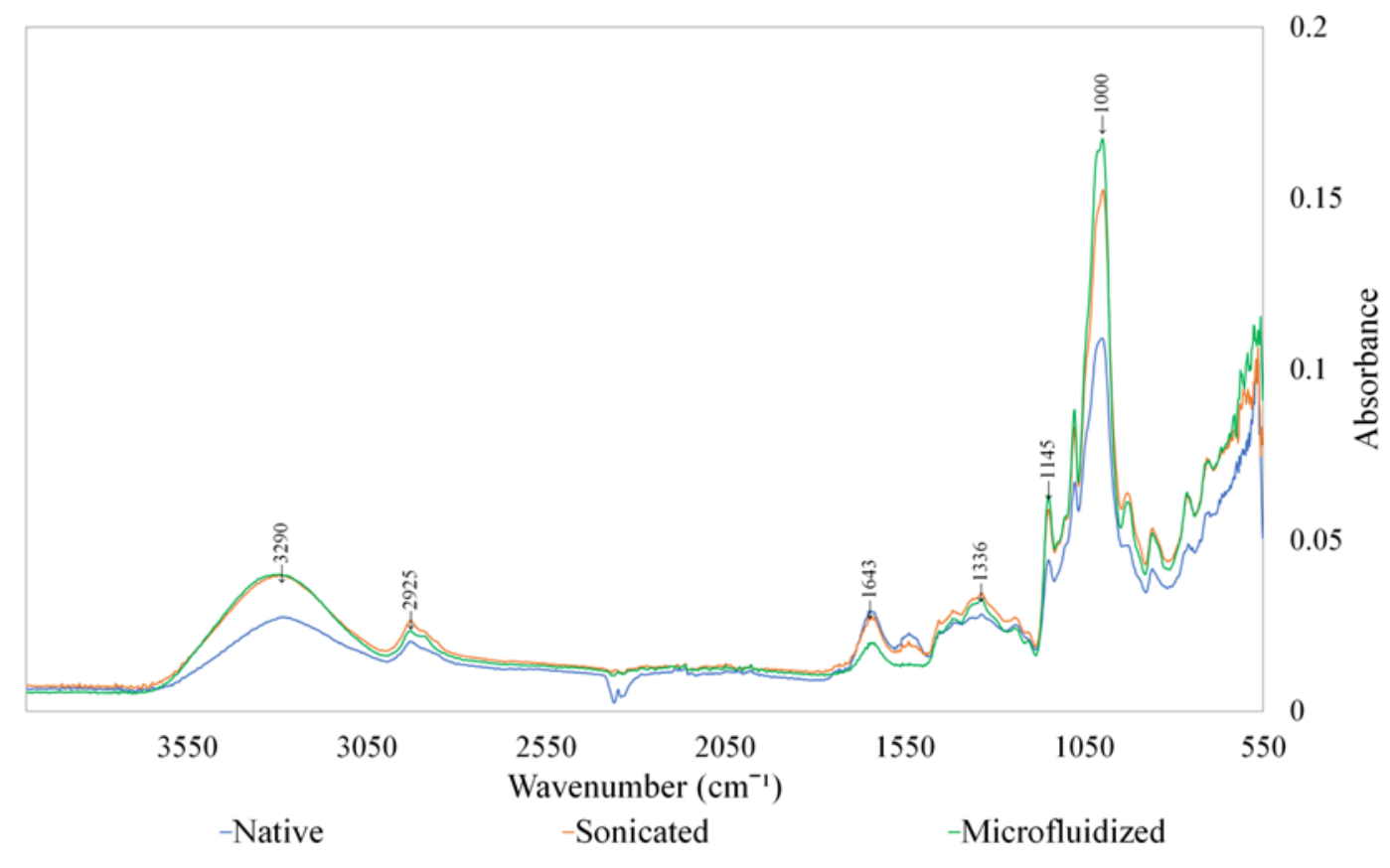

Figure 3.4. FTIR spectra of the native, sonicated and microfluidized chickpea starches

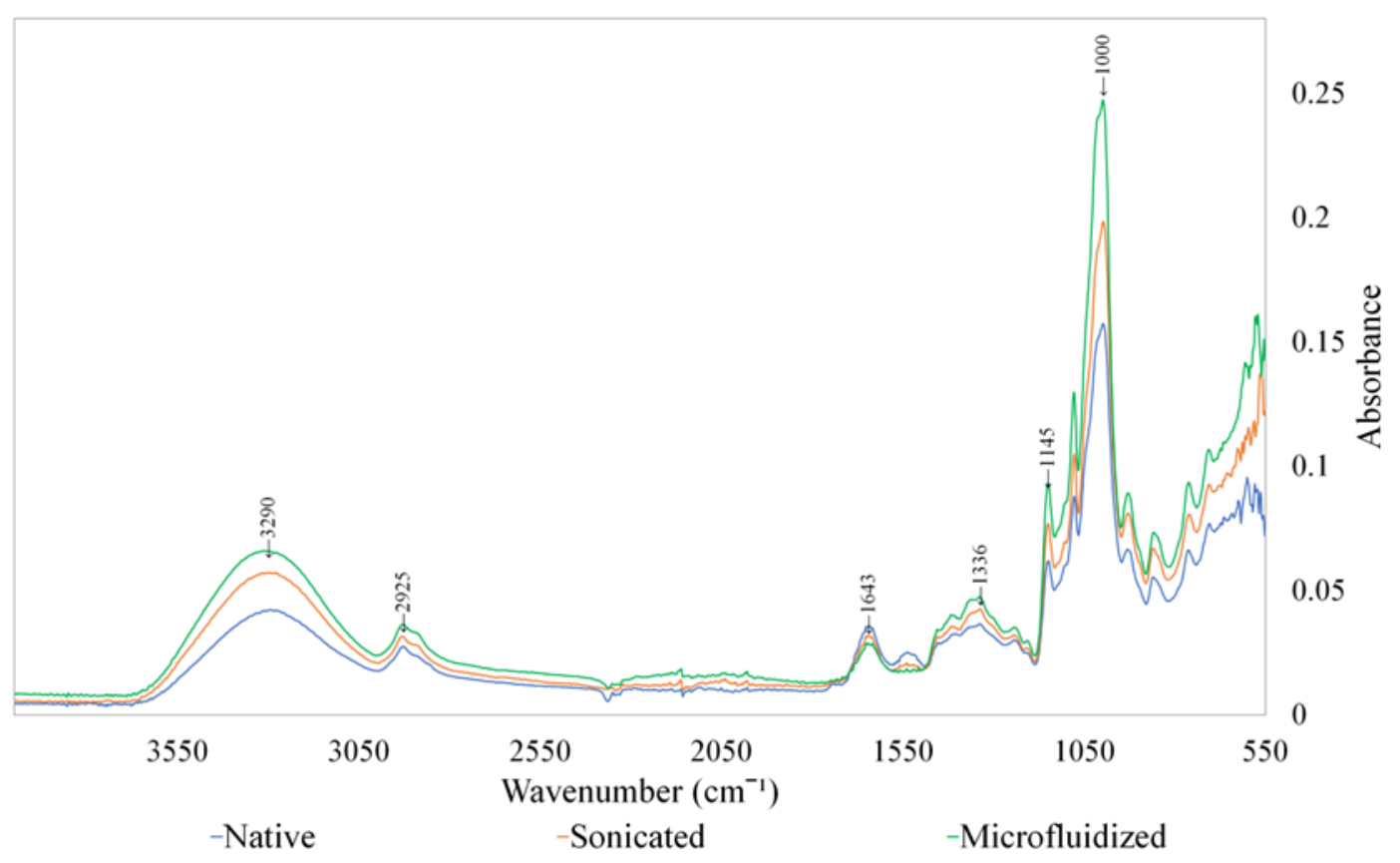

Figure 3.5. FTIR spectra of the native, sonicated and microfluidized lentil starches 


\section{CHAPTER 4}

\section{CONCLUSION AND RECOMMENDATIONS}

In this study, the changes in the physicochemical properties of legume starches as a result of ultrasonication and microfluidization treatments were investigated. Solubility values of the native samples decreased, whereas swelling power values increased with both treatments. Both methods were found to be effective in terms of decreasing particle size of native starches significantly. Both treatments decreased apparent viscosity of native chickpea starch. Microfluidization was more significant to decrease $\mathrm{T}_{\mathrm{o}}$ and gelatinization enthalpy of both legume native starches. NMR results showed that modified starch samples showed higher $T_{2}$ values which was directly related to the free water content of the samples. Like SEM results, FTIR results was also a proof that both ultrasonication and microfluidization treatments caused a change in the structure of the native samples.

The study showed that ultrasonication and microfluidization were the effective methods for the modification of chickpea and lentil starches. Regarding the desired improved properties, method type to use for modification could differ. For obtaining easily gelatinized starches, microfluidization was found to be more effective. When usages of these methods were analyzed, ultrasonication method was found to be more valuable in practice due to its higher isolation efficiency and lower production cost.

For future studies, modified starches may be used in food applications to observe how final food product will be affected by usage of modified starches instead of native ones. Parameters of ultrasonication such as sonication time and power, and parameters of microfluidization such as pass number and pressure may be changed in order to observe the effects of treatment parameters on properties of native starch types. 
Moreover, comparison of these two methods may be conducted on other legume types such as black bean, kidney bean and soybean which are nutritionally focus on interest. 


\section{REFERENCES}

Adebowale, K. O., \& Lawal, O. S. (2003). Functional properties and retrogradation behaviour of native and chemically modified starch of mucuna bean (Mucuna pruriens). Journal of the Science of Food and Agriculture, 83(15), 1541-1546. https://doi.org/10.1002/jsfa.1569

Aguilera, Y., Esteban, R. M., Benítez, V., Mollá, E., \& Martín-Cabrejas, M. A. (2009). Starch, functional properties, and microstructural characteristics in chickpea and lentil as affected by thermal processing. Journal of Agricultural and Food Chemistry, 57(22), 10682-10688. https://doi.org/10.1021/jf902042r

Ahmeda,J.; Thomasa,L.; Tahera, A.; Joseph, A. (2016). Impact of high pressure treatment on functional, rheological, pasting,and structural properties of lentil starch dispersions. Carbohydrate Polymers, 152, 639-647. https://doi.org/10.1016/j.carbpol.2016.07.008

Alcázar-Alay, S. C., \& Meireles, M. A. A. (2015). Physicochemical properties, modifications and applications of starches from different botanical sources. Food Science and Technology (Campinas), 35(2), 215-236. https://doi.org/10.1590/1678-457X.6749

Arp, C. G., Correa, M. J., \& Ferrero, C. (2018). Rheological and Microstructural Characterization of Wheat Dough Formulated with High Levels of Resistant Starch. Food and Bioprocess Technology, 1149-1163.

Ashogbon, A. O., \& Akintayo, E. T. (2014). Recent trend in the physical and chemical modification of starches from different botanical sources: A review. Starch/Staerke, 66(1-2), 41-57. https://doi.org/10.1002/star.201300106 
Bemiller, J. N., Lafayette, W., \& In, U. S. A. (1997). 1 U bersichtsbeitrag / Review Starch Modification : Challenges and Prospects. Starch - Stärke, 49(4), 127-131.

Bertoft, E. (2017). Understanding Starch Structure: Recent Progress. Agronomy, 7(3), 56. https://doi.org/10.3390/agronomy7030056

Botosoa, E. P., Chèné, C., Blecker, C., \& Karoui, R. (2015). Nuclear Magnetic Resonance, Thermogravimetric and Differential Scanning Calorimetry for Monitoring Changes of Sponge Cakes During Storage at $20^{\circ} \mathrm{C}$ and $65 \%$ Relative Humidity. Food and Bioprocess Technology, 1020-1031. https://doi.org/10.1007/s11947-014-1467-7

Buléon, A., Colonna, P., Planchot, V., \& Ball, S. (1998). Starch granules: Structure and biosynthesis. International Journal of Biological Macromolecules, 23(2), 85-112. https://doi.org/10.1016/S0141-8130(98)00040-3

Carmona-García, R., Bello-Pérez, L. A., Aguirre-Cruz, A., Aparicio-Saguilán, A., Hernández-Torres, J., \& Alvarez-Ramirez, J. (2016). Effect of ultrasonic treatment on the morphological, physicochemical, functional, and rheological properties of starches with different granule size. Starch/Staerke, 68(9-10), 972979. https://doi.org/10.1002/star.201600019

Che, L. M., Wang, L. J., Li, D., Bhandari, B., Özkan, N., Chen, X. D., \& Mao, Z. H. (2009). Starch pastes thinning during high-pressure homogenization. Carbohydrate $\quad$ Polymers, $\quad$ 35(1), 38. https://doi.org/10.1016/j.carbpol.2008.06.004

Choi, H. S., Kim, H. S., Park, C. S., Kim, B. Y., \& Baik, M. Y. (2009). Ultra high pressure (UHP)-assisted acetylation of corn starch. Carbohydrate Polymers, 78(4), 862-868. https://doi.org/10.1016/j.carbpol.2009.07.005

Choi, S. G., \& Kerr, W. L. (2003). 1H NMR studies of molecular mobility in wheat starch. Food Research International, 36(4), 341-348. https://doi.org/10.1016/S0963-9969(02)00225-9 
Czechowska-Biskup, R., Rokita, B., Lotfy, S., Ulanski, P., \& Rosiak, J. M. (2005). Degradation of chitosan and starch by $360-\mathrm{kHz}$ ultrasound. Carbohydrate Polymers, 60(2), 175-184. https://doi.org/10.1016/j.carbpol.2004.12.001

Devi, A. F., Fibrianto, K., Torley, P. J., \& Bhandari, B. (2009). Physical properties of cryomilled rice starch. Journal of Cereal Science, 49(2), 278-284. https://doi.org/10.1016/j.jcs.2008.11.005

Duan, D., Tu, Z., Wang, H., Sha, X., \& Zhu, X. (2017). Physicochemical and rheological properties of modified rice amylose by dynamic high-pressure microfluidization. International Journal of Food Properties, 20(4), 734-744. https://doi.org/10.1080/10942912.2016.1178283

Fang, J. M., Fowler, P. A., Tomkinson, J., \& Hill, C. A. S. (2002). The preparation and characterisation of a series of chemically modified potato starches. Carbohydrate Polymers, 47(3), 245-252. https://doi.org/10.1016/S01448617(01)00187-4

Fernando, S., Paranavithana, T., Dissanayaka, U., Premarathna, W., Atambawa, A., De Silva, N., \& Tissera, N. (2015). Effect of starch particle size reduction on the performance of sized warp yarns. MERCon 2015 - Moratuwa Engineering Research Conference, 60-63. https://doi.org/10.1109/MERCon.2015.7112321

Fu, Z., Luo, S. J., Bemiller, J. N., Liu, W., \& Liu, C. M. (2015). Influence of highspeed jet on solubility, rheological properties, morphology and crystalline structure of rice starch. Starch/Staerke, 67(7-8), 595-603. https://doi.org/10.1002/star.201400256

Gonçalves, P. M., Noreña, C. P. Z., da Silveira, N. P., \& Brandelli, A. (2014). Characterization of starch nanoparticles obtained from Araucaria angustifolia seeds by acid hydrolysis and ultrasound. LWT - Food Science and Technology, 58(1), 21-27. https://doi.org/10.1016/j.lwt.2014.03.015 
Grunin, Y. B., Grunin, L. Y., Masas, D. S., Talantsev, V. I., \& Sheveleva, N. N. (2016). Proton magnetic relaxation study of the thermodynamic characteristics of water adsorbed by cellulose fibers. Russian Journal of Physical Chemistry A, 90(11), 2249-2253. https://doi.org/10.1134/S003602441611008X

Han, I. H., \& Baik, B. (2006). Oligosaccharide Content and Composition of Legumes and Their Reduction by Soaking, Cooking, Ultrasound, and High Hydrostatic Pressure. Cereal Chemistry, (509), 428-433. https://doi.org/10.1094/CC-830428

Iida, Y., Tuziuti, T., Yasui, K., Towata, A., \& Kozuka, T. (2008). Control of viscosity in starch and polysaccharide solutions with ultrasound after gelatinization. Innovative Food Science and Emerging Technologies, 9(2), 140-146. https://doi.org/10.1016/j.ifset.2007.03.029

Jambrak, A. R., Herceg, Z., Šubarić, D., Babić, J., Brnčić, M., Brnčić, S. R., ...Gelo, J. (2010). Ultrasound effect on physical properties of corn starch. Carbohydrate Polymers, 79(1), 91-100. https://doi.org/10.1016/j.carbpol.2009.07.051

Joshi, M., Aldred, P., McKnight, S., Panozzo, J. F., Kasapis, S., Adhikari, R., \& Adhikari, B. (2013). Physicochemical and functional characteristics of lentil starch. Carbohydrate Polymers, 92(2), 1484-1496. https://doi.org/10.1016/j.carbpol.2012.10.035

Kalita, D., \& Netravali, A. N. (2017). Thermoset Resin Based Fiber Reinforced Biocomposites. Textile Finishing: Recent Developments and Future Trends. https://doi.org/10.1002/9781119426790.ch12

Kaltsa, O., \& Gatsi, I. (2014). Influence of Ultrasonication Parameters on Physical Characteristics of Olive Oil Model Emulsions Containing Xanthan. Food and Bioprocess Technology, 2038-2049. https://doi.org/10.1007/s11947-014-1266-1 
Karagiannidis, P. G., Hodge, S. A., Lombardi, L., Tomarchio, F., Decorde, N., Milana, S., ... Ferrari, A. C. (2017). Microfluidization of Graphite and Formulation of Graphene-Based Conductive Inks. ACS Nano, 11(3), 2742-2755. https://doi.org/10.1021/acsnano.6b07735

Kasemwong, K., Meejaiyen, K., Srisiri, S., \& Itthisoponkul, T. (2011). Effect of highpressure microfluidization on the structure and properties of waxy rice starch. Thai Journal of Agricultural Science, 44(5), 408-414. https://doi.org/10.1002/star.201000123

Kaur, B., Ariffin, F., Bhat, R., \& Karim, A. A. (2012). Progress in starch modification in the last decade. Food Hydrocolloids, 26(2), 398-404. https://doi.org/10.1016/j.foodhyd.2011.02.016

Kaur, M., Sandhu, K. S., \& Lim, S. T. (2010). Microstructure, physicochemical properties and in vitro digestibility of starches from different Indian lentil (Lens culinaris) cultivars. Carbohydrate Polymers, 79(2), 349-355. https://doi.org/10.1016/j.carbpol.2009.08.017

Keeling, P. L., \& Myers, A. M. (2010). Biochemistry and Genetics of Starch Synthesis. Annual Review of Food Science and Technology, 1(1), 271-303. https://doi.org/10.1146/annurev.food.102308.124214

Kizil, R., Irudayaraj, J., \& Seetharaman, K. (2002). Characterization of irradiated starches by using FT-Raman and FTIR spectroscopy. Journal of Agricultural and Food Chemistry, 50(14), 3912-3918. https://doi.org/10.1021/jf011652p

Kocakulak, S., Sumnu, G., \& Sahin, S. (2019). Chickpea flour-based biofilms containing gallic acid to be used as active edible films. Journal of Applied Polymer Science, 47704, 1-9. https://doi.org/10.1002/app.47704 
Koh, L. L. A., Chandrapala, J., Zisu, B., Martin, G. J. O., Kentish, S. E., \& Ashokkumar, M. (2013). A comparison of the effectiveness of sonication, high shear mixing and homogenisation on improving the heat stability of whey protein solutions. Food and Bioprocess Technology, 7(2), 556-566. https://doi.org/10.1007/s11947-013-1072-1

Kusumayanti, H., Handayani, N. A., \& Santosa, H. (2015). Swelling Power and Water Solubility of Cassava and Sweet Potatoes Flour. Procedia Environmental Sciences, 23(Ictcred 2014), 164-167. https://doi.org/10.1016/j.proenv.2015.01.025

Li, J., Han, W., Zhang, B., Zhao, S., \& Du, H. (2018). Structure and Physicochemical Properties of Resistant Starch Prepared by Autoclaving-Microwave. Starch Stärke, 70(9-10), 1800060. https://doi.org/10.1002/star.201800060

Li, W., Bai, Y., \& Mousaa, S. A. S. (2011). Effect of High Hydrostatic Pressure on Physicochemical and Structural Properties of Rice Starch. Food and Bioprocess Technology, (August 2017). https://doi.org/10.1007/s11947-011-0542-6

Lim, W. J., Liang, Y. T., Seib, P. a, \& Rao, C. S. (1992). Isolation of oat starch from oat flour. Cereal Chem, 69(3), 233-236. Retrieved from http://www.aaccnet.org/publications/cc/backissues/1992/documents/69_233.pdf

Liu, D., Wu, Q., Chen, H., \& Chang, P. R. (2009). Transitional properties of starch colloid with particle size reduction from micro- to nanometer. Journal of Colloid and Interface $\quad$ Science, $\quad 339(1), \quad 117-124$. https://doi.org/10.1016/j.jcis.2009.07.035

Luo, Z., Fu, X., He, X., Luo, F., Gao, Q., \& Yu, S. (2008). Effect of ultrasonic treatment on the physicochemical properties of maize starches differing in amylose content. Starch/Staerke, 60(11), 646-653. https://doi.org/10.1002/star.200800014 
Martinl, C., \& Smith, M. (1995). Starch Biosynthesis, The plant Cell, 7(7), 971-985.

Miao, M., Zhang, T., \& Jiang, B. (2009). Characterisations of kabuli and desi chickpea starches cultivated in China. Food Chemistry, 113(4), 1025-1032. https://doi.org/10.1016/j.foodchem.2008.08.056

Ölçer, H., Akin, B., \& Kampüs, M. (2008). Starch : Biosynthesis , granule structure and genetic modifications. Dumlupınar Üniversitesi Fen Bilimleri Enstitüsü Dergisi.

Ozel, B., Cikrikci, S., Aydin, O., \& Oztop, M. H. (2017). Polysaccharide blended whey protein isolate-(WPI) hydrogels: A physicochemical and controlled release study. Food Hydrocolloids, $\quad 71, \quad 35-46$. https://doi.org/10.1016/j.foodhyd.2017.04.031

Ozel, B., Dag, D., Kilercioglu, M., Sumnu, S. G., \& Oztop, M. H. (2017). NMR relaxometry as a tool to understand the effect of microwave heating on starchwater interactions and gelatinization behavior. LWT - Food Science and Technology, 83, 10-17. https://doi.org/10.1016/j.lwt.2017.04.077

Sandhu, K. S., \& Lim, S. T. (2008). Digestibility of legume starches as influenced by their physical and structural properties. Carbohydrate Polymers, 71(2), 245-252. https://doi.org/10.1016/j.carbpol.2007.05.036

Singh, N., Sandhu, K. S., \& Kaur, M. (2004). Characterization of starches separated from Indian chickpea (Cicer arietinum L.) cultivars. Journal of Food Engineering, 63(4), 441-449. https://doi.org/10.1016/j.jfoodeng.2003.09.003

Singh, S., \& Kaur, M. (2017). Steady and dynamic shear rheology of starches from different oat cultivars in relation to their physicochemical and structural properties. International Journal of Food Properties, 20(12), 3282-3294. https://doi.org/10.1080/10942912.2017.1286504 
Sit, N., Misra, S., \& Deka, S. C. (2014). Yield and Functional Properties of Taro Starch as Affected by Ultrasound. Food and Bioprocess Technology, 1950-1958. https://doi.org/10.1007/s11947-013-1192-7

Soria, A. C., \& Villamiel, M. (2010). Effect of ultrasound on the technological properties and bioactivity of food: A review. Trends in Food Science and Technology, 21(7), 323-331. https://doi.org/10.1016/j.tifs.2010.04.003

Subramanian, V., Hoseney, R. C., \& Bramel-cox, P. (1994). Shear Thinning Properties of Sorghum and Corn starches . Cereal Chemistry, 71(January 1994), $272-275$.

Sujka, M., \& Jamroz, J. (2013). Ultrasound-treated starch: SEM and TEM imaging, and functional behaviour. Food Hydrocolloids, 31(2), 413-419. https://doi.org/10.1016/j.foodhyd.2012.11.027

Tester, R. F., Karkalas, J., \& Qi, X. (2004). Starch - Composition, fine structure and architecture. Journal of Cereal Science, 39(2), 151-165. https://doi.org/10.1016/j.jcs.2003.12.001

Tharanathan, R. N. (2005). Starch - Value addition by modification. Critical Reviews in Food Science and Nutrition, 45(5), 371-384. https://doi.org/10.1080/10408390590967702

Tosh, S. M., \& Yada, S. (2010). Dietary fibres in pulse seeds and fractions: Characterization, functional attributes, and applications. Food Research International, 43(2), 450-460. https://doi.org/10.1016/j.foodres.2009.09.005

Tu, Z., Yin, Y., Wang, H., Liu, G., Chen, L., Zhang, P., ... Zhang, L. (2013). Effect of dynamic high-pressure microfluidization on the morphology characteristics and physicochemical properties of maize amylose. Starch/Staerke, 65(5-6), 390397. https://doi.org/10.1002/star.201200120 
Vallons, K. J. R., Ryan, L. A. M., \& Arendt, E. K. (2014). Pressure-Induced Gelatinization of Starch in Excess Water. Critical Reviews in Food Science and Nutrition, 54(3), 399-409. https://doi.org/10.1080/10408398.2011.587037

Wani, I. A., Sogi, D. S., Hamdani, A. M., Gani, A., Bhat, N. A., \& Shah, A. (2016). Isolation, composition, and physicochemical properties of starch from legumes: A review. $\quad$ Starch/Staerke, 68(9-10), 834-845. https://doi.org/10.1002/star.201600007

Warren, F. J., Gidley, M. J., \& Flanagan, B. M. (2016). Infrared spectroscopy as a tool to characterise starch ordered structure - A joint FTIR-ATR, NMR, XRD and DSC study. Carbohydrate Polymers, 139, 35-42. https://doi.org/10.1016/j.carbpol.2015.11.066

Zhu, F. (2017). NMR spectroscopy of starch systems. Food Hydrocolloids, 63, 611624. https://doi.org/10.1016/j.foodhyd.2016.10.015 

APPENDICES

A. Power Law Fitting Curves

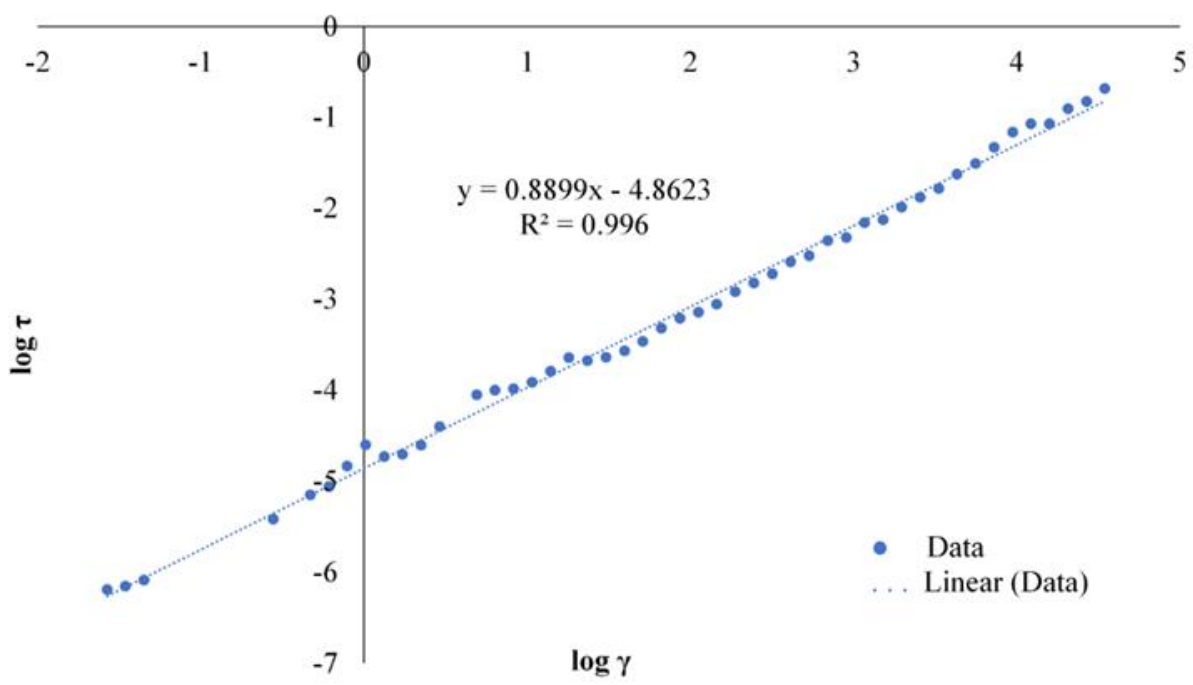

Figure A. 1. Power law fitting curve for native chickpea starch (sample 1)

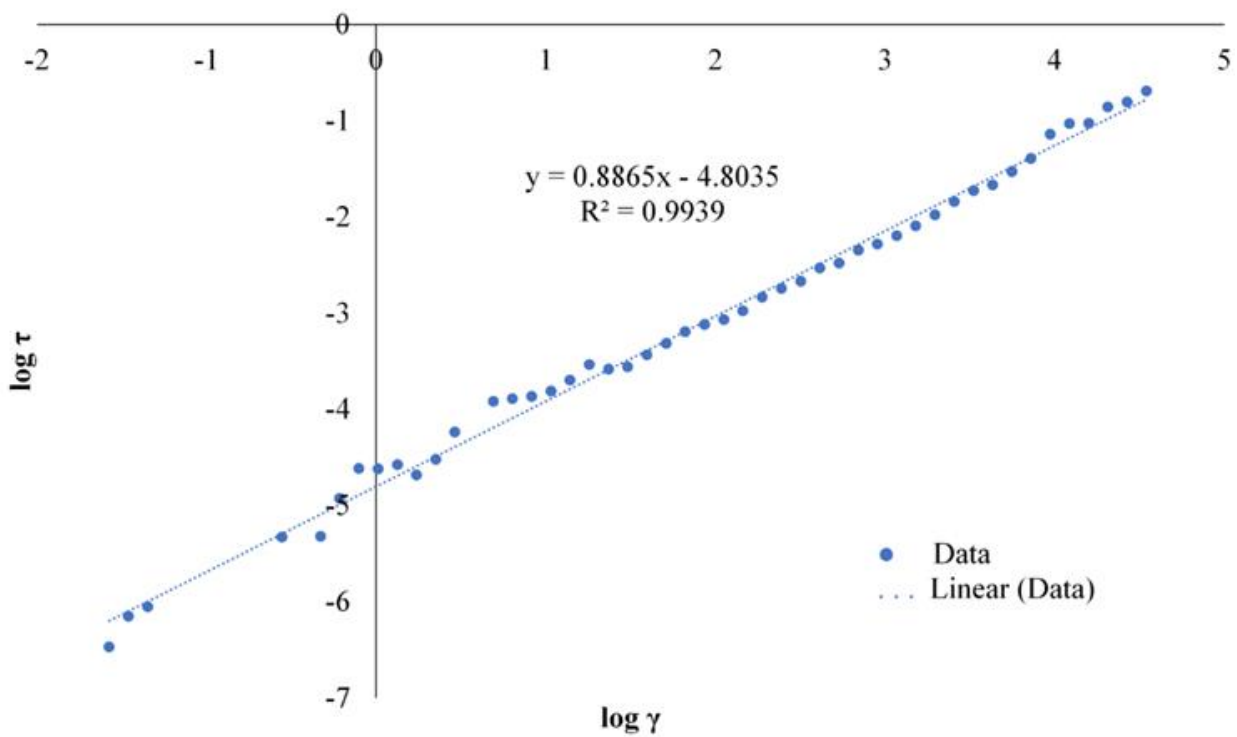

Figure A. 2. Power law fitting curve for native chickpea starch (sample 2) 


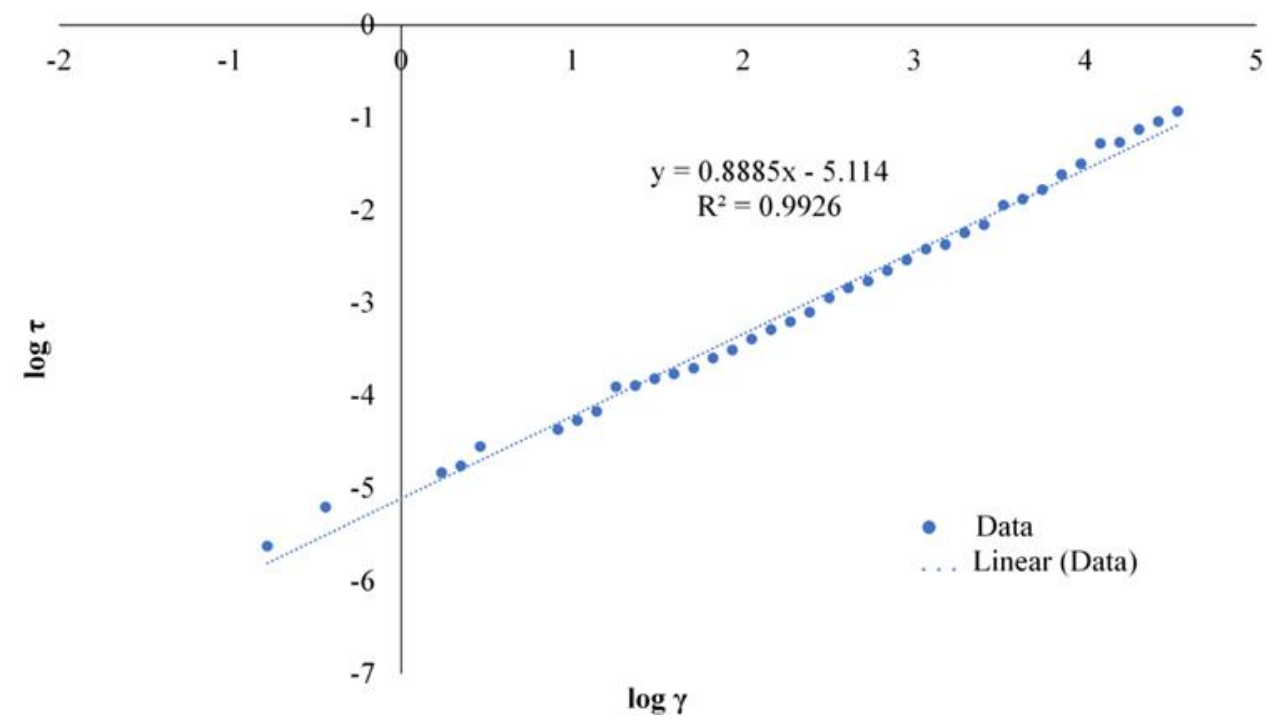

Figure A. 3. Power law fitting curve for sonicated chickpea starch (sample 1)

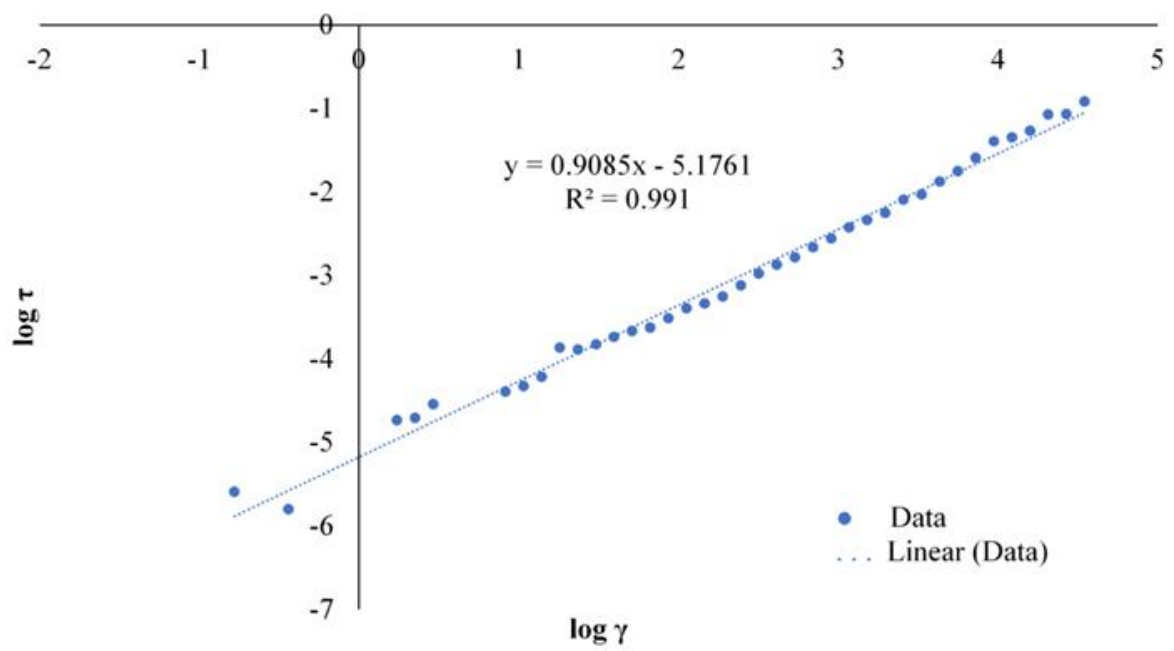

Figure A. 4. Power law fitting curve for sonicated chickpea starch (sample 2) 


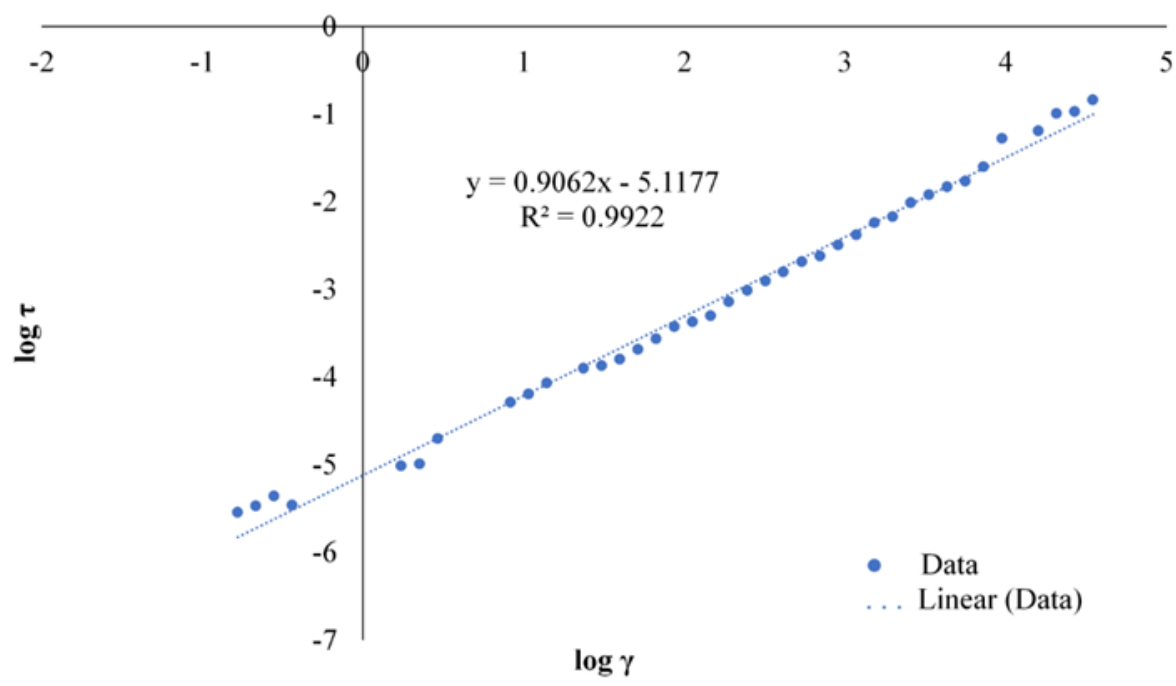

Figure A. 5. Power law fitting curve for microfluidized chickpea starch (sample 1)

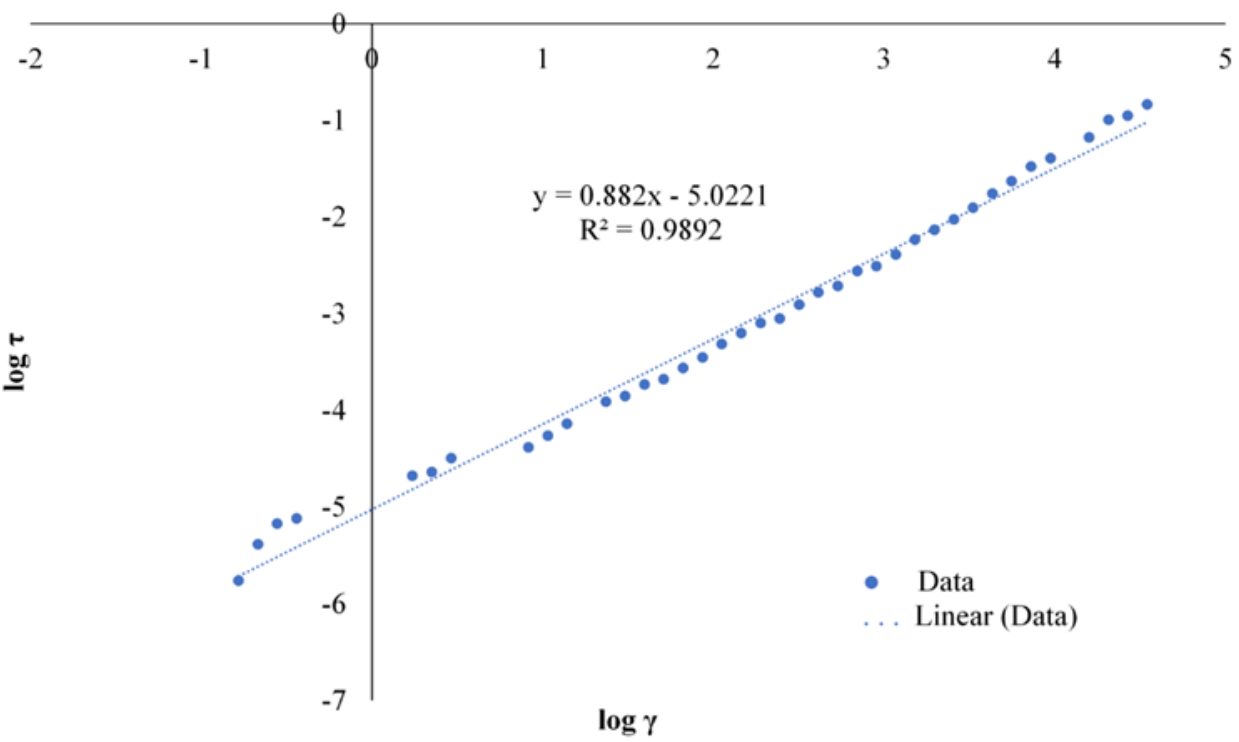

Figure A. 6. Power law fitting curve for microfluidized chickpea starch (sample 2) 


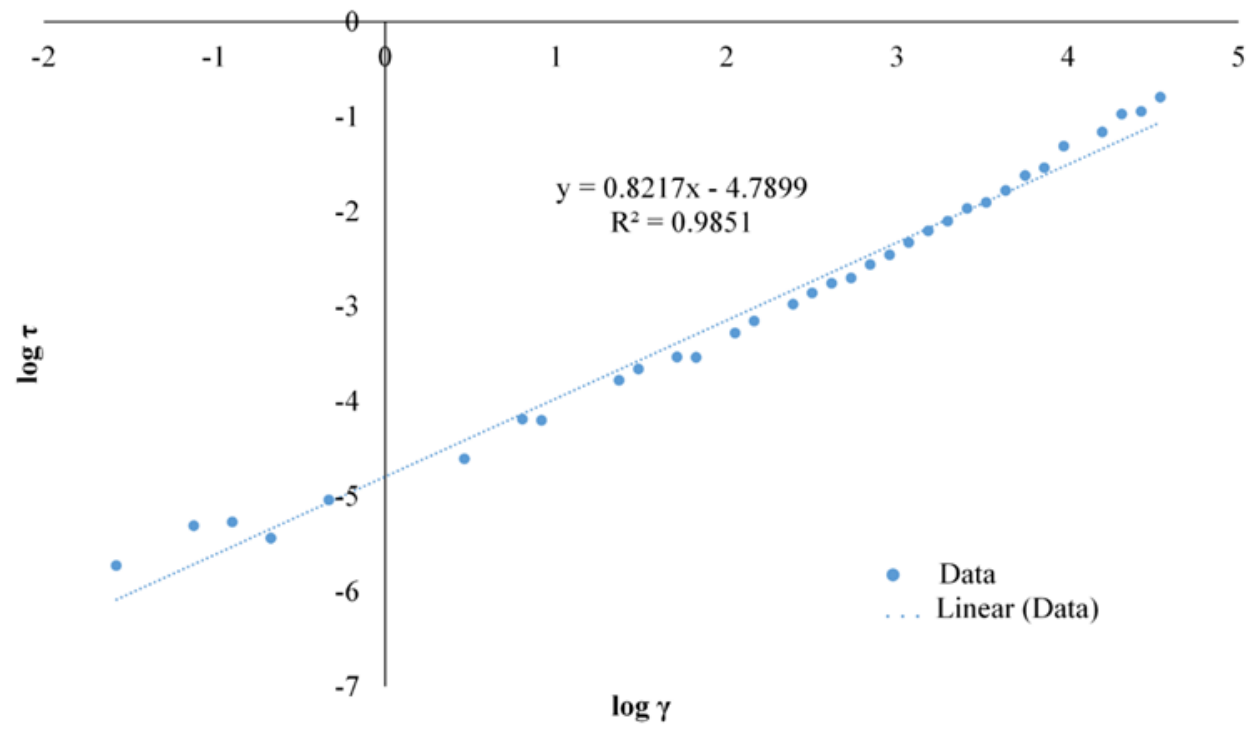

Figure A. 7. Power law fitting curve for native lentil starch (sample 1)

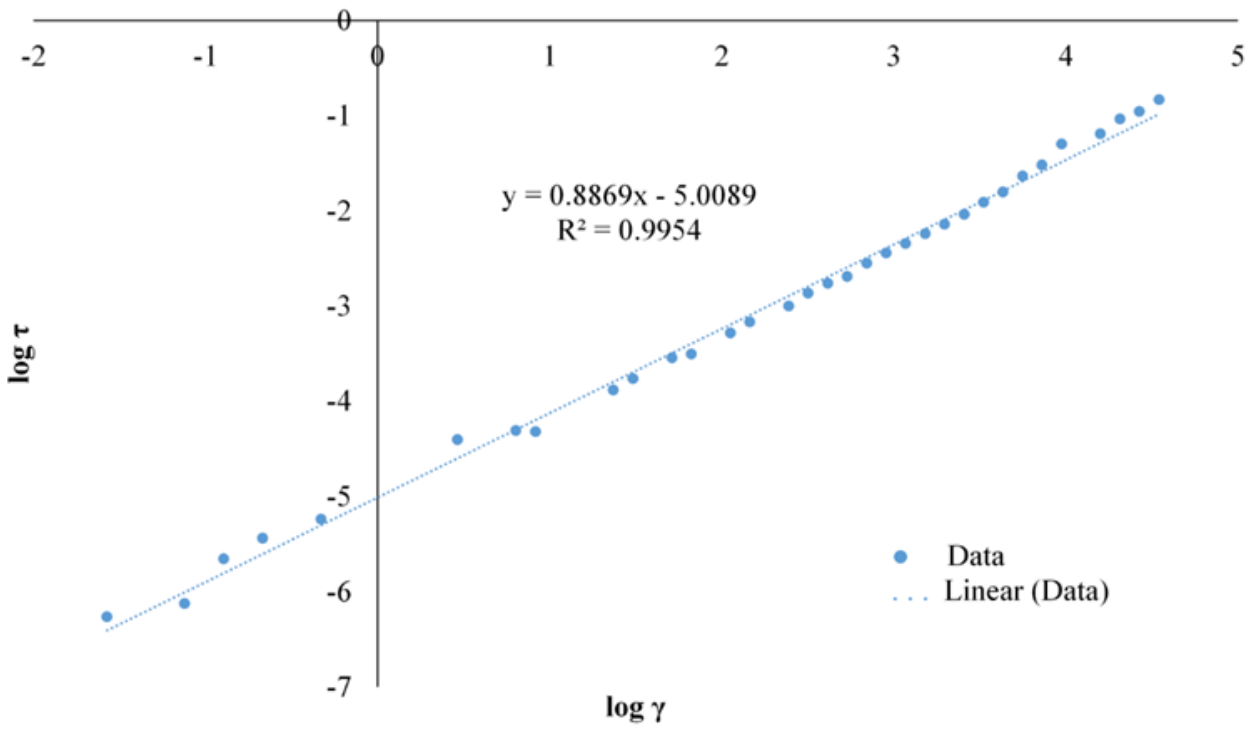

Figure A. 8. Power law fitting curve for native lentil starch (sample 2) 


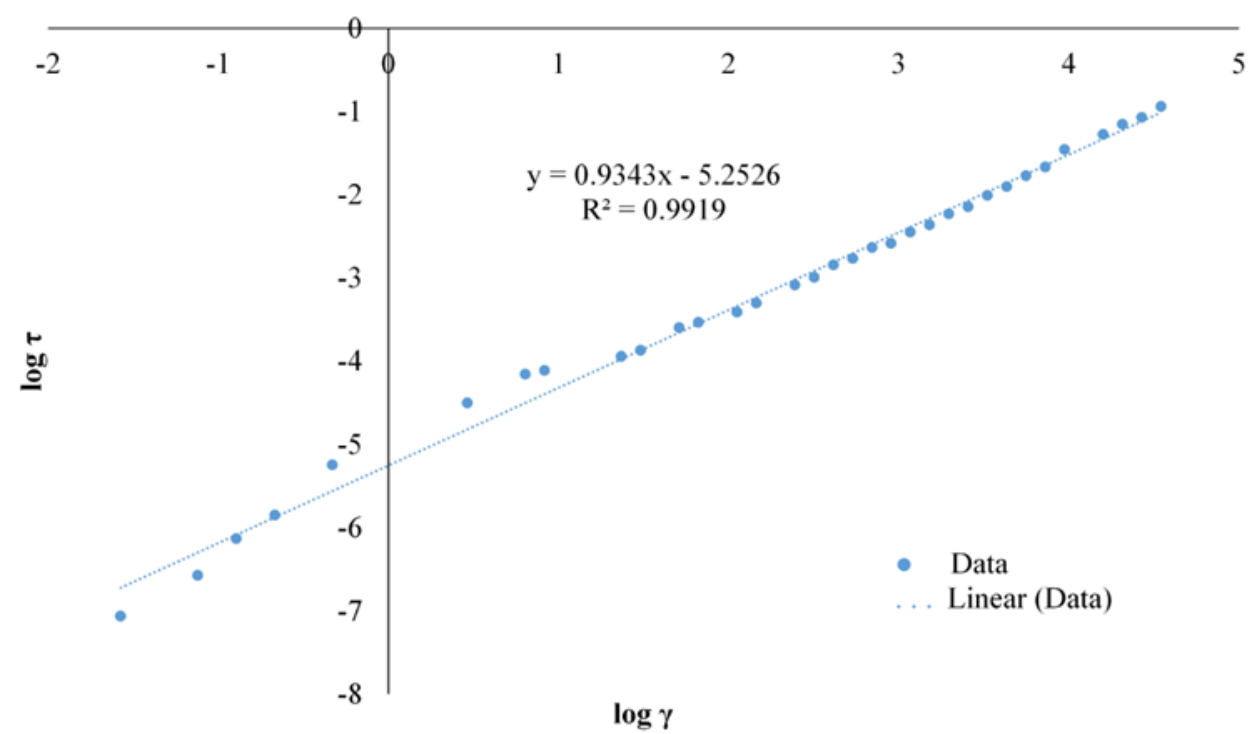

Figure A. 9. Power law fitting curve for sonicated lentil starch (sample 1)

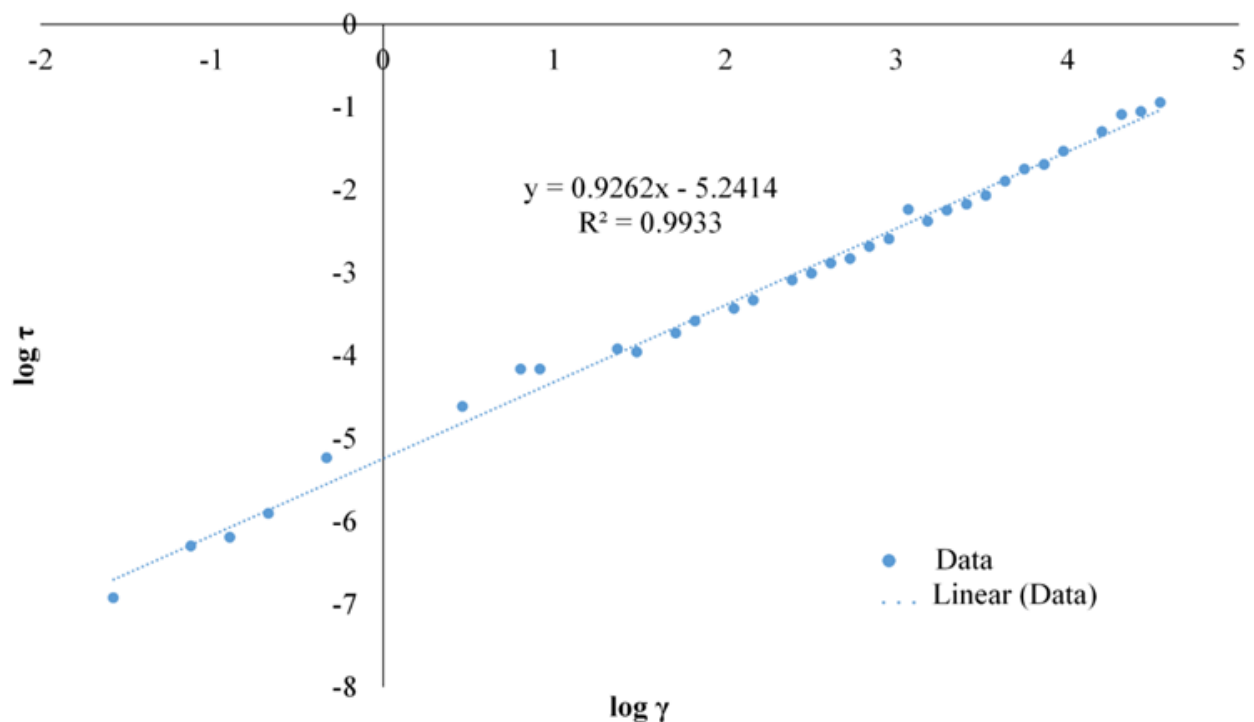

Figure A. 10. Power law fitting curve for sonicated lentil starch (sample 2) 


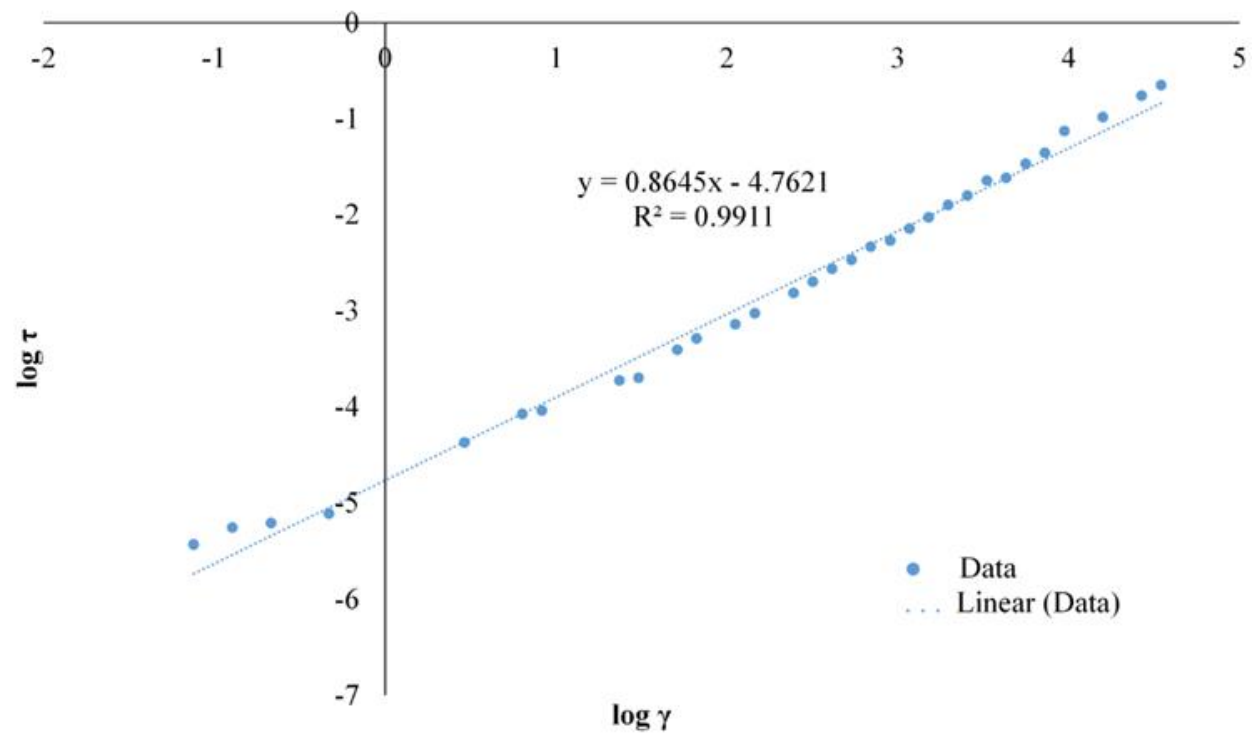

Figure A. 11. Power law fitting curve for microfluidized lentil starch (sample 1)

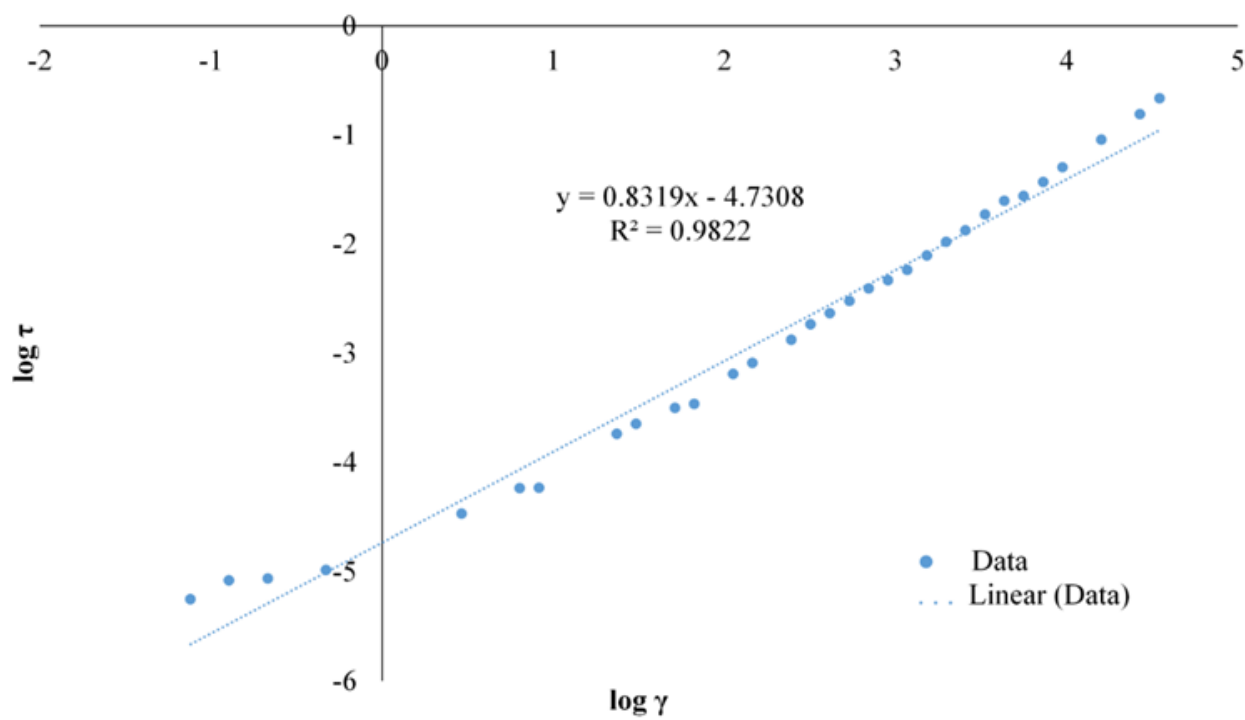

Figure A. 12. Power law fitting curve for microfluidized lentil starch (sample 2) 


\section{B. Statistical Analysis}

Table B. 1. Rheological properties of chickpea starches

General Linear Model: $\mathrm{n}$ versus Starch type

Factor Type Levels Values

Starch type Fixed 3 Chickpea Microfluidized; Chickpea Native; Chickpea

Sonicated

Analysis of Variance:

$\begin{array}{lccccc}\text { Source } & \text { DF } & \text { Adj SS } & \text { Adj MS } & \text { F-Value } & \text { P-Value } \\ \text { Starch type } & 2 & 0,000107 & 0,000053 & 0,32 & 0,747 \\ \text { Error } & 3 & 0,000499 & 0,000166 & & \\ \text { Total } & 5 & 0,000605 & & & \end{array}$

Model Summary:

\begin{tabular}{llll}
$\mathrm{S}$ & $\mathrm{R}$-sq & $\mathrm{R}$-sq(adj) & $\mathrm{R}$-sq(pred) \\
\hline 0,0128919 & $17,65 \%$ & $0,00 \%$ & $0,00 \%$
\end{tabular}

Coefficients:

$\begin{array}{lcllll}\text { Term } & \text { Coef SE } & \text { Coef } & \text { T-Value } & \text { P-Value } & \text { VIF } \\ \text { Constant } & 0,89360 & 0,00526 & 169,79 & 0,000\end{array}$

Starch type

$\begin{array}{llllll}\text { Chickpea Microfluidized } & 0,00050 & 0,00744 & 0,07 & 0,951 & 1,33\end{array}$

$\begin{array}{llllll}\text { Chickpea Native } & -0,00540 & 0,00744 & -0,73 & 0,521 & 1,33\end{array}$

Regression Equation:

$\mathrm{n} \quad=0,89360+0,00050$ Starch type_Chickpea $\quad$ Microfluidized

- 0,00540 Starch type_Chickpea Native + 0,00490 Starch type_Chickpea Sonicated 
General Linear Model: K versus Starch type

Factor Type Levels Values

Starch type Fixed 3 Chickpea Microfluidized; Chickpea Native; Chickpea

Sonicated

Analysis of Variance:

$\begin{array}{lccccc}\text { Source } & \text { DF } & \text { Adj SS } & \text { Adj MS } & \text { F-Value } & \text { P-Value } \\ \text { Starch type } & 2 & 0,000005 & 0,000003 & 21,32 & 0,017 \\ \text { Error } & 3 & 0,000000 & 0,000000 & & \\ \text { Total } & 5 & 0,000005 & & & \end{array}$

Model Summary:

\begin{tabular}{llll} 
S & R-sq & R-sq(adj) & R-sq(pred) \\
\hline 0,0003443 & $93,43 \%$ & $89,04 \%$ & $73,71 \%$
\end{tabular}

Coefficients:

$\begin{array}{lllcll}\text { Term } & \text { Coef } & \text { SE Coef } & \text { T-Value } & \text { P-Value VIF } \\ \text { Constant } & 0,006696 & 0,000141 & 47,63 & 0,000\end{array}$

Starch type

$\begin{array}{llllll}\text { Chickpea Microfluidized } & -0,000406 & 0,000199 & -2,04 & 0,134 & 1,33\end{array}$

$\begin{array}{llllll}\text { Chickpea Native } & 0,001271 & 0,000199 & 6,39 & 0,008 & 1,33\end{array}$

Regression Equation:

$\mathrm{K}=0,006696 \quad-0,000406$ Starch type_Chickpea Microfluidized + 0,001271 Starch type_Chickpea Native - 0,000865 Starch type_Chickpea Sonicated 
One-way ANOVA: $\mathrm{n}$ versus Starch type

Means:

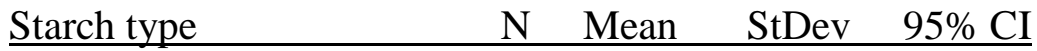

Chickpea Microfluidized $2 \quad 0,8941 \quad 0,0171 \quad(0,8651 ; 0,9231)$

Chickpea Native $\quad 2 \quad 0,888200,00240(0,85919 ; 0,91721)$

Chickpea Sonicated $\quad 2 \quad 0,8985 \quad 0,0141 \quad(0,8695 ; 0,9275)$

Tukey Pairwise Comparisons:

Grouping Information Using the Tukey Method and 95\% Confidence

$\begin{array}{llll}\text { Starch type } & \text { N } & \text { Mean } & \text { Grouping } \\ \text { Chickpea Sonicated } & 2 & 0,8985 & \text { A } \\ \text { Chickpea Microfluidized } & 2 & 0,8941 & \text { A } \\ \text { Chickpea Native } & 2 & 0,88820 & \text { A }\end{array}$

Means that do not share a letter are significantly different.

One-way ANOVA: K versus Starch type

Means:

$\begin{array}{lllll}\text { Starch type } & \text { N } & \text { Mean } & \text { StDev } & 95 \% \text { CI } \\ \text { Chickpea Microfluidized } & 2 & 0,006290 & 0,000425 & (0,005515 ; 0,007065) \\ \text { Chickpea Native } & 2 & 0,007967 & 0,000331 & (0,007192 ; 0,008742) \\ \text { Chickpea Sonicated } & 2 & 0,005831 & 0,000256 & (0,005056 ; 0,006606)\end{array}$

Tukey Pairwise Comparisons

Grouping Information Using the Tukey Method and 95\% Confidence 


\begin{tabular}{|c|c|c|c|}
\hline Starch type & $\mathrm{N}$ & Mean & Grouping \\
\hline Chickpea Native & 2 & 0,007967 & A \\
\hline Chickpea Microfluidized & 2 & 0,006290 & B \\
\hline Chickpea Sonicated & 2 & 0,005831 & B \\
\hline
\end{tabular}

Means that do not share a letter are significantly different.

Table B. 2. Rheological properties of lentil starches

General Linear Model: $n$ versus Starch type

Factor Type Levels Values

Starch type Fixed 3 Lentil Microfluidized; Lentil Native; Lentil

Sonicated

Analysis of Variance:

$\begin{array}{lccccc}\text { Source } & \text { DF } & \text { Adj SS } & \text { Adj MS } & \text { F-Value } & \text { P-Value } \\ \text { Starch type } & 2 & 0,008359 & 0,004179 & 4,66 & 0,120 \\ \text { Error } & 3 & 0,002690 & 0,000897 & & \\ \text { Total } & 5 & 0,011048 & & & \end{array}$

Model Summary:

$\begin{array}{llll}\text { S } & \text { R-sq } & \text { R-sq(adj) } & \text { R-sq(pred) } \\ 0,0299428 & 75,65 \% & 59,42 \% & 2,62 \%\end{array}$

Coefficients:

Term Coef SE Coef T-Value P-Value VIF

$\begin{array}{lllll}\text { Constant } & 0,8776 & 0,0122 & 71,79 & 0,000\end{array}$

Starch type

$\begin{array}{lrrrrr}\text { Lentil Microfluidized } & -0,0294 & 0,0173 & -1,70 & 0,188 & 1,33 \\ \text { Lentil Native } & -0,0233 & 0,0173 & -1,35 & 0,271 & 1,33\end{array}$


Regression Equation:

$\mathrm{n}=$ 0,8776 - 0,0294 Starch type_Lentil Microfluidized - 0,0233 Starch type_Lentil Native $+0,0527$ Starch type_Lentil Sonicated

General Linear Model: K versus Starch type

Factor Type Levels Values

Starch type Fixed $3 \quad$ Lentil Microfluidized; Lentil Native; Lentil Sonicated

Analysis of Variance:

$\begin{array}{llllll}\text { Source } & \text { DF } & \text { Adj SS } & \text { Adj MS } & \text { F-Value } & \text { P-Value } \\ \text { Starch type } & 2 & 0,000012 & 0,000006 & 13,15 & 0,033 \\ \text { Error } & 3 & 0,000001 & 0,000000 & & \\ \text { Total } & 5 & 0,000013 & & & \end{array}$

Model Summary:

$\begin{array}{llll}\text { S } & \text { R-sq } & \text { R-sq(adj) } & \text { R-sq(pred) } \\ 0,0006771 & 89,76 \% & 82,94 \% & 59,06 \%\end{array}$

Coefficients:

Term Coef SE Coef T-Value P-Value VIF

Constant $\quad 0,007148 \quad 0,000276 \quad 25,86 \quad 0,000$

Starch type

Lentil Microfluidized $0,001536 \quad 0,000391 \quad 3,93 \quad 0,029 \quad 1,33$

$\begin{array}{llllll}\text { Lentil Native } \quad 0,000348 & 0,000391 & 0,89 & 0,439 & 1,33\end{array}$

Regression Equation:

$\mathrm{K}=0,007148+0,001536$ Starch type_Lentil $\quad$ Microfluidized

+ 0,000348 Starch type_Lentil Native - 0,001884 Starch type_Lentil Sonicated 
One-way ANOVA: $\mathrm{n}$ versus Starch type

Means:

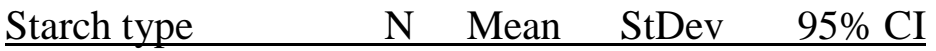

Lentil Microfluidized $2 \quad 0,8482 \quad 0,0231 \quad(0,7808 ; 0,9156)$

Lentil Native $\quad 2 \quad 0,8543 \quad 0,0461 \quad(0,7869 ; 0,9217)$

Lentil Sonicated $20,930250,00573 \quad(0,86287 ; 0,99763)$

Tukey Pairwise Comparisons

Grouping Information Using the Tukey Method and 95\% Confidence

$\begin{array}{lcll}\text { Starch type } & \text { N } & \text { Mean } & \text { Grouping } \\ \text { Lentil Sonicated } & 2 & 0,93025 & \text { A } \\ \text { Lentil Native } & 2 & 0,8543 & \text { A } \\ \text { Lentil Microfluidized } & 2 & 0,8482 & \text { A }\end{array}$

Means that do not share a letter are significantly different.

One-way ANOVA: K versus Starch type

Means:

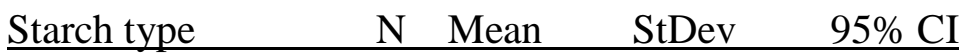

Lentil Microfluidized $20,0086840,000192 \quad(0,007160 ; 0,010207)$

Lentil Native $\quad 20,0074960,001156 \quad(0,005972 ; 0,009019)$

Lentil Sonicated $\quad 2 \quad 0,005263 \quad 0,000042 \quad(0,003740 ; 0,006787)$

Tukey Pairwise Comparisons 
Grouping Information Using the Tukey Method and 95\% Confidence

\begin{tabular}{lclc} 
Starch type & N & Mean & Grouping \\
\hline Lentil Microfluidized & 2 & 0,008684 & A \\
Lentil Native & 2 & 0,007496 & A B \\
Lentil Sonicated & 2 & 0,005263 & B
\end{tabular}

Means that do not share a letter are significantly different.

Table B. 3. NMR results of chickpea starches

General Linear Model: T2 versus Starch Type

Factor Type Levels Values

Starch Type Fixed 3 Chickpea Microfluidized; Chickpea Native; Chickpea

Sonicated

Analysis of Variance:

Source DF Adj SS Adj MS F-Value P-Value

Starch Type $2 \quad 0,034905 \quad 0,017452 \quad 42,50 \quad 0,001$

$\begin{array}{llll}\text { Error } \quad 5 & 0,002053 & 0,000411\end{array}$

Total $\quad 7 \quad 0,036958$

Model Summary:

\begin{tabular}{llll}
$\mathrm{S}$ & $\mathrm{R}$-sq & $\mathrm{R}$-sq(adj) & $\mathrm{R}$-sq(pred) \\
\hline 0,0202649 & $94,44 \%$ & $92,22 \%$ & $87,46 \%$
\end{tabular}


Coefficients:

Term

Coef SE Coef T-Value P-Value VIF

Constant

$\begin{array}{llll}0,24689 & 0,00730 & 33,84 & 0,000\end{array}$

Starch Type

$\begin{array}{llllll}\text { Chickpea Microfluidized } & -0,02056 & 0,00994 & -2,07 & 0,094 & 1,17\end{array}$

$\begin{array}{llllll}\text { Chickpea Native } & -0,07456 & 0,00994 & -7,50 & 0,001 & 1,17\end{array}$

Regression Equation:

$\mathrm{T} 2=0,24689 \quad-$ 0,02056 Starch Type_Chickpea Microfluidized

- 0,07456 Starch Type_Chickpea Native + 0,0951 Starch Type_Chickpea Sonicated

Fits and Diagnostics for Unusual Observations:

Obs T2 Fit Resid Std Resid

$7 \quad 0,2620 \quad 0,2263 \quad 0,0357 \quad 2,16 \mathrm{R}$

One-way ANOVA: T2 versus Starch Type

Means:

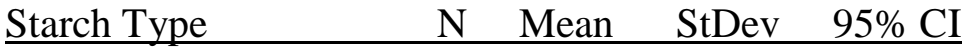

Chickpea Microfluidized $3 \quad 0,2263 \quad 0,0318 \quad(0,1963 ; 0,2564)$

Chickpea Native $\quad 3 \quad 0,172330,00351(0,14226 ; 0,20241)$

Chickpea Sonicated $20,34200 \quad 0,00283(0,30516 ; 0,37884)$

Tukey Pairwise Comparisons

Grouping Information Using the Tukey Method and 95\% Confidence

$\begin{array}{lrlc}\text { Starch Type } & \text { N } & \text { Mean } & \text { Grouping } \\ \text { Chickpea Sonicated } & 2 & 0,34200 & \text { A } \\ \text { Chickpea Microfluidized } & 3 & 0,2263 & \text { B } \\ \text { Chickpea Native } & 3 & 0,17233 & \text { C }\end{array}$


Means that do not share a letter are significantly different.

Table B. 4. NMR results of lentil starches

General Linear Model: T2 versus Starch Type

Factor Type Levels Values

Starch Type Fixed $3 \quad$ Lentil Microfluidized; Lentil Native; Lentil Sonicated

Analysis of Variance:

$\begin{array}{llllll}\text { Source } & \text { DF } & \text { Adj SS } & \text { Adj MS } & \text { F-Value } & \text { P-Value } \\ \text { Starch Type } & 2 & 0,029772 & 0,014886 & 51,38 & 0,000 \\ \text { Error } & 5 & 0,001448 & 0,000290 & & \\ \text { Total } & 7 & 0,031221 & & & \end{array}$

Model Summary:

\begin{tabular}{llll} 
S & R-sq & R-sq(adj) & R-sq(pred) \\
\hline 0,0170206 & $95,36 \%$ & $93,50 \%$ & $82,83 \%$
\end{tabular}

Coefficients:

$\begin{array}{llllll}\text { Term } & \text { Coef } & \text { SE Coef } & \text { T-Value } & \text { P-Value } & \text { VIF } \\ \text { Constant } & 0,26150 & 0,00613 & 42,67 & 0,000 & \\ \text { Starch Type } & & & & & \\ \text { Lentil Microfluidized } & 0,05250 & 0,00835 & 6,29 & 0,001 & 1,17 \\ \text { Lentil Native } & -0,08150 & 0,00835 & -9,76 & 0,000 & 1,17\end{array}$

Regression Equation:

$\mathrm{T} 2=0,26150+0,05250$ Starch Type_Lentil $\quad$ Microfluidized - 0,08150 Starch Type_Lentil Native + 0,02900 Starch Type_Lentil Sonicated 
Fits and Diagnostics for Unusual Observations

\begin{tabular}{cllll} 
Obs & T2 & Fit & Resid & Std Resid \\
\hline 4 & 0,2660 & 0,2905 & $-0,0245$ & $-2,04 \mathrm{R}$ \\
5 & 0,3150 & 0,2905 & 0,0245 & $2,04 \mathrm{R}$
\end{tabular}

One-way ANOVA: T2 versus Starch Type

Means:

Starch Type $\quad \mathrm{N}$ Mean StDev $95 \% \mathrm{CI}$

Lentil Microfluidized $3 \quad 0,31400 \quad 0,01114 \quad(0,28874 ; 0,33926)$

Lentil Native $\quad 3 \quad 0,1800 \quad 0,0000 \quad(0,1547 ; 0,2053)$

Lentil Sonicated $\quad 2 \quad 0,2905 \quad 0,0346 \quad(0,2596 ; 0,3214)$

Tukey Pairwise Comparisons

Grouping Information Using the Tukey Method and 95\% Confidence

Starch Type N Mean Grouping

Lentil Microfluidized $3 \quad 0,31400$ A

Lentil Sonicated $20,2905 \quad$ A

Lentil Native $\quad 30,1800 \quad$ B

Means that do not share a letter are significantly different. 
Table B. 5. Particle size analysis results of chickpea starches

General Linear Model: D[4,3] versus Starch Type

Factor Type Levels Values

Starch Type Fixed 3 Chickpea Microfluidized; Chickpea Native; Chickpea

Sonicated

Analysis of Variance:

Source DF Adj SS Adj MS F-Value P-Value

$\begin{array}{lllll}\text { Starch Type } 2 & 1493,59 & 746,795 & 229,43 & 0,001\end{array}$

$\begin{array}{llll}\text { Error } \quad 3,76 & 3,255\end{array}$

Total $\quad 5 \quad 1503,36$

Model Summary:

$\underline{\mathrm{S}} \quad \mathrm{R}$-sq $\quad \mathrm{R}$-sq(adj) R-sq(pred)

$1,80416 \quad 99,35 \% \quad 98,92 \% \quad 97,40 \%$

Coefficients:

Term Coef SE Coef T-Value P-Value VIF

Constant

$51,950 \quad 0,737 \quad 70,53 \quad 0,000$

Starch Type

$\begin{array}{lllll}\text { Chickpea Microfluidized }-14,65 & 1,04 & -14,06 & 0,001 & 1,33\end{array}$

$\begin{array}{llllll}\text { Chickpea Native } & 21,90 & 1,04 & 21,02 & 0,000 & 1,33\end{array}$

Regression Equation:

$\mathrm{D}[4,3] \quad=\quad 51,950 \quad-14,65$ Starch Type_Chickpea Microfluidized

+21,90 Starch Type_Chickpea Native - 7,25 Starch Type_Chickpea Sonicated 
General Linear Model: Span versus Starch Type

Factor Type Levels Values

Starch Type Fixed 3 Chickpea Microfluidized; Chickpea Native; Chickpea

Sonicated

Analysis of Variance:

Source DF Adj SS Adj MS F-Value P-Value

$\begin{array}{lllll}\text { Starch Type } 2 & 8,62550 & 4,31275 & 154,95 & 0,001\end{array}$

$\begin{array}{llll}\text { Error } & 3 & 0,08350 & 0,02783\end{array}$

Total $\quad 5 \quad 8,70900$

Model Summary:

$\underline{\text { S }} \quad$ R-sq $\quad$ R-sq(adj) $\quad$ R-sq(pred)

$0,166830 \quad 99,04 \% \quad 98,40 \% \quad 96,17 \%$

Coefficients:

Term Coef SE Coef T-Value P-Value VIF

$\begin{array}{lllll}\text { Constant } & 4,2843 & 0,0681 & 62,90 & 0,000\end{array}$

Starch Type

$\begin{array}{llllll}\text { Chickpea Microfluidized } & -1,1378 & 0,0963 & -11,81 & 0,001 & 1,33\end{array}$

$\begin{array}{llllll}\text { Chickpea Native } & 1,6577 & 0,0963 & 17,21 & 0,000 & 1,33\end{array}$

Regression Equation:

Span = 4,2843 - 1,1378 Starch Type_Chickpea Microfluidized

+ 1,6577 Starch Type_Chickpea Native - 0,5198 Starch Type_Chickpea Sonicated 
One-way ANOVA: D[4,3] versus Starch Type

Means:

$\begin{array}{llll}\text { Starch Type } & \text { N } & \text { Mean } & \text { StDev } 95 \% \text { CI }\end{array}$

Chickpea Microfluidized $2 \quad 37,300 \quad 0,283 \quad(33,240 ; 41,360)$

$\begin{array}{lllll}\text { Chickpea Native } & 2 & 73,8500 & 0,0707 & (69,7900 ; 77,9100)\end{array}$

Chickpea Sonicated $\quad 2 \quad 44,70 \quad 3,11 \quad(40,64 ; 48,76)$

Tukey Pairwise Comparisons

Grouping Information Using the Tukey Method and 95\% Confidence

Starch Type N Mean Grouping

Chickpea Native $\quad 273,8500$ A

Chickpea Sonicated $244,70 \quad$ B

Chickpea Microfluidized $2 \quad 37,300 \quad$ B

Means that do not share a letter are significantly different.

One-way ANOVA: Span versus Starch Type

Means:

\begin{tabular}{llll} 
Starch Type & N & Mean & StDev \\
\hline
\end{tabular}

Chickpea Microfluidized $2 \quad 3,1465 \quad 0,0163 \quad(2,7711 ; 3,5219)$

Chickpea Native $\quad 2 \quad 5,942 \quad 0,173 \quad(5,567 ; 6,317)$

Chickpea Sonicated $2 \quad 3,765 \quad 0,231 \quad(3,389 ; 4,140)$

Tukey Pairwise Comparisons 
Grouping Information Using the Tukey Method and 95\% Confidence

Starch Type N Mean Grouping

Chickpea Native $\quad 2 \quad 5,942$ A

Chickpea Sonicated $23,765 \quad$ B

Chickpea Microfluidized $2 \quad 3,1465 \quad$ B

Means that do not share a letter are significantly different.

Table B. 6. Particle size analysis results of lentil starches

General Linear Model: D[4,3] versus Starch Type

Factor Type Levels Values

Starch Type Fixed 3 Lentil Microfluidized; Lentil Native; Lentil Sonicated

Analysis of Variance:

Source DF Adj SS Adj MS F-Value P-Value

$\begin{array}{lllll}\text { Starch Type } 2 & 47,1633 & 23,5817 & 164,52 & 0,001\end{array}$

$\begin{array}{llll}\text { Error } & 3 & 0,4300 & 0,1433\end{array}$

Total $\quad 5 \quad 47,5933$

Model Summary:

$\underline{S} \quad$ R-sq $\quad R$-sq(adj) R-sq(pred)

$0,378594 \quad 99,10 \% \quad 98,49 \% \quad 96,39 \%$ 
Coefficients:

Term

Coef SE Coef T-Value P-Value VIF

Constant

$37,967 \quad 0,155 \quad 245,64 \quad 0,000$

Starch Type

Lentil Microfluidized $\quad 0,283 \quad 0,219 \quad 1,30 \quad 0,286 \quad 1,33$

$\begin{array}{lllll}\text { Lentil Native } \quad 3,283 & 0,219 & 15,02 & 0,001 & 1,33\end{array}$

Regression Equation:

$\mathrm{D}[4,3] \quad=\quad 37,967+0,283$ Starch Type_Lentil $\quad$ Microfluidized

+ 3,283 Starch Type_Lentil Native - 3,567 Starch Type_Lentil Sonicated

General Linear Model: Span versus Starch Type

Factor Type Levels Values

Starch Type Fixed 3 Lentil Microfluidized; Lentil Native; Lentil Sonicated

Analysis of Variance:

Source DF Adj SS Adj MS F-Value P-Value

Starch Type $2 \quad 1,61361 \quad 0,80681 \quad 59,20 \quad 0,004$

$\begin{array}{llll}\text { Error } \quad 3 & 0,04088 & 0,01363\end{array}$

Total $\quad 5 \quad 1,65450$

Model Summary:

$\underline{\mathrm{S}} \quad \mathrm{R}$-sq $\quad$ R-sq(adj) R-sq(pred)

$0,116740 \quad 97,53 \% \quad 95,88 \% \quad 90,12 \%$ 
Coefficients:

Term Coef SE Coef T-Value P-Value VIF

Constant

$2,3103 \quad 0,0477 \quad 48,48 \quad 0,000$

Starch Type

Lentil Microfluidized 0,2822 $0,0674 \quad 4,19 \quad 0,025 \quad 1,33$

$\begin{array}{lllll}\text { Lentil Native } \quad 0,4452 & 0,0674 & 6,60 & 0,007 & 1,33\end{array}$

Regression Equation:

Span $=2,3103+0,2822$ Starch Type_Lentil $\quad$ Microfluidized

+ 0,4452 Starch Type_Lentil Native - 0,7273 Starch Type_Lentil Sonicated

One-way ANOVA: D[4,3] versus Starch Type

Means:

Starch Type $\quad \mathrm{N}$ Mean $\quad$ StDev $95 \%$ CI

Lentil Microfluidized $2 \quad 38,2500 \quad 0,0707 \quad(37,3980 ; 39,1020)$

Lentil Native $\quad 2 \quad 41,250 \quad 0,495 \quad(40,398 ; 42,102)$

Lentil Sonicated $\quad 2 \quad 34,400 \quad 0,424 \quad(33,548 ; 35,252)$

Tukey Pairwise Comparisons

Grouping Information Using the Tukey Method and 95\% Confidence

Starch Type N Mean Grouping

Lentil Native $241,250 \quad$ A

Lentil Microfluidized $2 \quad 38,2500 \quad$ B

Lentil Sonicated $234,400 \quad$ C

Means that do not share a letter are significantly different.

One-way ANOVA: Span versus Starch Type 
Means:

Starch Type $\quad$ N Mean StDev $95 \%$ CI

Lentil Microfluidized $2 \quad 2,5925 \quad 0,0474 \quad(2,3298 ; 2,8552)$

Lentil Native $\quad 2 \quad 2,756 \quad 0,187 \quad(2,493 ; 3,018)$

Lentil Sonicated $\quad 2 \quad 1,5830 \quad 0,0594 \quad(1,3203 ; 1,8457)$

Tukey Pairwise Comparisons

Grouping Information Using the Tukey Method and 95\% Confidence

Starch Type N Mean Grouping

Lentil Native $\quad 2 \quad 2,756 \quad$ A

Lentil Microfluidized 2 2,5925 A

Lentil Sonicated $2 \quad 1,5830 \quad$ B

Means that do not share a letter are significantly different.

Table B. 7. Solubility of chickpea starches

General Linear Model: Solubility versus Starch Type

Factor Type Levels Values

Starch Type Fixed 3 Chickpea Microfluidized; Chickpea Native; Chickpea

Sonicated

Analysis of Variance:

Source DF AdjSS Adj MS F-Value P-Value

$\begin{array}{lllll}\text { Starch Type } 2 & 94,3290 & 47,1645 & 541,79 & 0,000\end{array}$

$\begin{array}{llll}\text { Error } & 7 & 0,6094 & 0,0871\end{array}$

Total $\quad 9 \quad 94,9384$ 
Model Summary:

$\underline{\mathrm{S}} \quad \mathrm{R}$-sq $\quad \mathrm{R}$-sq(adj) $\mathrm{R}$-sq(pred)

$0,295049 \quad 99,36 \% \quad 99,17 \% \quad 98,79 \%$

Coefficients:

$\underline{\text { Term }}$ Coef SE Coef T-Value P-Value VIF

Constant $11,7377 \quad 0,0942 \quad 124,65 \quad 0,000$

Starch Type

$\begin{array}{llllll}\text { Chickpea Microfluidized } & 0,807 & 0,127 & 6,35 & 0,000 & 1,28\end{array}$

$\begin{array}{llllll}\text { Chickpea Native } & 3,487 & 0,136 & 25,61 & 0,000 & 1,28\end{array}$

Regression Equation:

Solubility $=11,7377 \quad+0,807$ Starch Type_Chickpea Microfluidized

+ 3,487 Starch Type_Chickpea Native - 4,294 Starch Type_Chickpea Sonicated

One-way ANOVA: Solubility versus Starch Type

Means:

Starch Type $\quad$ N Mean StDev $95 \%$ CI

Chickpea Microfluidized $4 \quad 12,544 \quad 0,395 \quad(12,196 ; 12,893)$

Chickpea Native $\quad 315,22480,1555 \quad(14,8220 ; 15,6276)$

Chickpea Sonicated $\quad 3 \quad 7,444 \quad 0,216 \quad(7,041 ; 7,847)$

Tukey Pairwise Comparisons

Grouping Information Using the Tukey Method and 95\% Confidence

Starch Type N Mean Grouping

Chickpea Native $\quad 3 \quad 15,2248$ A

Chickpea Microfluidized $4 \quad 12,544 \quad$ B

$\begin{array}{llll}\text { Chickpea Sonicated } & 3 & 7,444 & \text { C }\end{array}$ 
Means that do not share a letter are significantly different.

Table B. 8. Swelling power of chickpea starches

General Linear Model: Swelling Power versus Starch Type

Factor Type Levels Values

Starch Type Fixed $3 \quad$ Chickpea Microfluidized; Chickpea Native; Chickpea

Sonicated

Analysis of Variance:

Source DF Adj SS Adj MS F-Value P-Value

$\begin{array}{lllll}\text { Starch Type } 2 & 7,0643 & 3,53217 & 61,45 & 0,000\end{array}$

Error $\quad 7 \quad 0,4024 \quad 0,05748$

Total $\quad 9 \quad 7,4667$

Model Summary:

$\begin{array}{llll}\text { S } & \text { R-sq } & \text { R-sq(adj) } & \text { R-sq(pred) }\end{array}$

$0,239748 \quad 94,61 \% \quad 93,07 \% \quad 88,39 \%$

Coefficients:

Term Coef SE Coef T-Value P-Value VIF

$\begin{array}{lllll}\text { Constant } & 9,2566 & 0,0765 & 120,98 & 0,000\end{array}$

Starch Type

$\begin{array}{llllll}\text { Chickpea Microfluidized } & 0,967 & 0,111 & 8,74 & 0,000 & 1,28\end{array}$

$\begin{array}{llllll}\text { Chickpea Native } & -1,043 & 0,103 & -10,11 & 0,000 & 1,28\end{array}$

Regression Equation:

Swelling Power $=9,2566+0,967$ Starch Type_Chickpea Microfluidized - 1,043 Starch Type_Chickpea Native + 0,076 Starch Type_Chickpea Sonicated 
One-way ANOVA: Swelling Power versus Starch Type

Means:

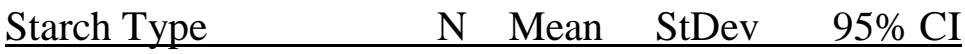

Chickpea Microfluidized $3 \quad 10,223 \quad 0,336 \quad(9,896 ; 10,551)$

Chickpea Native $\quad 4 \quad 8,2135 \quad 0,1642 \quad(7,9301 ; 8,4970)$

Chickpea Sonicated $3 \quad 3,333 \quad 0,219 \quad(9,006 ; 9,660)$

Tukey Pairwise Comparisons

Grouping Information Using the Tukey Method and 95\% Confidence

Starch Type N Mean Grouping

Chickpea Microfluidized $3 \quad 10,223$ A

Chickpea Sonicated $39,333 \quad$ B

Chickpea Native $\quad 4 \quad 8,2135 \quad$ C

Means that do not share a letter are significantly different.

Table B. 9. Solubility of lentil starches

General Linear Model: Solubility versus Starch Type

Factor Type Levels Values

Starch Type Fixed $3 \quad$ Lentil Microfluidized; Lentil Native; Lentil Sonicated

Analysis of Variance:

Source DF Adj SS Adj MS F-Value P-Value

$\begin{array}{lllll}\text { Starch Type } 2 & 26,761 & 13,3807 & 29,55 & 0,001\end{array}$

Error $\quad 6 \quad 2,717 \quad 0,4529$

Total $\quad 8 \quad 29,478$ 
Model Summary:

$\underline{S} \quad$ R-sq $\quad$ R-sq(adj) R-sq(pred)

$0,672948 \quad 90,78 \% \quad 87,71 \% \quad 79,26 \%$

Coefficients:

Term Coef SE Coef T-Value P-Value VIF

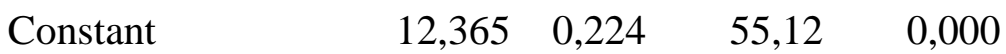

Starch Type

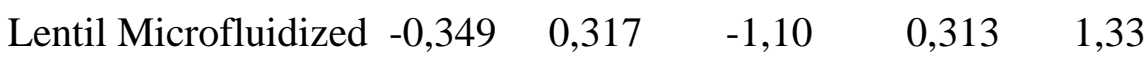

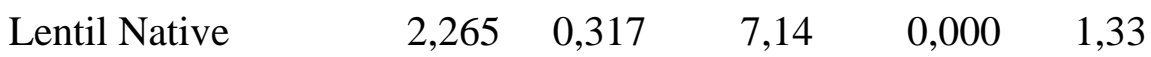

Regression Equation:

Solubility $=12,365 \quad-0,349$ Starch Type_Lentil $\quad$ Microfluidized

+ 2,265 Starch Type_Lentil Native - 1,916 Starch Type_Lentil Sonicated

One-way ANOVA: Solubility versus Starch Type

Means:

Starch Type $\quad \mathrm{N}$ Mean StDev $95 \%$ CI

Lentil Microfluidized $3 \quad 12,016 \quad 0,581 \quad(11,065 ; 12,967)$

Lentil Native $\quad 3 \quad 14,630 \quad 0,922 \quad(13,679 ; 15,581)$

Lentil Sonicated $\quad 3 \quad 10,450 \quad 0,414 \quad(9,499 ; 11,400)$

Tukey Pairwise Comparisons

Grouping Information Using the Tukey Method and 95\% Confidence

\begin{tabular}{lrcc} 
Starch Type & N & Mean & Grouping \\
\hline Lentil Native & 3 & 14,630 & A \\
Lentil Microfluidized & 3 & 12,016 & B \\
Lentil Sonicated & 3 & 10,450 & B
\end{tabular}


Means that do not share a letter are significantly different.

Table B. 10. Swelling power of lentil starches

General Linear Model: Swelling Power versus Starch Type

Factor Type Levels Values

Starch Type Fixed 3 Lentil Microfluidized; Lentil Native; Lentil Sonicated

Analysis of Variance:

$\begin{array}{lccccc}\text { Source } & \text { DF } & \text { Adj SS } & \text { Adj MS } & \text { F-Value } & \text { P-Value } \\ \text { Starch Type } & 2 & 2,16746 & 1,08373 & 138,58 & 0,000 \\ \text { Error } & 6 & 0,04692 & 0,00782 & & \\ \text { Total } & 8 & 2,21438 & & & \end{array}$

Model Summary:

\begin{tabular}{llll} 
S & R-sq & R-sq(adj) & R-sq(pred) \\
\hline 0,0884310 & $97,88 \%$ & $97,17 \%$ & $95,23 \%$
\end{tabular}

Coefficients:

$\begin{array}{llllll}\text { Term } & \text { Coef } & \text { SE Coef } & \text { T-Value } & \text { P-Value VIF } \\ \text { Constant } & 10,9559 & 0,0295 & 371,68 & 0,000\end{array}$

Starch Type

Lentil Microfluidized $\quad 0,4155 \quad 0,0417 \quad 9,97 \quad 0,000 \quad 1,33$

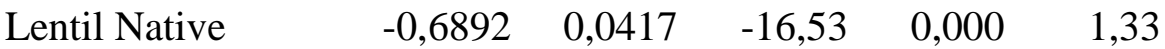

Regression Equation:

Swelling Power $=10,9559+0,4155$ Starch Type_Lentil Microfluidized - 0,6892 Starch Type_Lentil Native + 0,2737 Starch Type_Lentil Sonicated 
One-way ANOVA: Swelling Power versus Starch Type

Means:

Starch Type N Mean StDev $95 \%$ CI

Lentil Microfluidized $3 \quad 11,3713 \quad 0,0709 \quad(11,2464 ; 11,4963)$

Lentil Native $\quad 3 \quad 10,2667 \quad 0,1180 \quad(10,1418 ; 10,3916)$

Lentil Sonicated $311,2296 \quad 0,0672 \quad(11,1047 ; 11,3545)$

Tukey Pairwise Comparisons

Grouping Information Using the Tukey Method and 95\% Confidence

Starch Type N Mean Grouping

Lentil Microfluidized $3 \quad 11,3713$ A

Lentil Sonicated 311,2296 A

Lentil Native $\quad 3 \quad 10,2667 \quad$ B

Means that do not share a letter are significantly different.

Table B. 11. Thermal properties of chickpea starches

General Linear Model: To versus Starch Type

Factor Type Levels Values

Starch Type Fixed $3 \quad$ Chickpea Microfluidized; Chickpea Native; Chickpea

Sonicated

Analysis of Variance:

$\begin{array}{lcllll}\text { Source } & \text { DF } & \text { Adj SS } & \text { Adj MS } & \text { F-Value } & \text { P-Value } \\ \text { Starch Type } & 2 & 60,933 & 30,4667 & 60,59 & 0,000 \\ \text { Error } & 5 & 2,514 & 0,5028 & & \\ \text { Total } & 7 & 63,447 & & & \end{array}$


Model Summary:

$\underline{S} \quad$ R-sq $\quad$ R-sq(adj) R-sq(pred)

$0,709093 \quad 96,04 \% \quad 94,45 \% \quad 90,91 \%$

Coefficients:

$\underline{\text { Term }}$ Coef SE Coef T-Value P-Value VIF

Constant

$63,974 \quad 0,255 \quad 250,58 \quad 0,000$

Starch Type

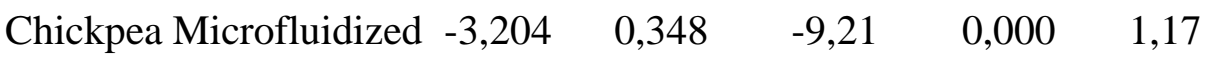

$\begin{array}{llllll}\text { Chickpea Native } & 3,169 & 0,348 & 9,11 & 0,000 & 1,17\end{array}$

Regression Equation:

To = 63,974 - 3,204 Starch Type_Chickpea Microfluidized

+3,169 Starch Type_Chickpea Native + 0,036 Starch Type_Chickpea Sonicated

Fits and Diagnostics for Unusual Observations:

$\begin{array}{lllll}\text { Obs } & \text { To } & \text { Fit } & \text { Resid } & \text { Std Resid } \\ 1 & 65,970 & 67,143 & -1,173 & -2,03 \text { R }\end{array}$

General Linear Model: Tp versus Starch Type

Factor Type Levels Values

Starch Type Fixed 3 Chickpea Microfluidized; Chickpea Native; Chickpea

Sonicated

Analysis of Variance:

$\begin{array}{llllll}\text { Source } & \text { DF } & \text { Adj SS } & \text { Adj MS } & \text { F-Value } & \text { P-Value } \\ \text { Starch Type } & 2 & 47,550 & 23,7751 & 84,07 & 0,000 \\ \text { Error } & 5 & 1,414 & 0,2828 & & \\ \text { Total } & 7 & 48,964 & & & \end{array}$


Model Summary:

$\underline{S} \quad$ R-sq $\quad$ R-sq(adj) R-sq(pred)

$0,531802 \quad 97,11 \% \quad 95,96 \% \quad 93,34 \%$

Coefficients:

Term Coef SE Coef T-Value P-Value VIF

Constant

$70,982 \quad 0,191 \quad 370,72 \quad 0,000$

Starch Type

$\begin{array}{llllll}\text { Chickpea Microfluidized } & -2,362 & 0,261 & -9,05 & 0,000 & 1,17\end{array}$

$\begin{array}{lllll}\text { Chickpea Native } \quad 3,144 & 0,261 & 12,05 & 0,000 & 1,17\end{array}$

Regression Equation:

$\mathrm{Tp} \quad=\quad 70,982 \quad-2,362$ Starch Type_Chickpea $\quad$ Microfluidized + 3,144 Starch Type_Chickpea Native - 0,782 Starch Type_Chickpea Sonicated

General Linear Model: Tc versus Starch Type

Factor Type Levels Values

Starch Type Fixed 3 Chickpea Microfluidized; Chickpea Native; Chickpea

Sonicated

Analysis of Variance:

Source DF Adj SS Adj MS F-Value P-Value

$\begin{array}{lllll}\text { Starch Type } 2 & 17,893 & 8,9466 & 10,45 & 0,016\end{array}$

Error $\quad 5 \quad 4,283 \quad 0,8565$

Total $\quad 7 \quad 22,176$

Model Summary:

$\underline{\mathrm{S}} \quad \mathrm{R}$-sq $\quad \mathrm{R}$-sq(adj) R-sq(pred)

$0,925476 \quad 80,69 \% \quad 72,96 \% \quad 55,64 \%$ 
Coefficients:

Term Coef SE Coef T-Value P-Value VIF

$\begin{array}{lllll}\text { Constant } & 79,333 & 0,333 & 238,09 & 0,000\end{array}$

Starch Type

$\begin{array}{llllll}\text { Chickpea Microfluidized } & -0,450 & 0,454 & -0,99 & 0,367 & 1,17\end{array}$

$\begin{array}{llllll}\text { Chickpea Native } & 2,043 & 0,454 & 4,50 & 0,006 & 1,17\end{array}$

Regression Equation:

Tc $=79,333 \quad-0,450$ Starch Type_Chickpea $\quad$ Microfluidized

+2,043 Starch Type_Chickpea Native - 1,593 Starch Type_Chickpea Sonicated

Fits and Diagnostics for Unusual Observations:

\begin{tabular}{lllll} 
Obs & Tc & Fit & Resid & Std Resid \\
\hline 2 & 83,000 & 81,377 & 1,623 & $2,15 \quad \mathrm{R}$
\end{tabular}

General Linear Model: Delta H versus Starch Type

Factor Type Levels Values

Starch Type Fixed 3 Chickpea Microfluidized; Chickpea Native; Chickpea

Sonicated

Analysis of Variance:

Source DF Adj SS Adj MS F-Value P-Value

$\begin{array}{lllll}\text { Starch Type } 2 & 5,9556 & 2,9778 & 23,11 & 0,003\end{array}$

Error $\quad 5 \quad 0,6443 \quad 0,1289$

Total $\quad 7 \quad 6,5999$

Model Summary:

$\begin{array}{llll}\text { S } & \text { R-sq } & \text { R-sq(adj) R-sq(pred) }\end{array}$

$0,358971 \quad 90,24 \% \quad 86,33 \% \quad 73,51 \%$ 
Coefficients:

Term Coef SE Coef T-Value P-Value VIF

Constant

$8,477 \quad 0,129 \quad 65,59 \quad 0,000$

Starch Type

Chickpea Microfluidized $-1,155 \quad 0,176 \quad-6,56 \quad 0,001 \quad 1,17$

$\begin{array}{llllll}\text { Chickpea Native } & 0,734 & 0,176 & 4,17 & 0,009 & 1,17\end{array}$

Regression Equation:

Delta $\mathrm{H}=8,477 \quad-1,155$ Starch Type_Chickpea Microfluidized + 0,734 Starch Type_Chickpea Native + 0,421 Starch Type_Chickpea Sonicated

One-way ANOVA: To versus Starch Type

Means:

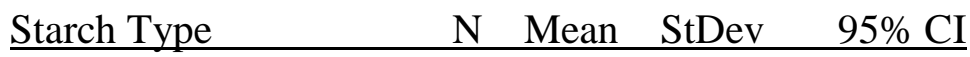

Chickpea Microfluidized $3 \quad 60,770 \quad 0,250 \quad(59,718 ; 61,822)$

Chickpea Native $\quad 3 \quad 67,143 \quad 1,078 \quad(66,091 ; 68,196)$

Chickpea Sonicated $\quad 2 \quad 64,010 \quad 0,255 \quad(62,721 ; 65,299)$

Tukey Pairwise Comparisons

Grouping Information Using the Tukey Method and 95\% Confidence

Starch Type N Mean Grouping

Chickpea Native $\quad 367,143$ A

Chickpea Sonicated $264,010 \quad$ B

Chickpea Microfluidized $3 \quad 60,770 \quad$ C

Means that do not share a letter are significantly different. 
One-way ANOVA: Tp versus Starch Type

Means:

Starch Type $\quad$ N Mean StDev 95\% CI

Chickpea Microfluidized $3 \quad 68,6200 \quad 0,1153 \quad(67,8307 ; 69,4093)$

$\begin{array}{lllll}\text { Chickpea Native } & 3 & 74,127 & 0,819 & (73,337 ; 74,916)\end{array}$

Chickpea Sonicated $\quad 2 \quad 70,200 \quad 0,212 \quad(69,233 ; 71,167)$

Tukey Pairwise Comparisons

Grouping Information Using the Tukey Method and 95\% Confidence

$\begin{array}{lccc}\text { Starch Type } & \text { N } & \text { Mean } & \text { Grouping } \\ \text { Chickpea Native } & 3 & 74,127 & \text { A } \\ \text { Chickpea Sonicated } & 2 & 70,200 & \text { B } \\ \text { Chickpea Microfluidized } & 3 & 68,6200 & \text { C }\end{array}$

Means that do not share a letter are significantly different.

One-way ANOVA: Tc versus Starch Type

Means:

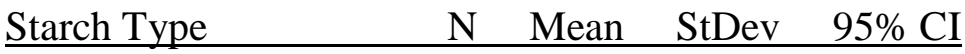

Chickpea Microfluidized $3 \quad 78,88330,0404 \quad(77,5098 ; 80,2569)$

Chickpea Native $\quad 3 \quad 81,377 \quad 1,443 \quad(80,003 ; 82,750)$

Chickpea Sonicated $\quad 2 \quad 77,740 \quad 0,339 \quad(76,058 ; 79,422)$

Tukey Pairwise Comparisons 
Grouping Information Using the Tukey Method and 95\% Confidence

Starch Type N Mean Grouping

Chickpea Native $\quad 3 \quad 81,377$ A

Chickpea Microfluidized $3 \quad 78,8833 \quad$ B

Chickpea Sonicated $277,740 \quad$ B

Means that do not share a letter are significantly different.

One-way ANOVA: Delta H versus Starch Type

Means:

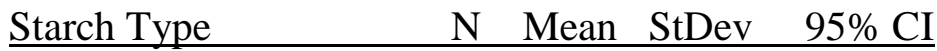

Chickpea Microfluidized $3 \quad 7,322 \quad 0,355 \quad(6,789 ; 7,854)$

$\begin{array}{lllll}\text { Chickpea Native } & 3 & 9,211 & 0,333 & (8,679 ; 9,744)\end{array}$

Chickpea Sonicated $2 \quad 8,898 \quad 0,413 \quad(8,246 ; 9,551)$

Tukey Pairwise Comparisons

Grouping Information Using the Tukey Method and 95\% Confidence

$\begin{array}{lrrr}\text { Starch Type } & \text { N } & \text { Mean } & \text { Grouping } \\ \text { Chickpea Native } & 3 & 9,211 & \text { A } \\ \text { Chickpea Sonicated } & 2 & 8,898 & \text { A } \\ \text { Chickpea Microfluidized } & 3 & 7,322 & \text { B }\end{array}$

Means that do not share a letter are significantly different. 
Table B. 12. Thermal properties of lentil starches

General Linear Model: To versus Starch Type

Factor Type Levels Values

Starch Type Fixed 3 Lentil Microfluidized; Lentil Native; Lentil Sonicated

Analysis of Variance:

Source DF Adj SS Adj MS F-Value P-Value

Starch Type $2 \quad 15,3672 \quad 7,68362 \quad 306,94 \quad 0,000$

$\begin{array}{llll}\text { Error } & 3 & 0,0751 & 0,02503\end{array}$

Total $\quad 5 \quad 15,4423$

Model Summary:

$\underline{\mathrm{S}} \quad \mathrm{R}$-sq $\quad \mathrm{R}$-sq(adj) R-sq(pred)

$0,158219 \quad 99,51 \% \quad 99,19 \% \quad 98,05 \%$

Coefficients:

Term Coef SE Coef T-Value P-Value VIF

$\begin{array}{lllll}\text { Constant } & 56,9567 & 0,0646 & 881,78 & 0,000\end{array}$

Starch Type

$\begin{array}{llllll}\text { Lentil Microfluidized } & -1,9517 & 0,0913 & -21,37 & 0,000 & 1,33\end{array}$

Lentil Native $\quad \begin{array}{lllll}1,9683 & 0,0913 & 21,55 & 0,000 & 1,33\end{array}$

Regression Equation:

To $=56,9567 \quad-1,9517$ Starch Type_Lentil $\quad$ Microfluidized

+ 1,9683 Starch Type_Lentil Native - 0,0167 Starch Type_Lentil Sonicated

General Linear Model: Tp versus Starch Type

Factor Type Levels Values

Starch Type Fixed 3 Lentil Microfluidized; Lentil Native; Lentil Sonicated 
Analysis of Variance:

$\begin{array}{llllll}\text { Source } & \text { DF } & \text { Adj SS } & \text { Adj MS } & \text { F-Value } & \text { P-Value } \\ \text { Starch Type } & 2 & 8,5874 & 4,29372 & 104,34 & 0,002 \\ \text { Error } & 3 & 0,1235 & 0,04115 & & \\ \text { Total } & 5 & 8,7109 & & & \end{array}$

Model Summary:

$\begin{array}{llll}\text { S } & \text { R-sq } & \text { R-sq(adj) } & \text { R-sq(pred) }\end{array}$

$0,202855 \quad 98,58 \% \quad 97,64 \% \quad 94,33 \%$

Coefficients:

Term Coef SE Coef T-Value P-Value VIF

$\begin{array}{lllll}\text { Constant } & 63,3383 & 0,0828 & 764,82 & 0,000\end{array}$

Starch Type

$\begin{array}{llllll}\text { Lentil Microfluidized } & -0,958 & 0,117 & -8,18 & 0,004 & 1,33\end{array}$

$\begin{array}{llllll}\text { Lentil Native } & 1,687 & 0,117 & 14,40 & 0,001 & 1,33\end{array}$

Regression Equation:

Tp $=63,3383-0,958$ Starch Type_Lentil Microfluidized + 1,687 Starch Type_Lentil Native - 0,728 Starch Type_Lentil Sonicated

General Linear Model: Tc versus Starch Type

Factor Type Levels Values

Starch Type Fixed 3 Lentil Microfluidized; Lentil Native; Lentil Sonicated 
Analysis of Variance:

Source DF Adj SS Adj MS F-Value P-Value

$\begin{array}{lllll}\text { Starch Type } 2 & 18,2414 & 9,12072 & 242,04 & 0,000\end{array}$

$\begin{array}{llll}\text { Error } & 3 & 0,1131 & 0,03768\end{array}$

$\begin{array}{lll}\text { Total } & 5 & 18,3545\end{array}$

Model Summary:

$\underline{S} \quad$ R-sq $\quad$ R-sq(adj) R-sq(pred)

$0,194122 \quad 99,38 \% \quad 98,97 \% \quad 97,54 \%$

Coefficients:

Term Coef SE Coef T-Value P-Value VIF

$\begin{array}{lllll}\text { Constant } & 72,2183 & 0,0792 & 911,27 & 0,000\end{array}$

Starch Type

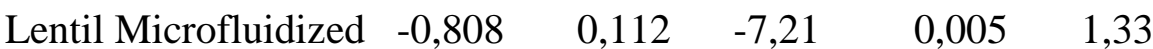

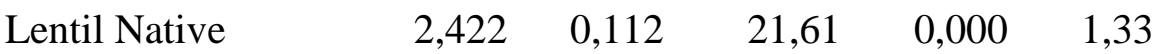

Regression Equation:

Tc $=72,2183-0,808$ Starch Type_Lentil Microfluidized $+2,422$ Starch Type_Lentil

Native - 1,613 Starch Type_Lentil Sonicated

General Linear Model: Delta H versus Starch Type

Factor Type Levels Values

Starch Type Fixed 3 Lentil Microfluidized; Lentil Native; Lentil Sonicated

Analysis of Variance:

Source DF Adj SS Adj MS F-Value P-Value

Starch Type $2 \quad 11,2161 \quad 5,60804 \quad 2003,49 \quad 0,000$

Error $\quad 3 \quad 0,0084 \quad 0,00280$

Total $\quad 5 \quad 11,2245$ 
Model Summary:

$\underline{\mathrm{S}} \quad \mathrm{R}$-sq $\mathrm{R}$-sq(adj) R-sq(pred)

$0,0529068 \quad 99,93 \% \quad 99,88 \% \quad 99,70 \%$

Coefficients:

$\underline{\text { Term }}$

Coef SE Coef T-Value P-Value VIF

Constant

$5,8373 \quad 0,0216 \quad 270,26 \quad 0,000$

Starch Type

Lentil Microfluidized $-1,8881 \quad 0,0305 \quad-61,81 \quad 0,000 \quad 1,33$

$\begin{array}{lllll}\text { Lentil Native } \quad 1,3051 & 0,0305 & 42,73 & 0,000 & 1,33\end{array}$

Regression Equation:

Delta $\mathrm{H}=5,8373 \quad-1,8881$ Starch Type_Lentil Microfluidized

+ 1,3051 Starch Type_Lentil Native + 0,5830 Starch Type_Lentil Sonicated

One-way ANOVA: To versus Starch Type

Means:

Starch Type $\quad \mathrm{N}$ Mean StDev $95 \% \mathrm{CI}$

Lentil Microfluidized $2 \quad 55,005 \quad 0,205 \quad(54,649 ; 55,361)$

Lentil Native $\quad 2 \quad 58,925 \quad 0,177 \quad(58,569 ; 59,281)$

Lentil Sonicated $\quad 2 \quad 56,9400 \quad 0,0424 \quad(56,5840 ; 57,2960)$ 
Tukey Pairwise Comparisons

Grouping Information Using the Tukey Method and 95\% Confidence

Starch Type N Mean Grouping

Lentil Native 258,925 A

Lentil Sonicated $256,9400 \quad B$

Lentil Microfluidized $2 \quad 55,005 \quad$ C

Means that do not share a letter are significantly different.

One-way ANOVA: Tp versus Starch Type

Means:

Starch Type $\quad \mathrm{N}$ Mean StDev $95 \%$ CI

Lentil Microfluidized $2 \quad 62,380 \quad 0,226 \quad(61,924 ; 62,836)$

Lentil Native $\quad 2 \quad 65,025 \quad 0,219 \quad(64,569 ; 65,481)$

Lentil Sonicated $\quad 2 \quad 62,610 \quad 0,156 \quad(62,154 ; 63,066)$

Tukey Pairwise Comparisons

Grouping Information Using the Tukey Method and 95\% Confidence

Starch Type N Mean Grouping

Lentil Native $\quad 265,025$ A

Lentil Sonicated $262,610 \quad B$

Lentil Microfluidized $262,380 \quad$ B

Means that do not share a letter are significantly different. 
One-way ANOVA: Tc versus Starch Type

Means:

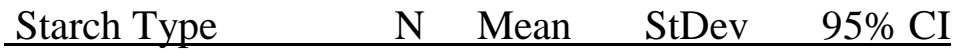

Lentil Microfluidized $2 \quad 71,4100 \quad 0,1273 \quad(70,9732 ; 71,8468)$

Lentil Native $\quad 2 \quad 74,640 \quad 0,311 \quad(74,203 ; 75,077)$

Lentil Sonicated $\quad 2 \quad 70,6050 \quad 0,0071 \quad(70,1682 ; 71,0418)$

Tukey Pairwise Comparisons

Grouping Information Using the Tukey Method and 95\% Confidence

$\begin{array}{lccc}\text { Starch Type } & \text { N } & \text { Mean } & \text { Grouping } \\ \text { Lentil Native } & 2 & 74,640 & \text { A } \\ \text { Lentil Microfluidized } & 2 & 71,4100 & \text { B } \\ \text { Lentil Sonicated } & 2 & 70,6050 & \text { B }\end{array}$

Means that do not share a letter are significantly different.

One-way ANOVA: Delta H versus Starch Type

Means:

Starch Type $\quad \mathrm{N}$ Mean $\quad$ StDev $95 \%$ CI

Lentil Microfluidized $2 \quad 3,9492 \quad 0,0348 \quad(3,8301 ; 4,0683)$

Lentil Native $\quad 2 \quad 7,1424 \quad 0,0737 \quad(7,0233 ; 7,2615)$

Lentil Sonicated $\quad 2 \quad 6,4203 \quad 0,0419 \quad(6,3012 ; 6,5393)$

Tukey Pairwise Comparisons 
Grouping Information Using the Tukey Method and 95\% Confidence

Starch Type N Mean Grouping

Lentil Native 27,1424 A

Lentil Sonicated $26,4203 \quad$ B

Lentil Microfluidized $2 \quad 3,9492 \quad$ C

Means that do not share a letter are significantly different. 